INSTITUTO DE PESQUISAS ENERGÉTICAS E NUCLEARES Autarquia Associada à Universidade de São Paulo

\title{
SEPARAÇÃO E RECUPERAÇÃO DE CHUMBO-208 DOS RESÍDUOS DE TÓRIO E TERRAS RARAS GERADOS NA UNIDADE PILOTO DE PURIFICAÇÃO DE NITRATO DE TÓRIO
}

JOSÉ ANTONIO SENEDA

Tese apresentada como parte dos requisitos para obtenção do Grau de Doutor em Ciências na Área de Tecnologia Nuclear - Materiais.

Orientador:

Dr. Alcídio Abrão

SÃo PAULO

2006 
Aos Mentores de minha vida profissional, social e espiritual.

A Abele D. Bianchi e Maria S. D. Bianchi "in memorium" meus agradecimentos. 


\section{AGRADECIMENTOS}

Ao Instituto de Pesquisas Energéticas e Nucleares-CNEN/SP, pela possibilidade de concretizar este trabalho.

Ao Dr. Alcídio Abrão pela sua orientação, consideração e paciência, sem o qual não seria possível a realização desta Tese de Doutorado.

Aos meus Incentivadores(as) que ajudaram nas adversidades para a realização deste trabalho Drs(as) Suemi Sugavara, Carlos A. S. Queiroz, Mauro S. Dias, Soraia M. R. Rocha, Maurício H. Kakazu, Priscilla S. Seneda, M. Cecília B. Carvalho e Martiniano M. Carvalho.

Aos Amigo(a)s e Profissionais Drs(as) Cristina Forbicini, Vera I. R. Salvador, Hélio Ferreto, Fátima M. S. Carvalho, David Brandão, Marcos Scapin, Sandra R. D. Moreira, Cristina Sisti, Cleide M. da Silva, Augusta V. da Silva, Antonio A. Freitas, Maria I. Cantagallo, Isabel Moreno, Maria A. Alves, Álvaro Ikuta e Mari Estela de Vasconcellos.

Ao Instituto de Geociências da USP, Dr(s) Key Sato e Umberto g. Cordani, pela realização das análises de espectrometria de massa.

Aos Colegas de sala Vanderlei S. Bergamaschi, Jamil M. S. Ayoub e Edgar F. da Cunha pelas conversas "light and hard" na hora do café.

A Banca Examinadora Drs(a) Roberto Tokoro, Key Sato, Wagner dos Santos Oliveira, Afonso R. Aquino, J. Oscar W. V. Bustillos e Rosângela A. Hanna pela disposição de averiguar e comentar esta Tese.

Aos membros da Comissão de Pós Graduação e corpo administrativo, grupos da bibilioteca, manutenção ( Takeshi, João, Ricardo e Pedro) e apoio ( Marta e Eleosmar) e ao grupo do Centro de Química e Meio Ambiente.

A firma Rohm and Haas Química LTDA, Eng. Osmar Cunha, pelo fornecimento das resinas e informações técnicas. 


\title{
SEPARAÇÃO E RECUPERAÇÃO DE CHUMBO-208 DOS RESÍDUOS DE TÓRIO E TERRAS RARAS GERADOS NA UNIDADE PILOTO DE PURIFICAÇÃO DE NITRATO DE TÓRIO
}

\author{
José Antonio Seneda
}

\section{RESUMO}

O Brasil tem uma longa tradição na tecnologia do tório, desde a abertura do principal mineral, a monazita, até compostos de pureza grau nuclear, com reservas minerais estimados em 1.200.000 ton - $\mathrm{ThO}_{2}$. Como conseqüência desta produção, foi acumulado um resíduo produzido na unidade piloto de purificação de nitrato de tório, do Instituto de Pesquisas Energéticas e Nucleares$\mathrm{CNEN/SP}$, mais de 25 toneladas ao longo das últimas três décadas, proveniente dos rafinados e soluções de lavagem do processo de extração por solventes, conhecido como RETOTER. Sua composição, um hidróxido, contendo tório, terras raras e impurezas menores, incluindo o chumbo-208 do decaimento do ${ }^{232} \mathrm{Th}$, com abundância isotópica em $88,34 \%$, enriquecido naturalmente ao longo das eras geológicas. Neste trabalho são discutidos os estudos dos principais parâmetros do processo de recuperação deste chumbo, 0,42 \% em massa no RETOTER seco, utilizando-se a técnica de troca iônica com resinas aniônicas em meio clorídrico. A abundância isotópica do chumbo foi analisada por espectrometria de massa termoiônica (TIMS) e de alta resolução (ICPMS), e com os dados calculou-se a secção de choque de captura para nêutrons térmicos. $O$ valor resultante foi de $s ?^{\circ}=14,6+/-0,7 \mathrm{mb}$ diferentemente do chumbo natural de $\mathrm{s}^{0}{ }^{0}=174,2+/-7,0 \mathrm{mb}$. Estudos preliminares de recuperação do tório e terras raras neste resíduo também foram apresentados. 
RECOVERY OF RADIOGENIC LEAD- 208 FROM A RESIDUE OF THORIUM AND RARE EARTHS OBTAINED DURING THE OPERATION OF A THORIUM PURIFICATION PILOT PLANT

\author{
José Antonio Seneda
}

\begin{abstract}
Brazil has a long tradition in thorium technology, from mineral dressing (monazite) to the nuclear grade thorium compounds. The estimate reserves are 1200,000 . ton of $\mathrm{ThO}_{2}$. As a consequence from the work of thorium purification pilot plant at Instituto de Pesquisas Energéticas e Nucleares-CNEN/SP, about 25 ton of a sludge containing thorium and rare earths was accumulated. It comes as a raffinate and washing solutions from thorium solvent extraction. This sludge, a crude hydroxide named RETOTER contains thorium, rare earths and minor impurities including the radiogenic lead-208, with abundance $88.34 \%$. This work discusses the results of the studies and main parameters for its recovery by anionic ion exchange technique in the hydrochloric system. The isotope abundance of this lead was analyzed by high resolution mass spectrometer (ICPMS) and thermoionic mass spectrometer (TIMS) and the data was used to calculate the thermal neutron capture cross section. The value of $s ?^{0}=14.6+/-$ $0.7 \mathrm{mb}$ was found, quite different from the $\mathrm{s}^{0}{ }^{0}=174.2+/-7.0 \mathrm{mb}$ measure cross section for the natural lead. Preliminary study for the thorium and rare earths separation and recovery was discussed as well.
\end{abstract}




\section{SUMÁRIO}

1 INTRODUÇÃO

1.1 Mineração ............................................................................................................................1

1.2 Processo de Abertura da Monazita...................................................................................2

$1.3 \quad$ A Indústria de Tório no Brasil ..........................................................................................

$1.4 \quad$ Retoter....................................................................................................................................

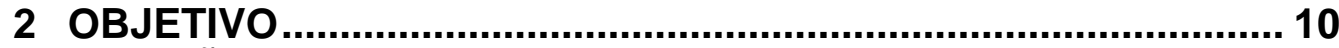

3 REVISÃO DA LITERATURA .................................................. 12

3.1 Tório ..................................................................................................................................17

3.1.1 Minerais.......................................................................................................... 17

3.1.2 Aplicações ...................................................................................................17

3.1.3 Processamento de tório para fabricação de combustível nuclear........................ 19

3.1.4 Propriedade físicas e químicas.................................................................20

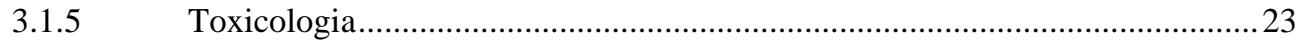

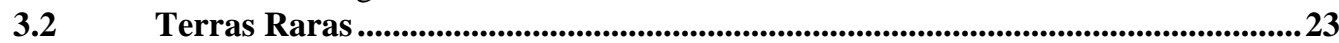

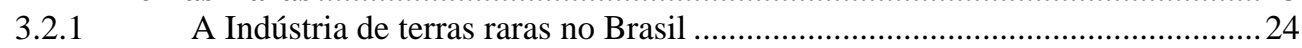

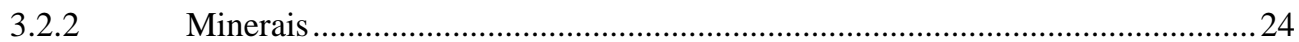

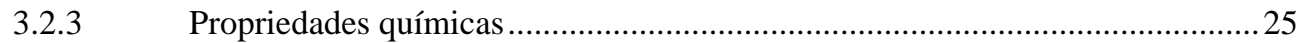

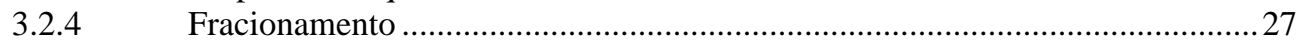

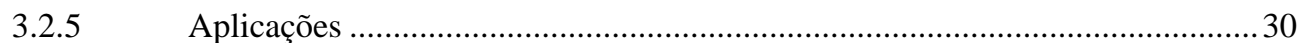

3.3

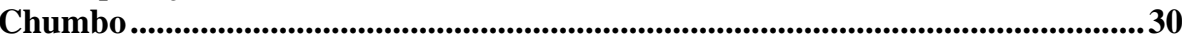

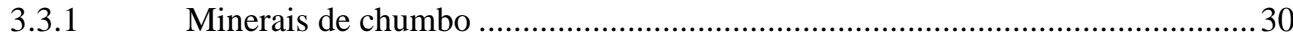

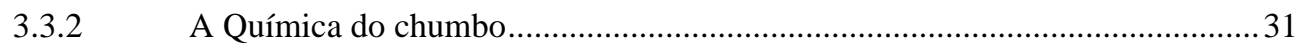

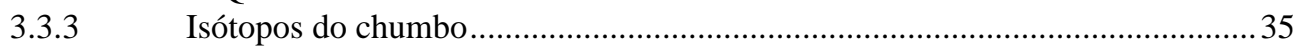

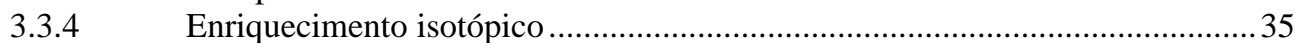

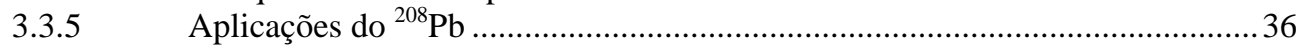

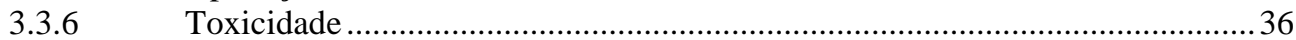

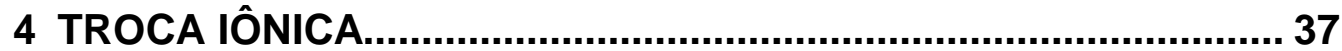

5 MATERIAS E MÉTODOS.................................................... 41

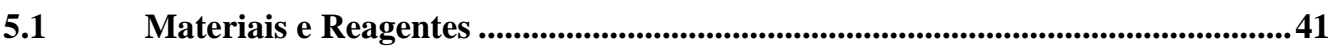

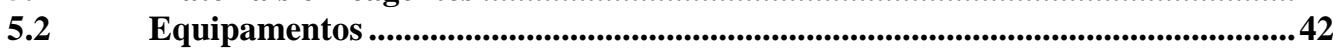

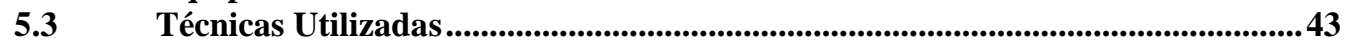

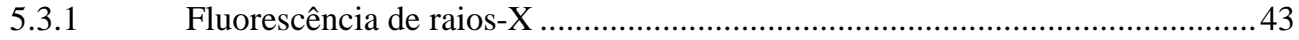

5.3.2 Espectrometria de massa ....................................................................... 45

5.3.3 Voltametria .................................................................................... 47

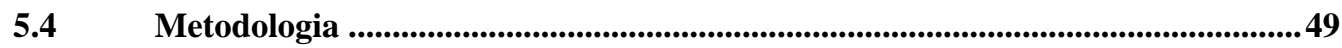

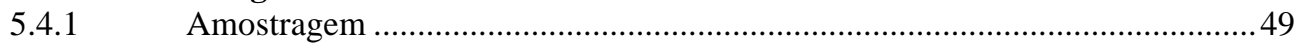

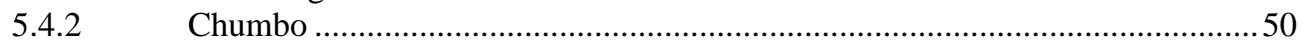

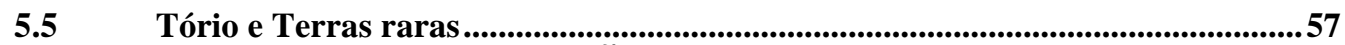

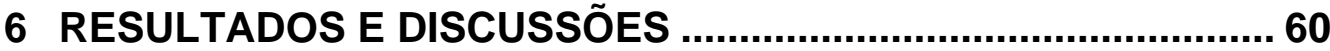

6.1 Dissolução do RETOTER .................................................................................60

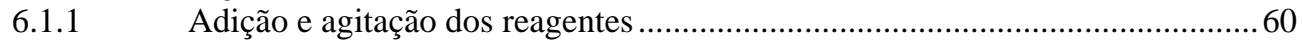

6.1.2 Efeito do tempo de adição e digestão ........................................................6 60

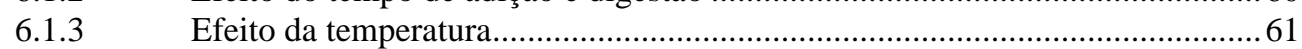

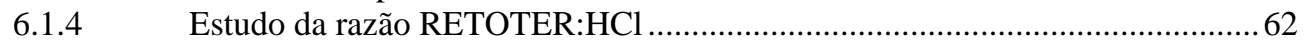

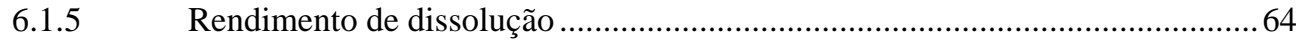

6.2 Estudo do Sistema Resina-Cloreto-Metal...............................................................6 64

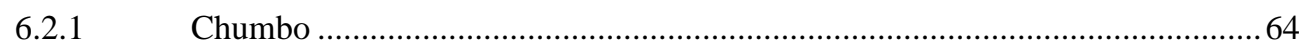

Tório e terras raras .................................................................................... 73

6.3 Cálculo da Secção de Choque de Captura para Nêutrons Térmicos do Chumbo ...........................................................................................................................74

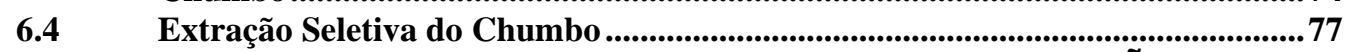

7 UNIDADE DE PROCESSAMENTO PARA RECUPERAÇÃO DE

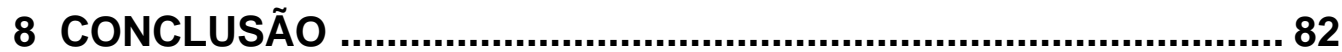


TRABALHOS FUTUROS

84

ANEXO A - RESULTADOS DO ESPECTRÔMETRO DE MASSA ICPMS .

ANEXO B - RESULTADOS DO ESPECTRÔMETRO DE MASSA -

REFERÊNCIAS BIBLIOGRÁFICAS 85 93 111 


\section{LISTA DE FIGURAS}

Página

Figura 1 - Unidade piloto de produção de nitrato de tório................................ 6

Figura 2- Tambores de PVC contendo RETOTER ............................................ 6

Figura 3- Fluxograma de obtenção do RETOTER ......................................... 7

Figura 4-Série de decaimento do Tório (SEELMANN-EGGBERT et al., 1981) ....9

Figura 5- Unidade piloto de terras raras do IPEN-CNEN/SP ............................ 29

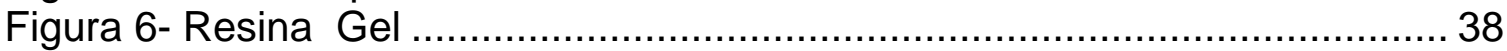

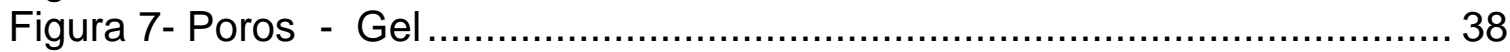

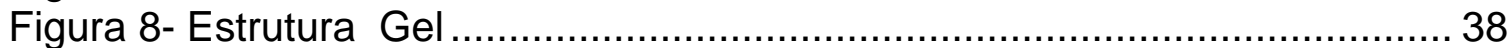

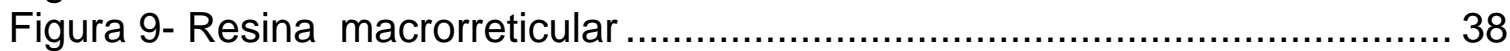

Figura10-Poros - macrorreticular ............................................................. 38

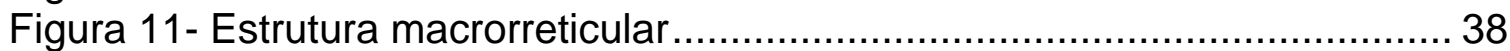

Figura 12- Curva teórica de breakthrough..................................................... 40

Figura13- Curva de eluição ....................................................................... 40

Figura 14- Amostragem no tambor de RETOTER ........................................... 50

Figura 15- Diagrama de blocos do processo para obtenção do óxido de chumbo por troca iônica e por complexação com $\mathrm{NaOH}$........... 51

Figura 16 - Pasta de RETOTER .................................................................. 52

Figura 17- Reator de Dissolução do RETOTER ............................................. 53

Figura 18- Espectro EDXRF da solução estoque .......................................... 54

Figura 19- Solução estoque ....................................................................... 55

Figura 20- Coluna cromatográfica ........................................................... 55

Figura 21- Diagrama de blocos do processo de obtenção de tório e terras raras58

Figura22-Colunas cromatográficas............................................................... 59

Figura 23- Colunas Catiônicas .............................................................. 59

Figura 24- Infuência da acidez livre na retenção de chumbo .........................67 67

Figura 25- Influência do fluxo na retenção do chumbo................................6 68

Figura 26-Espectro EDXRF do eluído em Resina Macrorreticular - IRA $900 \mathrm{Cl} .71$

Figura 27- Espectro de EDXRF do eluído em Resina Gel - IRA 458................. 72

Figura 28 - Espectro dos eluídos em resina macrorreticular e gel...................... 73

Figura 29- Curva de Eluição do tório ........................................................... 74

Figura 30 - Espectro dos isótopos de chumbo - Pb pesado (HR-ICPMS) .......... 76

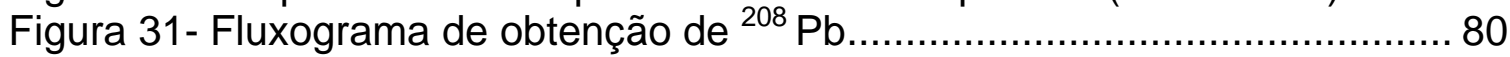

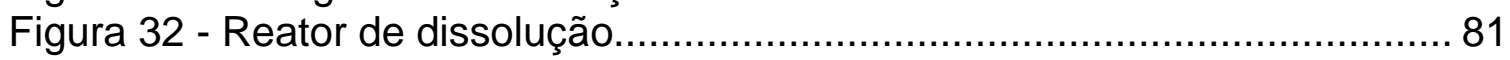

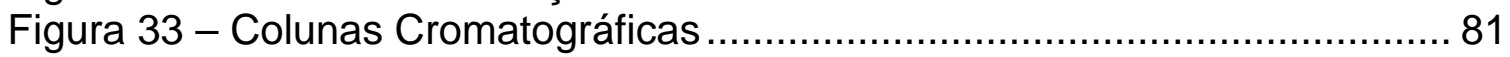




\section{LISTA DE TABELAS}

Página

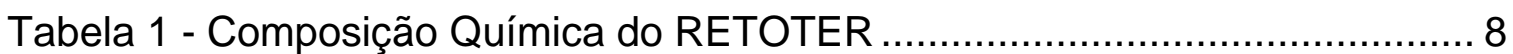

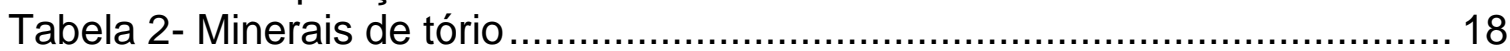

Tabela 3- Minerais de Terras Raras ............................................................. 26

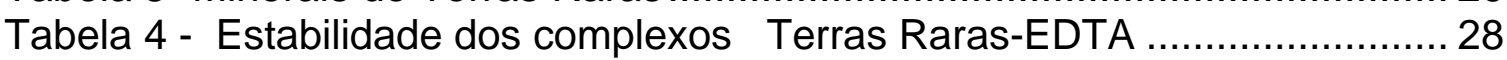

Tabela 5- Pricipais Minerais de chumbo........................................................ 31

Tabela 6- Composição Química da solução estoque .................................... 54

Tabela 7- Efeito do tempo de digestão na dissolução do RETOTER ..................62 62

Tabela 8- Efeito da temperatura na dissolução do RETOTER .........................63 63

Tabela 9- Efeito da razão RETOTER:HCl conc. na dissolução do RETOTER ... 63

Tabela 10 - Efeito da acidez livre na retenção do chumbo...............................6 67

Tabela 11 - Efeito do fluxo de solução na retenção do chumbo ........................68 68

Tabela 12 - Eluído da coluna aniônica - tipo macroreticular (IRA $900 \mathrm{Cl}$ ) ........70

Tabela 13 - Eluído da coluna aniônica - tipo Gel ( IRA 458 ) .............................. 71

Tabela 14 - Comparação das resinas Macrorreticular e Gel para o chumbo. ... 72

Tabela 15 - Razão isotópica do chumbo Natural............................................. 75

Tabela 16- Razão Isotópica do chumbo proveniente do RETOTER .................. 75

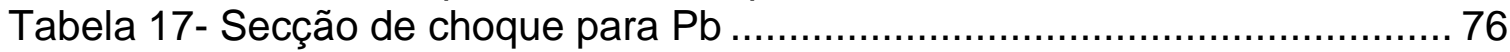

Tabela 18- Efeito de $\mathrm{NaOH}$ na extração do $\mathrm{Pb}$.............................................. 78

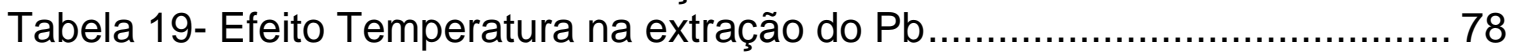

Tabela 20 - Efeito tempo de extração........................................................... 79 


\section{INTRODUÇÃO}

Um dos principais desafios da humanidade, para este século e os próximos, será o de sustentar o crescimento econômico e social mantendo e expandindo as vantagens tecnológicas existentes, sem criar enormes demandas dos recursos ambientais, sobretudo as fontes de geração de energia.

Dentre as fontes de energia existentes, a nuclear representa uma excelente opção, especialmente a do ciclo do combustível nuclear com tório, pois novos desenvolvimentos tecnológicos, ora existentes na área, possibilitarão diminuir os riscos de proliferação de armamentos nucleares e rejeitos radioativos. Inclui-se a pequena emissão de $\mathrm{CO}_{2}$, minimizando o efeito estufa, e usos de recursos minerais bem menores para o seu retorno em energia gerada, além de co-geração de hidrogênio (KAKODKAR et al., 2002, LAKE,2000; ÜNAK,2000; MOREIRA et al. ,1996; NASCIMENTO,2000; PEREIRA,2002).

O processamento do tório (BRIL et al., 1965a; BRIL et al., 1965b; CUTHBERT, 1958; FIGUEIREDO et al.,1976; IKUTA,1977; KRUMHOLZ,1949) engloba diversas fases desde sua mineração até a obtenção de elementos combustíveis ou tório metálico.

\subsection{Mineração}

O principal mineral para obtenção do tório, no Brasil, é a monazita, proveniente da areia monazítica, uma associação mineralógica de monazita, zirconita, ilmenita e rutilo, que ocorre ao longo da costa brasileira. O seu processamento compreende as seguintes fases: extração, separação e concentração. 


\section{- Extração}

Inicia-se pela lavra do minério, realizado a céu aberto. $O$ minério extraído é levado, então, para um recipiente onde é misturado com água, a seguir é feito um processo de separação hidrogravimétrica, mediante a utilização de um sistema de espirais (espirais de Humphrey). Essa operação permite a separação dos minerais leves (quartzo e outros) do minério bruto, concentrando os minerais pesados. $\mathrm{O}$ minério concentrado é submetido à secagem, em forno rotativo, para eliminar a umidade do mesmo, sendo submetido à primeira operação de separação.

- Separação

O minério, ao passar por rolos eletrostáticos, separa-se em fases condutoras e não condutoras de eletricidade, baseando-se apenas nas diferenças de condutividade elétrica dos constituintes do concentrado . A fração condutora concentra ilmenita e rutilo e a não condutora monazita e zirconita. Cada porção obtida na operação anterior é submetida à nova separação, feita com equipamento especial que se baseia na suscetibilidade magnética dos minerais, separando a monazita, magnética, da zirconita, não magnética, contidas na fração não condutora e a ilmenita, magnética, do rutilo, não magnético, contidas na fração condutora, formando concentrados separados de ilmenita, rutilo, monazita e zirconita .

- Concentração

A monazita tem sua concentração aumentada até $95 \%$ utilizando-se de mesas oscilantes ou em separadores eletrostáticos.

\subsection{Processo de Abertura da Monazita}

Dois processos químicos são empregados para romper a estrutura da monazita: ácido ou alcalino 
- Ácido

O tratamento ácido (SNELL,1974; CALVET,1962) é realizado aquecendo-se o minério moído, malha 270 mesh, com ácido sulfúrico concentrado, em cápsulas de ferro fundido, temperatura de $300^{\circ} \mathrm{C}$, durante 12 horas. O produto do ataque ácido, um sulfato de terras raras, tório e urânio, é dissolvido em água fria, separando-se dos compostos insolúveis, silicatos. A seguir, ajusta-se para $\mathrm{pH}=1$, com hidróxido de amônio, para precipitar o tório com um pouco de terras raras. Este é dissolvido com ácido nítrico e enviado para alimentar o processo de extração por solventes empregando-se o fosfato de trin-butila (TBP) como agente extrator e o varsol ou querosene como diluente na proporção de 45:55 (v/v) .

\section{- Alcalino}

O processo alcalino (IKUTA,1977; KRUMHOLZ, 1949) emprega uma solução de hidróxido de sódio $45 \%$ a $138{ }^{\circ} \mathrm{C}$ para abertura do minério . O tório, urânio e as terras raras são recuperados como óxidos insolúveis em água , estes são lixiviados em ácido clorídrico a $80^{\circ} \mathrm{C}$. A solução é ajustada até pH 5,8 com hidróxido de sódio, para precipitar tório, urânio e pequenas quantidades de terras raras. A seguir purifica-se o tório, dissolvido em ácido nítrico, em colunas de extração por solventes, processo TBP. O nitrato de tório pode ser cristalizado na forma de nitrato de tório tetrahidratado ou precipitado com hidróxido de amônio e calcinado a óxido de tório .

\subsection{A Indústria de Tório no Brasil}

A indústria de Tório no Brasil iniciou-se na década de 40 usando o minério monazita, proveniente da areia monazítica, como matéria-prima para a produção de alguns compostos como: sulfato de tório, oxicarbonato de tório e nitrato de tório, este principalmente para camisas incandescentes de lampião a gás (BRIL et al.,1965a). 
Uma planta piloto de purificação de nitrato de tório foi construída no Instituto de Pesquisas Energéticas e Nucleares na década de 70, para atender ao desenvolvimento do programa nuclear brasileiro iniciando suas atividades em 1978. Foi a principal unidade fornecedora de compostos de tório para os diversos trabalhos realizados no Instituto de Pesquisas Energéticas e Nucleares, atendendo também outras instituições.

O processo de purificação utilizado era o de extração de nitrato de tório por solventes, usando TBP-Varsol (45/55) (v/v) (BRIL et al.,1965b; IKUTA,1977). O nitrato de tório, obtido da dissolução nítrica de seu concentrado, proveniente do processo alcalino, depois das correções com nitrato de sódio $(2,2$ Mol.L $\left.{ }^{-1} \mathrm{NaNO}_{3}\right)$ e acidez livre ( 0,8 Mol.L $\mathrm{L}^{-1} \mathrm{HNO}_{3}$ ), necessárias para a extração com TBP, era purificado em colunas pulsadas, onde realizavam-se as operações compostas de extração (TBP/Varsol)-lavagem e reversão (água desmineralizada)-lavagem. A seguir, a fase orgânica, para iniciar um novo ciclo, passava por um tratamento com solução de carbonato de sódio e correção da acidez livre, utilizando-se ácido nítrico. Todos os efluentes eram estocados em tanques de aço inox para serem tratados posteriormente.

A planta piloto, mostrada na Figura 1, foi equipada para ser um fornecedor de nitrato de tório tetrahidratado, oxalato de tório e solução de nitrato de tório de alta concentração $\left(\sim 800 \mathrm{~g} \cdot \mathrm{L}^{-1} \quad \mathrm{ThO}_{2}\right)$ de pureza nuclear. Esta se destinava à obtenção de óxido de tório para reatores nucleares, porém, tornou-se fornecedora de nitrato de tório, grau de pureza para camisas incandescentes de lampião a gás, pois o programa nuclear brasileiro teve seu desenvolvimento voltado ao ciclo nuclear do urânio (SYLLUS et al.,1995).

O processamento químico para obter nitrato de tório com pureza para camisas incandescentes no Instituto de Pesquisas Energéticas e Nucleares, iniciou-se em 1986 operando até 2002. 


\subsection{Retoter}

Todos os refugados do ciclo de purificação do nitrato de tório, soluções de lavagem contendo tório residual, terras raras e as impurezas contidas na matéria-prima de nitrato tório, eram tratados com hidróxido de sódio, formando uma pasta úmida, conhecida como RETOTER. Este precipitado foi estocado inicialmente em tambores metálicos especiais, reembalados posteriormente em tambores de PVC, tendo um estoque de aproximadamente 25 toneladas. $\mathrm{Na}$ Figura 2 é mostrado o almoxarifado de materiais radioativos salvaguardados contendo os tambores de PVC com RETOTER. Na Figura 3 mostra-se o diagrama de blocos de sua obtenção.

Este resíduo, uma mistura de hidróxidos, radioativo, contendo valores como tório, terras raras, e chumbo radiogênico, necessitava de um processo de separação, concentração e recuperação de seus valores. Na Tabela 1 apresentase a composição típica do RETOTER. O seu acúmulo nos depósitos de materiais radioativos salvaguardados diminuiria e concomitantemente manter-se-iam os estudos visando a continuidade do desenvolvimento tecnológico do ciclo do combustível do tório no Brasil.

O resíduo pode ser separado em três principais frações: o tório, as terras raras e os filhos do decaimento do tório natural, mostrado na Figura 4, tendo relevância o ${ }^{208} \mathrm{~Pb}$. O teor de umidade presente neste é de $64,7 \%$. Este resíduo devido a falta de uma classificação mais precisa em termos de proteção radiológica, pela mistura existente de vários radionuclídeos poderá ser enquadrado em duas categorias: 1ํ. . ) Segundo a classificação de rejeitos sólidos ( Norma CNEN NE 6.05 - Dez/85 ) por ter uma taxa de exposição encostado, para tambores em PVC de $200 \mathrm{~L}$ contendo $155 \mathrm{~kg}$ de RETOTER, média de 150 $m R . h^{-1}$, esta enquadrado em categoria de Baixo Nível de Radiação (SBN); 2 ${ }^{a}$.) Segundo a classificação de licenciamento para instalações radiativas ( Norma CNEN NE 6.02 Jul/98 ) por conter o material nuclear tório natural ( $\left.{ }^{232} \mathrm{Th}\right)$ é enquadrado na categoria de Classe B - Alta Radiotoxicidade. 


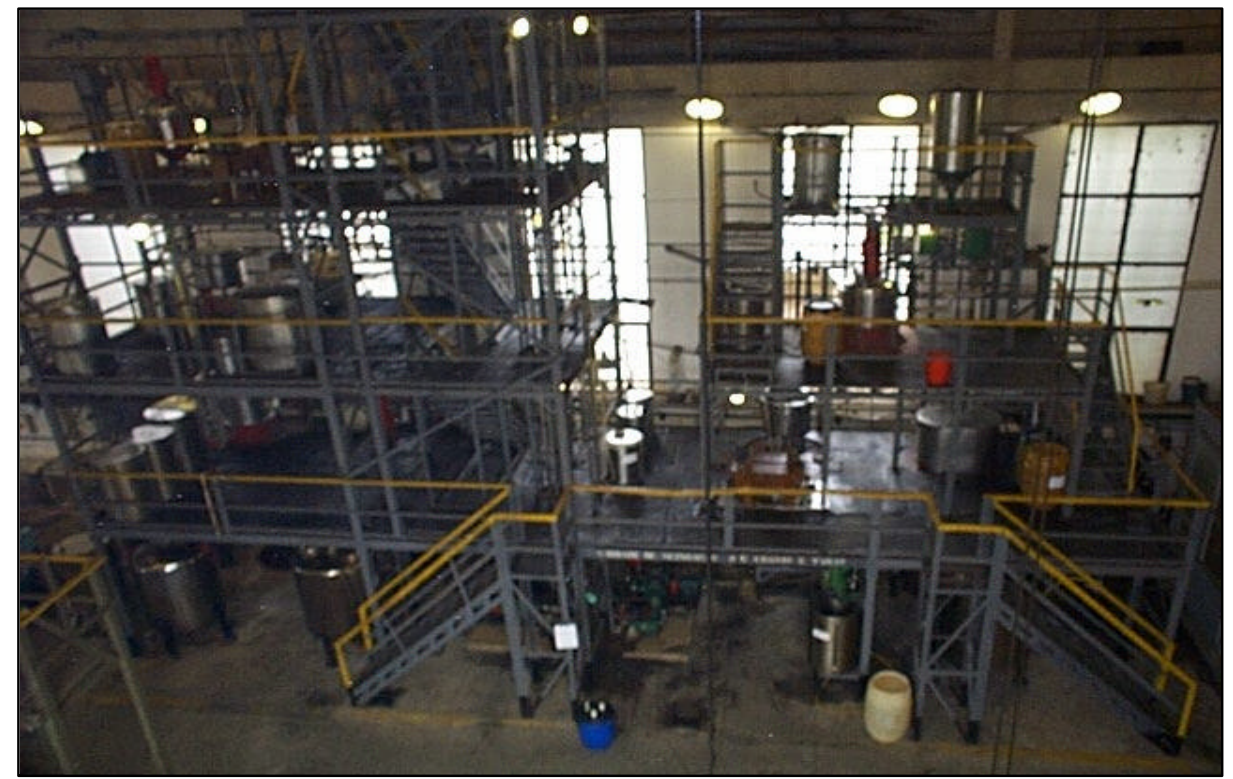

Figura 1 - Unidade piloto de produção de nitrato de tório

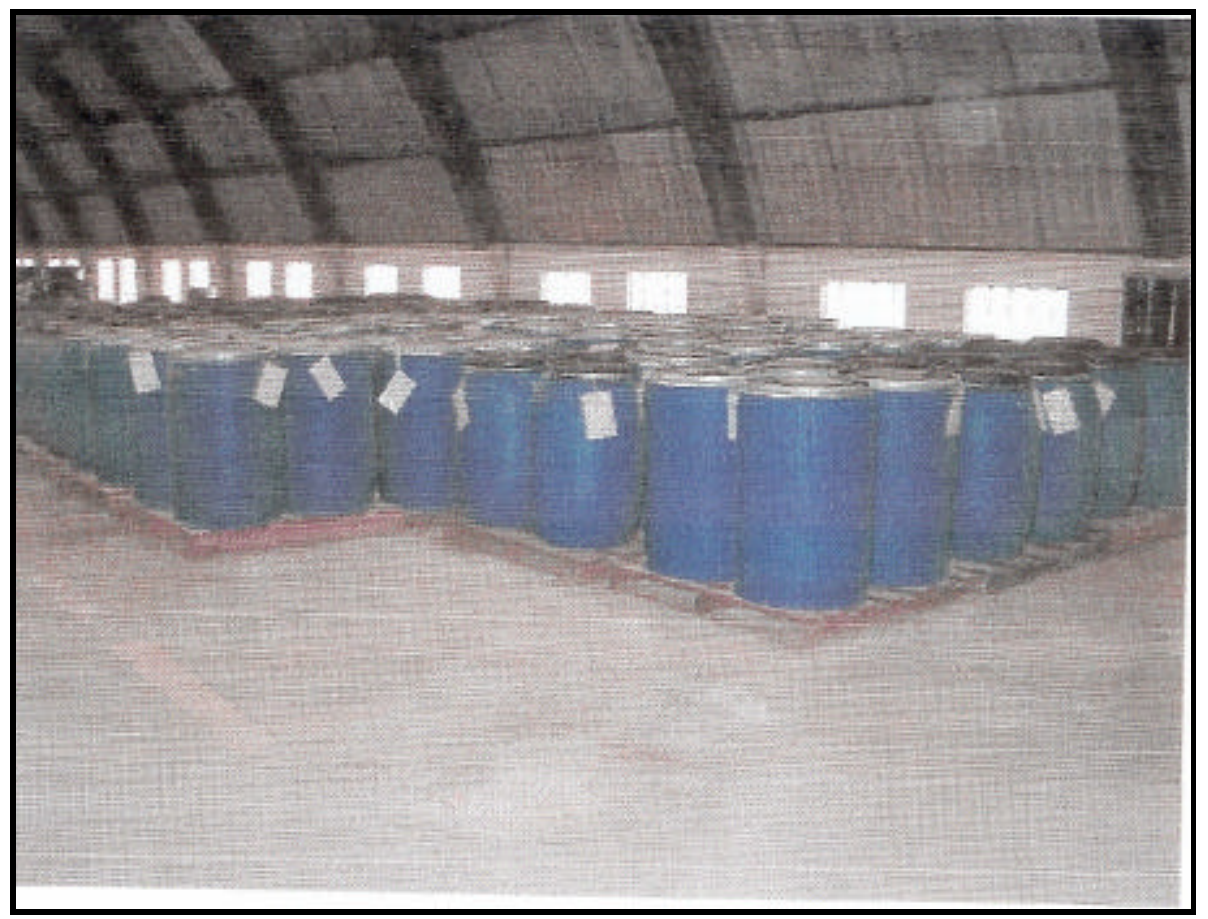

Figura 2- Tambores de PVC contendo RETOTER 


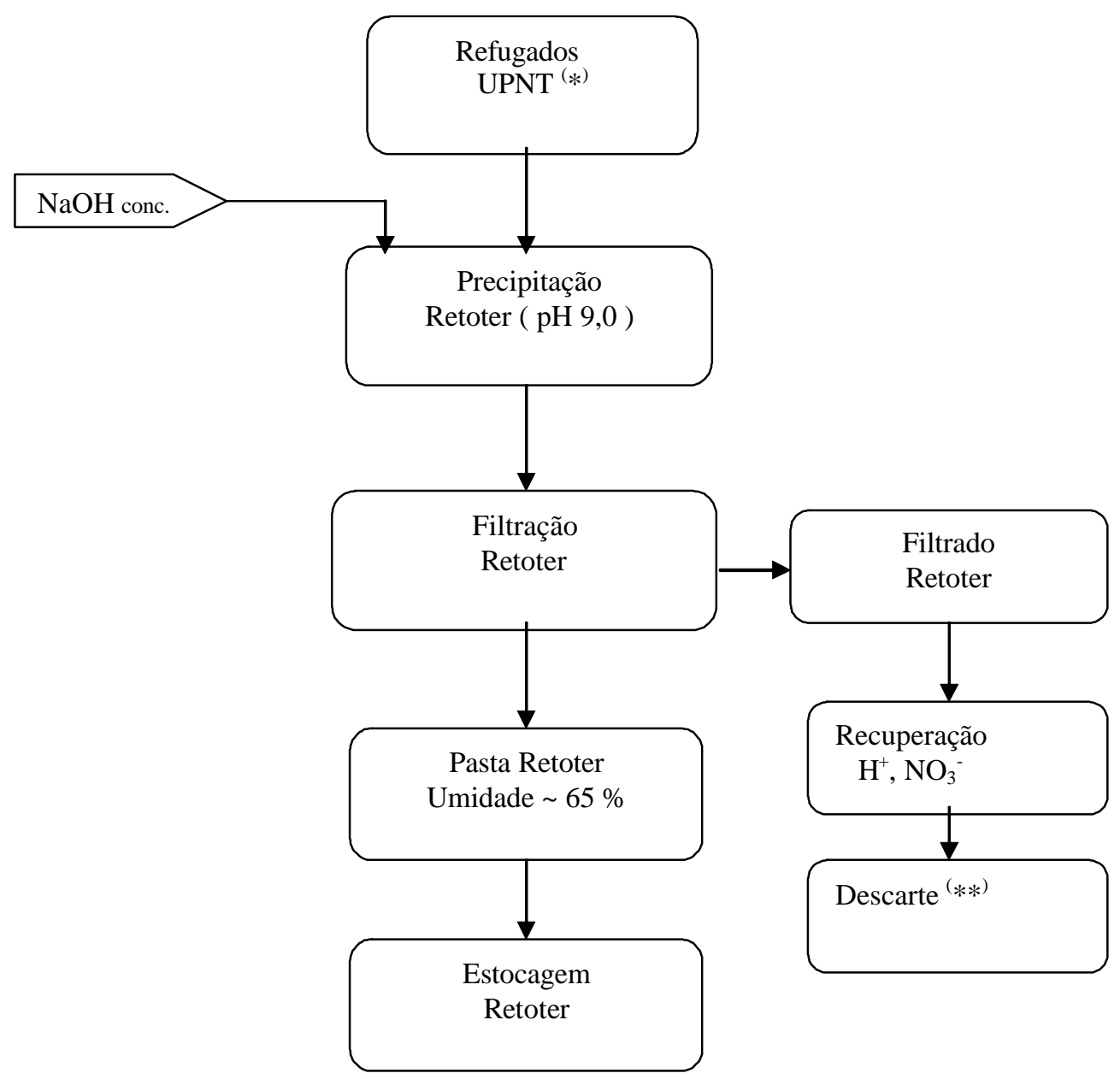

Figura 3- Fluxograma de obtenção do RETOTER

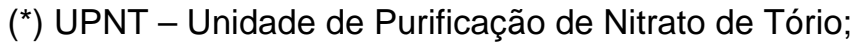

$\left.{ }^{* *}\right)$ Obedecendo as normas de descarte de rejeitos líquidos ( NE- 6.05-CNEN) e ambientais 
Tabela 1 - Composição Química do RETOTER

\begin{tabular}{lc}
\hline Constituinte & $\%$ \\
$\mathrm{Na}$ & $0,23+/-0,01$ \\
$\mathrm{Mg}$ & $0,28+/-0,01$ \\
$\mathrm{Al}$ & $0,65+/-0,01$ \\
$\mathrm{Si}$ & $3,10+/-0,06$ \\
$\mathrm{P}$ & $3,42+/-0,07$ \\
$\mathrm{~K}$ & $0,16+/-0,01$ \\
$\mathrm{Ca}$ & $3,23+/-0,07$ \\
$\mathrm{Fe}$ & $1,01+/-0,02$ \\
$\mathrm{Cu}$ & $0,11+/-0,01$ \\
$\mathrm{Zn}$ & $0,34+/-0,01$ \\
$\mathrm{~Pb}$ & $\mathbf{0 , 4 2 + / - 0 , 0 1}$ \\
$\mathrm{ThO}$ & $55,76+/-1,15$ \\
$\mathrm{TR} \mathrm{O}_{3}$ & $13,76+/-0,28$ \\
\hline
\end{tabular}

Análise do elemento efetuado por fluorescência de Raios-X (WDXRF) 


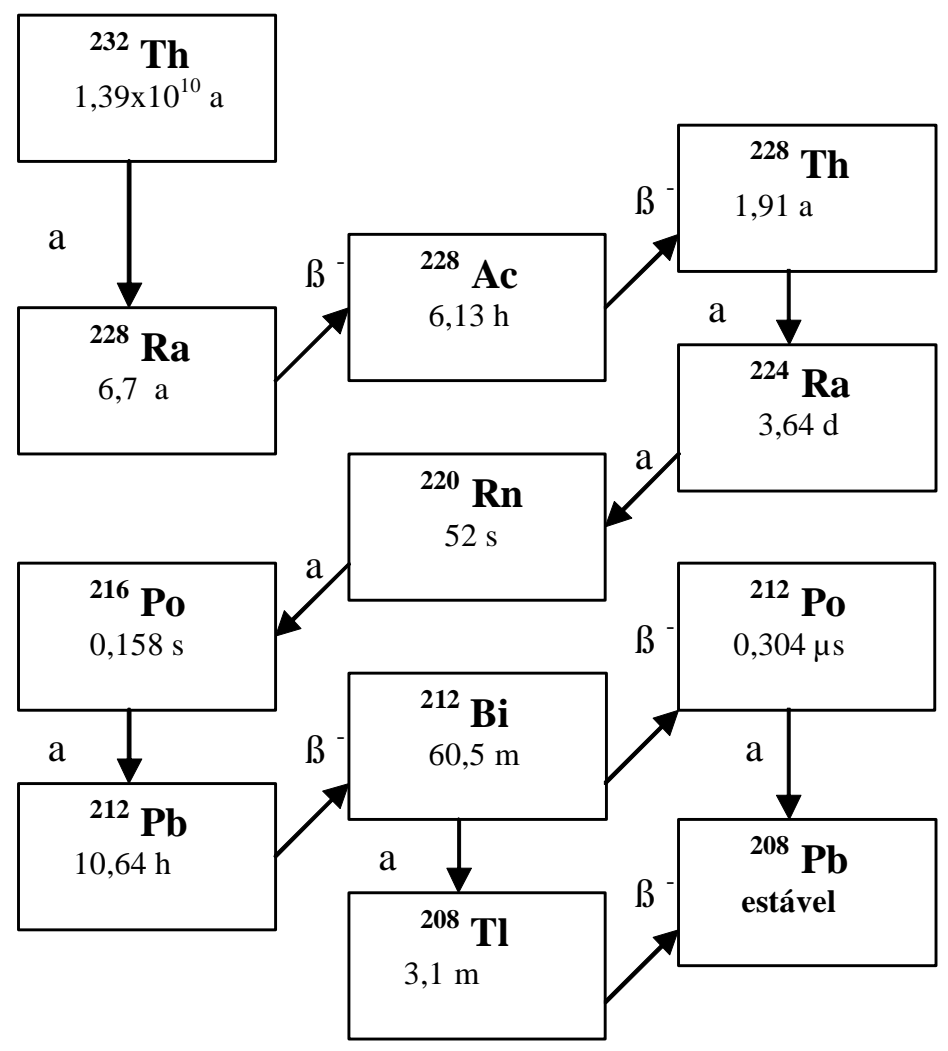

Figura 4-Série de decaimento do Tório (SEELMANN-EGGBERT et al., 1981)

em que :

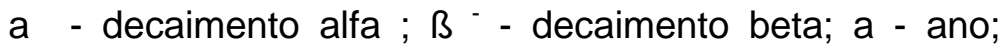

$\mathrm{d}$ - dia; $\mathrm{h}$ - hora ; $\mathrm{s}$ - segundos; $\mu \mathrm{s}$ - microsegundos 


\section{OBJETIVO}

Ao se iniciar o desenvolvimento de uma tese deve-se levar em conta os aspectos acadêmicos envolvidos, as regras e normas científicas, e o pesquisador atento busca em seu trabalho a relevância deste para a sociedade, presente e futura, e também os aspectos éticos que por ventura possam ser questionados.

O trabalho desenvolvido nesta tese é o de encontrar um processo e estudar procedimentos que possibilitem a recuperação do chumbo, contendo chumbo-208 enriquecido, no resíduo proveniente da unidade piloto de tratamento de tório, conhecido como RETOTER.

O processo poderá servir como referência, para resolver o passivo ambiental decorrente dos resíduos provenientes das unidades pilotos de purificação de tório do ciclo do combustível nuclear brasileiro, estocados no depósito de materiais radioativos, com salvaguardas nucleares, do Instituto de Pesquisas Energéticas e Nucleares-CNEN/SP.

O resíduo proveniente de unidades de tório contém o elemento chumbo contendo chumbo-208 com abundância isotópica diferente do chumbo natural que contém $52,4 \%$ de ${ }^{208} \mathrm{~Pb}$, (MUGHABGHAB, 1984) cujo enriquecimento é devido ao decaimento radioativo do elemento ${ }^{232} \mathrm{Th}$.

Este trabalho tem como objetivo desenvolver um processo para a separação, recuperação e obtenção de óxidos ou sais de chumbo, quantificar o seu enriquecimento, calcular alguns parâmetros nucleares, mais especificamente a secção de choque de captura para nêutrons térmicos e iniciar estudos preliminares para a obtenção de concentrados de tório e terras raras, no resíduo de tório e terras raras, RETOTER, proveniente de uma unidade de produção de nitrato de tório no IPEN. 
Pretende-se que os dados sejam úteis para a elaboração de um projeto conceitual para construção de uma unidade piloto de obtenção de chumbo, contendo o ${ }^{208} \mathrm{~Pb}$, a partir dos resíduos - RETOTER - que se acham estocados nos depósitos de materiais radioativos do IPEN. 


\section{REVISÃO DA LITERATURA}

O ciclo do combustível nuclear - ciclo tório utilizando-se de solventes orgânicos teve seu início em 1948 (TUCKER,1961) e no Brasil, com importância comercial, teve seu início após a década de 50 (IKUTA, 1977). Foi necessário o trabalho por algumas décadas para obtenção de concentrados provenientes dos resíduos das unidades de purificação de tório.

BRANDÃO $F^{O}$ e outros (1992) estudaram um processo químico, meio nítrico, visando o reaproveitamento do tório contido no RETOTER em usinas provenientes de purificação de tório, utilizando-se a técnica de extração por solventes em contra-corrente, agente extrator o fosfato de tri-n-butila (TBP). O estudo permitiu uma melhora no rendimento de produção, reduzindo as perdas de tório. Não se estabeleceram parâmetros de processo para recuperação dos outros elementos que se concentravam no resíduo.

A British Nuclear Fuels - PLC ( 1990 ) em sua patente detalha um processo de remoção de tório no efluente (refugado) gerado do processo de extração por solvente para purificação de urânio em minas. O processo inicia-se por uma pré-lavagem com querosene do efluente, seguido pela remoção do tório por extração com solvente, sendo o agente extrator o óxido de tri-n-octilfosfina diluído em querosene. O tório é revertido do solvente carregado, em contracorrente, com solução de carbonato de potássio a $60{ }^{\circ} \mathrm{C}$, e subseqüentemente precipitado pelo ajuste de $\mathrm{pH}$.

MARTINS (1990) estudou o reaproveitamento de valor nos efluentes líquidos das unidades pilotos de urânio e tório do Instituto de Pesquisas Energéticas e Nucleres-CNEN/SP. Estes valores eram principalmente a recuperação, para reciclo, dos ácidos e bases descartados pelo processo.

IKUTA (1977) descreveu um estudo de purificação, por solventes, de concentrados de tório transformado-os em compostos de elevada pureza, apropriados para utilização na fabricação de elementos combustíveis de reatores 
nucleares. Estes permitiram o planejamento, instalação e operação de uma unidade piloto de purificação de tório no Brasil.

ABRÃO et al. (2001) investigaram a separação química do tório, pureza técnica, utilizando-se de uma precipitação preferencial do peróxido de tório, separando das impurezas presentes como terras raras.

VASCONCELLOS (2000) investigou a obtenção de compostos de tório com separação de terras raras, a partir de um concentrado típico de tório proveniente do processamento industrial da monazita brasileira, por meio de precipitação fracionada associada à técnica de troca iônica. A precipitação fracionada baseia-se na dissolução ácida a quente do concentrado de tório para insolubilizar a maior parte da sílica existente, solubilizando tório e terras raras. A solução resultante pode seguir duas rotas: na primeira o tório é precipitado pelo ajuste de $\mathrm{pH}$; e na segunda pela separação em colunas de troca aniônica, onde o complexo de tório $\left[\mathrm{Th}\left(\mathrm{NO}_{3}\right)_{6}\right]^{2-}$ é retido pela resina e eluído quantitativamente com água desmineralizada.

WEI-FAN et al. (2003) investigaram a porcentagem de extração do tório, em meios clorídrico e nítrico, em produtos de reações nucleares, utilizando-se do agente extrator 1-fenil-3-metil-4-benzoil-pirazolone-5 diluído em benzeno. Os resultados apresentam uma melhor extração do tório em meio clorídrico. Verificou-se que o acréscimo do agente extrator proporciona uma melhor extração de tório.

BRIL et al. (1965a) descreveram os desenvolvimentos no processamento da produção de tório no Brasil, desde seu beneficiamento mineral até a tório pureza nuclear, com especial referência à experiência de uma planta piloto de extração por solventes com fosfato de tri-n-butila (TBP).

GORSUCH (1959) investigou dois métodos de separação do chumbo212 do tório: extração por solventes com dietilditiocarbamato de sódio e por troca iônica que envolve a retenção do chumbo, bismuto, tálio e polônio em uma coluna

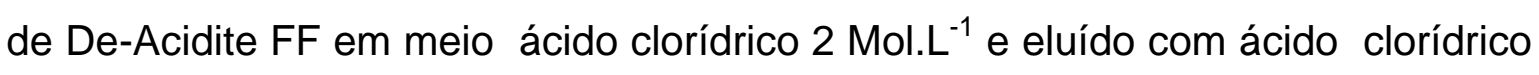


8 Mol.L $\mathrm{L}^{-1}$ ou água destilada, para obter informações do comportamento do chumbo.

KRAUS et al. (1954) descreveram um estudo do comportamento hidrolítico do tório (IV) em soluções de perclorato e de cloreto por meio de potenciometria.

ALLISON et al. ( 1954 ) descreveram um processo de separação do tório de seus descendentes, utilizando-se o agente extrator Tenoiltrifluoroacetona (TTA) em benzeno. Informações sobre a quebra do equilíbrio secular radioativo, entre o tório e seus descendentes foram apresentados.

CHUNG (1989) detalhou a precipitação química como uma alternativa de tratamento em resíduos aquosos perigosos contendo constituintes tóxicos, tais como: arsênio, bário, cádmio, prata, tálio, chumbo, cobre, mercúrio, crômio e zinco, que devem ser convertidos a formas insolúveis com seu agente precipitante adequado e removidos por filtração ou centrifugação.

BRAY et al. ( 1996 ) em sua patente demonstraram a separação de radionuclídeos de meia-vida curta a partir de suas misturas utilizando uma coluna de troca iônica, em meio nítrico.

TURAN et al. (2004) investigaram a recuperação de chumbo no resíduo de uma planta de obtenção de zinco. O agente extrator utilizado foi uma solução de cloreto de sódio de $200 \mathrm{~g} \cdot \mathrm{L}^{-1}$ à temperatura ambiente no tempo de 10 minutos, obtendo uma recuperação de 89 \% de chumbo.

PICHTEL et al. (2001) descreveram a remoção de chumbo, em solos contaminados com resíduos de descartes de baterias, utilizando-se a lavagem em bateladas com ácido etilenodiaminotetraacético (EDTA) , ácido piridina-2,6dicarboxílico (PDA) ou $\mathrm{HCL}\left(0.1\right.$ a $\left.1,0 \mathrm{Mol} . \mathrm{L}^{-1}\right)$. O método conseguiu uma remoção de no máximo 30 \% quando o estudo foi efetuado com $\mathrm{HCl}$, devido a presença de chumbo insolúvel no meio pelo seu envelhecimento. 
PAGANO et al. (2000) investigaram a separação e recuperação de chumbo em efluentes de bateria automotiva, utilizando-se resina catiônica fraca ( Purolite C106, da Purolite Co, UK).

JUANG et al. (1999) apresentaram a recuperação de EDTA e chumbo ( II ) de uma solução quelato usando uma membrana de troca iônica.

MOREIRA (1993) descreveu um estudo para a determinação de chumbo radioativo em águas minerais. O chumbo-210 foi determinado por meio do bismuto-210, pela medida da atividade beta total de um precipitado de ${ }^{210} \mathrm{PbCrO}_{4}$, após separação de elementos interferentes por complexação com ácido nitrilo tri-acético em pH básico.

KORKISCH et al. (1975) investigaram a determinação de chumbo em águas naturais utilizando resinas aniônicas para a separação. Inicialmente foi corrigida a acidez da água com $\mathrm{HBr}$, seguido de ajuste com ácido ascórbico para percolar em resina Dowex 1-X8 ( forma $\mathrm{Br}^{-}$). A eluição foi efetuada com ácido nítrico 1 Mol.L ${ }^{-1}$. Fez-se sua determinação por espectrometria de absorção atômica.

KORKISCH (1964) descreveu um método para a separação de chumbo de vários elementos empregando uma resina aniônica forte Dowex 1, X8. Utilizou uma mistura de $90 \%$ tetrahidrofurano e $10 \%$ ácido nítrico. Nestas condições o chumbo é mais fortemente adsorvido à resina do que muitos elementos, exceto terras raras. Sua eluição é feita com mistura de $80 \%$ tetrahidrofurano e $20 \%$ ácido nítrico 2,5 Mol.L ${ }^{-1}$.

GIBSON ( 1961) desc

LIMA e ABRÃO (1960) descreveram a separação do chumbo em uma mistura chumbo-bismuto utilizando-se da complexação com EDTA, precipitando ambos com hidróxido de sódio, mantendo uma concentração de 0,1 Mol.L-1, dissolvendo o chumbo com uma quantidade em excesso de hidróxido pela formação do plumbito de sódio. 
FEIGL (1958) detalhou diversos testes para detecção de chumbo, tório e algumas terras raras.

SHAVINSKII et al. (2000) descreveram um método de separação de terras raras por troca iônica, escala de laboratório, em meio ácido clorídrico, usando resina tipo AV-17-8ChS.

QUEIROZ et al. (2000) descreveram uma unidade piloto para obtenção de $10 \mathrm{~kg}$ de óxido de lantânio-grau espectrográfico. Esta unidade possui um conjunto de colunas catiônicas, que permitem o fracionamento das terra raras de uma solução clorídrica de terras raras. O controle analítico das impurezas do óxido de lantânio, após fracionamento, foi efetuado por um espectrômetro de massa de alta resolução (HR-ICPMS).

PUCHE et al.(1998) e ABRÃO (1994) elaboraram uma revisão da química e tecnologia das terras raras.

QUEIROZ (1988) detalhou o fracionamento, purificação e o controle analítico das terras raras a partir de uma solução de cloretos mistos de terras raras proveniente de uma unidade de produção brasileira. Apresentou uma unidade piloto para produção de terras raras, grau pureza espectrográfica, de diversos elementos obtidos após fracionamento.

AMPHLETT (1964 ) descreveu estudos com trocadores inorgânicos para a separação e recuperação do chumbo, tório e terras raras.

STEVENSON et al. ( 1961) descreveram a radioquímica e a química das terras raras e actínio.

KRUMHOLZ et al. (1958) descreveram as principais técnicas existentes para o fracionamento de terras raras no Brasil, incluindo princípios básicos, precipitação fracionada e cristalização, separação por troca iônica em resinas Dowex 50 - X8 utilizando como agente eluente o sal de amônio de EDTA tamponando o meio em $\mathrm{pH}$ 8,5.

KRAUS et al. (1956) investigaram o comportamento químico dos elementos, em resina aniônica, sumarizando os dados do comportamento de 
adsorção, em meio clorídrico, por uma série de gráficos que apresentam o logaritmo do coeficiente de distribuição versos a molaridade de $\mathrm{HCl}$.

\subsection{Tório}

O elemento Tório foi descoberto em 1828 por J. J. Berzelius que o isolou de uma amostra de mineral achado em uma ilha norueguesa . O elemento e o mineral torita tiveram seus nomes em honra ao deus escandinavo Thor. $\mathrm{O}$ elemento chamou atenção quando, em 1890, von Welsbach apresentou sua camisa de gás incandescente. Este dispositivo consistiu em um capuz de óxido do metal refratário que cerca a chama na qual o óxido torna-se incandescente e emite uma luz branca brilhante. A composição da camisa de lampião de Welsbach que contém, além de óxido de tório, aproximadamente 1\% óxido de cério, permaneceu essencialmente inalterada até os dias de hoje. CUTHBERT (1958) descreveu as principais informações tecnológicas de obtenção de tório. HYDE (1960) descreveu as principais informações sobre a radioquímica e a química do tório.

\subsubsection{Minerais}

O Tório não é um elemento raro, pois sua abundância na litosfera é de 0,001-0,002\%. Encontra-se em diversos minerais, usualmente associados com terras raras, e muitas vezes com titânio, nióbio, tântalo e urânio . Na hidrosfera seu conteúdo varia entre $10^{-5}$ e $10^{-9} \mathrm{mg} \cdot \mathrm{mL}^{-1}$ (RYABCHIKOV, 1960). Os principais minerais do tório (SNELL,1974; DANA, 1981) são listados na Tabela 2.

\subsubsection{Aplicações}

As principais aplicações do tório e seus compostos podem ser classificados em: energéticas e não energéticas: 


\subsubsection{Não energéticas}

As principais aplicações englobam produção de camisas de lampião à base de tório e cério, $50 \%$ da produção de tório; ligas de tório-magnésio contendo $3,0 \%$ de tório, $30 \%$ do consumo; ligas de endurecimento por dispersão, sendo $2,0 \%$ da liga $\mathrm{ThO}_{2}$, possibilitando tenacidade superior e resistência à corrosão para metais como níquel, cobalto, tungstênio e molibdênio a altas temperaturas, $10 \%$ do consumo. O restante do consumo está na produção de eletrodos refratários e eletrônicos.

Tabela 2- Minerais de tório

\begin{tabular}{lcc}
\hline Nome & Composição & $\mathrm{ThO}_{2} \%$ \\
\hline Queralita & $(\mathrm{Th}, \mathrm{Ca}, \mathrm{Ce})\left(\mathrm{PO}_{4}, \mathrm{SiO}_{4}\right)$ & $\sim 30$ \\
Hutonita & $\mathrm{ThSiO}_{4}$ & 81,5 \\
Pilbarita & $\mathrm{ThO}_{2} \cdot \mathrm{UO}_{3} \cdot \mathrm{PbO}_{2} 2 \mathrm{SiO}_{2} \cdot 4 \mathrm{H} 20$ & $\sim 31$ \\
Torianita & $\mathrm{ThO}_{2}$ & 100 \\
Torita & $\mathrm{ThSiO}_{4}$ & $23-65$ \\
Torogumita & $\mathrm{Th}\left(\mathrm{SiO}_{4}\right)_{1}-\mathrm{x}(\mathrm{OH})_{4}-\mathrm{x}[\mathrm{x}<\mathrm{O}, 25]$ & $24-58$ \\
Monazita $^{*}$ & $(\mathrm{Ce}, \mathrm{La}, \mathrm{Y}, \mathrm{Th})-\mathrm{PO} 0_{4}$ & $1-15$
\end{tabular}

${ }^{*}$ A Monazita é um mineral de terras raras que contém tório, porém, é o mineral mais importante comercialmente para obtenção de tório.

\subsubsection{Energéticas}

O ciclo de combustível de tório para reatores nucleares iniciou-se desde o começo da era nuclear, pelo uso do ${ }^{232} \mathrm{Th}$ como material fértil, pela sua transformação em ${ }^{233} \mathrm{U}$, material físsil, conforme a Eq. 1.

$$
{ }_{90}^{232} T h \longrightarrow{ }_{n, \gamma} \longrightarrow{ }_{90}^{233} T h \stackrel{\beta^{-}}{\longrightarrow}{ }_{91}^{233} \mathrm{~Pa} \stackrel{\beta^{-}}{\longrightarrow}{ }_{92}^{233} \mathrm{U}
$$


Estudos em diversos países para utilização de tório como combustível permitiram desenvolvimento em reatores do tipo LWR (CORREIA,1976; KOSAKA,1976; FAYA, 1975), reatores térmicos regeneradores moderados e refrigerados a água leve (FREEMAN, 1989), reatores a alta temperatura refrigerados a gás com combustível de carbeto de tório denominados pebble-bed (THEYNAMN,1990). Propostas mais recentes estudadas no Japão e Estados Unidos consideram reatores do tipo sais fundidos acoplados a um acelerador linear (MITACHI,1990; FURUKAWA,1992). Outra proposta bastante recente, um amplificador de energia, proposta pelo Prof. Dr. Carlos Rubia (RUBIA,1995a;RUBIA,1995b), considera um reator rápido com combustível de $\mathrm{ThO}_{2}$, refrigerado a chumbo e acoplado a um acelerador cíclotron. Estes 2 últimos permitem a incineração de actnídeos diminuindo os problemas de estocagem dos rejeitos radioativos além de se constituir em geradores de energia abundante.

O processo de separação e recuperação do tório e terras raras no resíduo RETOTER pode ser efetuado por diversos processos, entre eles cita-se o reaproveitamento inicial do tório por extração com o fosfato de tri-n-butila (TBP) (BRANDÃO $F^{\circ}$., 1992).

\subsubsection{Processamento de tório para fabricação de combustível nuclear}

O processamento do tório inicia-se pela mineração, abertura da monazita e a sua purificação. A obtenção de pastilhas de $\mathrm{ThO}_{2}$ e $(\mathrm{Th}-\mathrm{U}) \mathrm{O}_{2} \mathrm{e}$ fabricação de combustível nuclear do tipo PWR (MOREIRA, 1996) são feitas a partir do $\mathrm{UF}_{6}$, enriquecido em $5 \%$, que por reconversão a nitrato de uranilo é misturado a nitrato de tório nas proporções desejadas ( somente para ( Th-U) $\mathrm{O}_{2}$ ). A seguir, produzem-se pastilhas verdes de $\mathrm{ThO}_{2}$ e de $(\mathrm{Th}-\mathrm{U}) \mathrm{O}_{2}$, sinterizam-se e retificam-se as pastilhas produzidas. Faz-se a fabricação de tubos de revestimento e montagem das varetas de combustível e podem ser utilizadas nos reatores do tipo PWR (OSTERKANP, 1976; CORREIA,1976), e para a utilização de tório em reatores subcríticos acoplados a acelerados do tipo amplificadores de energia . 


\subsubsection{Propriedade físicas e químicas}

O metal tório quando cortado tem um brilho metálico prateado, mas escurece lentamente em exposição ao ar. O metal tem baixa dureza e pode ser cortado ou arranhado prontamente com uma faca. Em temperatura ambiente é frágil e muito dúctil. É trabalhado melhor através de extrusão mas pode ser forjado, estampado, laminado e estirado (SNELL, 1974).

O tório em pó é pirofórico e a combustão de fitas forma dióxido de tório, mas o metal maciço é estável à temperatura ambiente . Reage violentamente com halogêneos e enxofre a temperatura acima de $450^{\circ} \mathrm{C}$, e com nitrogênio a $650^{\circ} \mathrm{C}$. $\mathrm{O}$ hidrogênio reage com o pó à temperatura ambiente e com o metal maciço acima de $300{ }^{\circ} \mathrm{C}$ com liberação de calor, formando $\mathrm{ThH}_{2}$. Quando o metal é aquecido com carbono, fósforo ou boro, os carbetos $\mathrm{ThC}_{\mathrm{e}} \mathrm{ThC}_{2}$, os fosfetos $\mathrm{Th}_{3} \mathrm{P}_{4}$, e os boretos, $\mathrm{ThB}_{4}$, são formados (SNELL, 1974).

Água régia ou ácido clorídrico concentrado dissolvem o tório rapidamente . A reação inicial com ácido nítrico concentrado é rápida mas o metal logo se torna apassivado, podendo ser evitado pela adição de 0,05 MoL. $\mathrm{L}^{-1}$ de íons fluoretos ou fluorsilicato (SNELL, 1974).

Os ácidos diluídos fluorídrico, clorídrico, nítrico e sulfúrico atacam o metal vagarosamente, assim como os ácidos perclórico ou fosfórico.

A configuração eletrônica do tório é ( Radônio ) $6 \mathrm{~s}^{2} 7 \mathrm{~s}^{2}$, apresentando estado de oxidação +4 em todos os seus compostos , e caráter básico com seus sais, hidrolisando como as espécies tetravalentes de $\mathrm{Ti}, \mathrm{Zr}, \mathrm{Hf}$ e $\mathrm{Ce}$. Propriedades ácidas são quase sempre inexistentes . O ânion, incolor, e todos os sais de tório formam soluções incolores.

O tório tetravalente é pouco solúvel com fluoretos, carbonatos, hidróxidos, oxalatos e fosfatos. 
O tório forma uma grande variedade de compostos anidros e hidratados, com números de coordenação geralmente 6 ou 8 . Complexos quelatos são formados com carbonato, oxalato, tartarato, citrato, salicilato, cupferron, acetil-acetona, 2 fenoltrifluoroacetona e outros compostos orgânicos. Muitos são de importância analítica.

O fluoreto de tório hidratado, $\mathrm{ThF}_{4} \cdot(2,5-3) \mathrm{H}_{2} \mathrm{O}$, forma-se pelo adição de ácido fluorídrico a uma solução de sais de tório à temperatura ambiente . É decomposto por vapor superaquecido dando o dióxido de tório e fluoreto de hidrogênio . Esta reação é a base de métodos analíticos para determinação do teor de fluoreto em compostos de tório.

Quase todos os compostos de tório são convertidos em $\mathrm{ThF}_{4}$ pela ação do ácido fluorídrico. Para ajudar a precipitação de fluoreto de tório, ítrio ou lantânio são usados como carregador . O precipitado é insolúvel em água, em ácido fluorídrico em excesso e em ácidos minerais diluídos. Dissolve-se o fluoreto de tório com digestão prolongada de ácido sulfúrico ou ácido perclórico e rapidamente com fusão utilizando pirosulfato de sódio ou potássio . Quando o precipitado é recente dissolve-se com agentes complexantes como oxalato de amônio, ácido bórico ou nitrato de alumínio ( SNELL,1974).

O oxalato de tório $\mathrm{Th}\left(\mathrm{C}_{2} \mathrm{O}_{4}\right)_{2} \cdot 6 \mathrm{H}_{2} \mathrm{O}$, precipita-se com adição de ácido oxálico a uma solução contendo $\mathrm{Th}^{4+}$, sendo levemente solúvel em ácidos minerais . O oxalato de tório tem sua solubilidade afetada pelos íons amônio e terras raras. É dissolvido por aquecimento com ácido sulfúrico ou por ácido nítrico em ebulição e facilmente em excesso de oxalato de amônio, precipitando completamente se o meio é ácido.

Um precipitado floculante de iodato de tório forma-se quando uma solução de iodato entra em contato com soluções de sais de tório, sendo insolúvel em excesso de reagente. Serve para separar tório dos elementos terras raras, escândio e fosfato. Uma solução quente de ácido oxálico converte o iodato para oxalato de tório com liberação de iodo. O iodato também dissolve em ácido 
nítrico concentrado a quente. Soluções de iodeto de potássio, em meio ácido, são também eficientes em métodos titulométricos na determinação de tório.

O molibdato de amônio forma um precipitado gelatinoso de molibdato de tório, $\mathrm{Th}\left(\mathrm{MoO}_{4}\right)_{2}$, em meio ácido acético ou solução tampão de acetato . Dissolve-se rapidamente em ácidos fortes. Esta precipitação também serve para diversas titulações.

Dependendo da acidez do meio, vários fosfatos de tório são precipitados, por meio da reação entre fosfato e sais de tório. Utilizando o zircônio como carregador, microgramas de amostras de tório podem ser completamente co-precipitados, mesmo em soluções contendo ácido mineral até $10 \%$, mas em presença de muito ferro ou alumínio a precipitação de tório é incompleta.

A precipitação do peróxido de tório, em $\mathrm{pH}$ 0,5 - 1,5, é seletiva para separar tório de muitos cátions (FEIGL,1958).

O nitrato de tório, o composto comercial mais importante, normalmente é obtido pela dissolução de hidróxido de tório com ácido nítrico, purificando-se com extração por solvente ( sistema TBP/Varsol ), e cristalizando-o para a obtenção do produto tetrahidratado (IKUTA,1977). O nitrato de tório é solúvel em água, acetona, etanol e em muitos compostos orgânicos oxigenados e também em TBP. Um precipitado gelatinoso de hidroxihidrato de tório é obtido quando solução de hidróxidos alcalinos ou de amônia é adicionada à solução de tório, sendo insolúvel em excesso de reagente. Agentes complexantes como ácidos tartáricos e álcoois como glicerol previnem a precipitação. Na presença de elevado teor de sulfato a precipitação é incompleta a pH 6,0 sendo necessário o uso de amônio ou hidróxido alcalino.

O óxido de tório é obtido comercialmente pela calcinação de hidróxidos, oxalatos ou outros sais de algum oxiácido. É um pó branco, ponto de fusão, $3200 \stackrel{\circ}{\circ}$, e sua ebulição está entre 4200-4500 ำ . 
A densidade aparente do dióxido de tório varia dependendo da fonte; sendo que para se obter alta densidade é necessária à calcinação do hidróxido de tório.

\subsubsection{Toxicologia}

Existem três fontes de riscos do tório: toxicidade química, toxicidade radiológica e risco de combustão. Ainda que incidentes sérios não tenham sido registrados com tório, risco potencial existe e precauções de segurança são indicadas no manuseio de seus compostos ou metais, e especial cuidado com o óxido de tório que tende a ser um pó fino (SILVERNAIL E MCCOY,1969).

A toxicidade química considera-se pequena se ingerida oralmente, por causa da precipitação do óxido básico de tório a pH do trato digestivo. Os sais solúveis como nitrato podem causar hemólise se introduzido na corrente sanguínea.

A toxicidade radiológica resulta da radioatividade do tório e dos seus filhos, principalmente o Rádio-228 .

Perigos de combustão são principalmente do manuseio com pó de tório elementar.

\subsection{Terras Raras}

Os elementos escândio, ítrio, lantânio, cério, praseodímio, neodímio, promécio, samário, európio, gadolínio, térbio, disprósio, hôlmio, érbio, túlio, itérbio e lutércio são conhecidos como terras raras. O termo terras raras tem sua origem com a descoberta de minerais destes elementos, no final do século XVIII. 


\subsubsection{A Indústria de terras raras no Brasil}

O início da produção de terras raras no Brasil foi durante a segunda guerra mundial, incentivado pelo governo brasileiro. A firma ORQUIMA S/A iniciou as pesquisas para obtenção de urânio, tório e terras raras, a partir das areias monazíticas brasileiras. Iniciou-se então a venda de terras raras em concentrados e os subprodutos urânio e tório, devido aos seus usos nucleares, eram repassados para o governo brasileiro. Esta firma depois veio a ser nacionalizada pelo governo brasileiro repassando as suas instalações para a Comissão Nacional de Energia Nuclear ( LIMA,1969).

O processo químico utilizado no Brasil para produção de elementos de terras raras inicia-se pela abertura em meio alcalino da monazita. A seguir as terras raras são lixiviadas com ácido clorídrico a $80^{\circ} \mathrm{C}$, obtendo-se uma solução concentrada, conhecida como cloretos mistos de terras raras. Após correção de concentração e pH passam pelo processo de fracionamento, onde podem ser empregados a técnica de extração por solventes, com agentes extratores fosfato de tri-n-butila (TBP) ou ácido di(2-etilhexil)fosfórico (D2EHPA), ou troca iônica utilizando-se de resinas catiônicas fortes ( QUEIROZ,1988; ABRÃO,1994).

\subsubsection{Minerais}

Os minerais de terras raras são da ordem de 100, e seus principais minerais são listados na Tabela 3. Pode-se dividi-los em grupos das terras céricas, com maior concentração de terras raras leves ( $\mathrm{La}$ - Eu ), terras ítricas, contendo maior concentração de terras raras pesadas ( $G d-L u / Y)$, e considera-se o grupo de terras raras médias ( $\mathrm{Sm}-\mathrm{Ho}$ ). 


\subsubsection{Propriedades químicas}

Os elementos do Grupo VI e família IIIB, da classificação periódica, chamados de terras raras, apresentam propriedades químicas semelhantes, ocorrendo na natureza freqüentemente associados no mesmo mineral. Sua estrutura atômica caracteriza-se pelo preenchimento progressivo e preferencial de elétrons à camada $4 \mathrm{f}$

[ Xe ] $4 \mathrm{f}^{\mathrm{n}}, 5 \mathrm{~d}^{1}, 6 \mathrm{~s}^{2}$ sendo $\mathrm{n}$ o número de elétrons, $1<\mathrm{n}<14$.

Os elétrons da sub-camada $4 f$ encontram-se na região interna à camada de valência, sendo blindados pelos elétrons da camada 5 sub-camadas $\mathrm{S}$ e $p$, explicando facilmente a semelhança química por apresentarem o estado de oxidação +3 como o mais estável. O Cério e o Térbio podem apresentar também o estado de oxidação +4. O Európio e o Itérbio apresentam também os estados de oxidação +2 (ABRÃO,1994;QUEIROZ,1988;STEVENSON,1961).

As diferenças das propriedade químicas e físicas dependem do número de elétrons do orbital $4 \mathrm{f}$. $\mathrm{O}$ aumento de elétrons f produz uma atração maior em relação ao núcleo, aproximando as camadas eletrônicas, fenômeno denominado de contração lantanídica. Em conseqüência, há diminuição do raio e do volume atômico e aumento da densidade, levando a variações na atividade química, na basicidade dos íons trivalentes, na solubilidade dos compostos e na estabilidade dos complexos (STEVENSON,1961). 
Tabela 3- Minerais de Terras Raras

\begin{tabular}{cccc}
\hline Composto & Monazita (\%) & Bastnasita (\%) ${ }^{(*)}$ & Xenotima (\%) $\left(^{* *}\right)$ \\
\hline $\mathrm{La}_{2} \mathrm{O}_{3}$ & 22 & 32 & 3,7 \\
$\mathrm{CeO}_{2}$ & 46 & 50 & 7,1 \\
$\mathrm{Pr}_{6} \mathrm{O}_{11}$ & 5 & 4 & 0,8 \\
$\mathrm{Nd}_{2} \mathrm{O}_{3}$ & 18 & 13 & 3,8 \\
$\mathrm{Sm}_{2} \mathrm{O}_{3}$ & 3 & 0,5 & 2,2 \\
$\mathrm{Eu}_{2} \mathrm{O}_{3}$ & 0,07 & 0,08 & 0,3 \\
$\mathrm{Gd}_{2} \mathrm{O}_{3}$ & 1 & 0,2 & 5,0 \\
$\mathrm{Y}_{2} \mathrm{O}_{3}$ & 3 & 0,22 & 47,7 \\
$\mathrm{ThO}_{2}$ & 7 & n.d. & n.d. \\
$\mathrm{P}_{2} \mathrm{O}_{5}$ & 28 & n.d. & n.d \\
$\mathrm{SiO}_{2}$ & 1 & n.d. & n.d. \\
$\mathrm{F}$ & n.d. & 5 & n.d. \\
\hline n.d. - não determinado $;$ & $\left({ }^{*}\right)(\mathrm{BROWN}, 1979) ;\left({ }^{* *}\right)(\mathrm{ZINNER,} \mathrm{1982)}$ &
\end{tabular}

Os sais de terras raras são solúveis nos ácidos clorídrico, nítrico, perclórico, sulfúrico e acético.

A basicidade das terras raras diminui na seguinte seqüência:

La, $\mathrm{Ce}^{3+}, \mathrm{Pr}, \mathrm{Nd}, \mathrm{Sm}, \mathrm{Eu}, \mathrm{Gd}, \mathrm{Tb}, \mathrm{Dy}, \mathrm{Y}, \mathrm{Ho}, \mathrm{Er}, \mathrm{Tm}, \mathrm{Yb}, \mathrm{Lu}, \mathrm{Sc}, \mathrm{Ce}^{4+}$

Verifica-se que $\mathrm{o} \mathrm{La}(\mathrm{OH})_{3}$ possui a mais alta solubilidade, o maior $\mathrm{pH}$ de precipitação e produto de solubilidade, mas $\circ \mathrm{Ce}(\mathrm{OH})_{4}$, neste caso o elemento vizinho, o de menor solubilidade.

O fluoreto de terras raras é insolúvel e precipita em soluções de ácidos fortes, permitindo a separação de diversos elementos. 
O ânion oxalato é muito utilizado na precipitação das terras raras, pois, em soluções de ácidos diluídos, é considerado uma precipitação seletiva para este grupo de elementos. A precipitação é feita com solução de oxalato diluída no pH 2,0 a 3,0 (ABRÃO,1994).

\subsubsection{Fracionamento}

Os principais métodos de fracionamento das terras raras são a de troca iônica (POWELL et al. ,1960) e extração por solventes.

\subsubsection{Troca iônica}

O processo para o fracionamento das terras raras, utilizando-se troca iônica, é baseado na afinidade retentora das resinas catiônicas, combinadas com o efeito seletivo do agente complexante. Inicia-se pela percolação de uma solução de cloretos mistos de terras raras em colunas contendo resinas cationicas fortes ciclo amônio. A Eq. 2 descreve a reação de adsorção entre a resina e as terras raras.

$\left.\left.3 \mathrm{R}^{-\mathrm{SO}_{3}}{ }^{-}\right) \mathrm{NH}_{4}{ }^{+}{ }_{(\mathrm{s})}+\mathrm{TR}^{3+}{ }_{(\mathrm{aq})} \rightarrow \mathrm{R}^{-}-\mathrm{SO}_{3}{ }^{-}\right)_{3} \mathrm{TR}^{3+}{ }_{(\mathrm{s})}+3 \mathrm{NH}_{4}{ }^{+}{ }_{\text {(aq) }} \quad$ Eq. 2

Verifica-se que o número de oxidação das terras raras é principalmente +3 , tornando suas similaridades e afinidades químicas pela resina praticamente idênticas. Conseqüentemente, a percolação não permite uma separação entre os elementos.

A separação para ser efetivada deve ter um agente complexante que promova esta separação. O ácido etilenodiaminotetraacético (EDTA) é um dos mais empregados. Na Tabela 4 são apresentados os valores das constantes de estabilidade dos complexos Terras Raras-EDTA. 
Tabela 4 - Estabilidade dos complexos Terras Raras-EDTA

\begin{tabular}{cccc}
\hline Ín complexo & pk $^{(*)}$ & Íon complexo & pk $^{(*)}$ \\
\hline LaEDTA $^{-}$ & 14,72 & TbEDTA $^{-}$ & 17,25 \\
CeEDTA $^{-}$ & 15,39 & DyEDTA $^{-}$ & 17,57 \\
PrEDTA $^{-}$ & 15,75 & HoEDTA $^{-}$ & 17,67 \\
NdEDTA $^{-}$ & 16,06 & ErEDTA $^{-}$ & 17,98 \\
SmEDTA $^{-}$ & 16,55 & TmEDTA $^{-}$ & 18,59 \\
EuEDTA $^{-}$ & 16,69 & YbEDTA $^{-}$ & 18,68 \\
GdEDTA & 16,70 & YEDTA $^{-}$ & 17,38 \\
\hline$\left.{ }^{*}\right)$ & & &
\end{tabular}

O EDTA complexa cada uma das terras raras em sua molécula, tendo nos íons menores a maior estabilidade, ou seja, a estabilidade dos complexos cresce com o aumento no número atômico.

$\mathrm{O}$ fracionamento inicia-se com solução de $\left(\mathrm{NH}_{4}\right)_{3} \mathrm{EDTA}$ - $\mathrm{pH}$ tamponado. $\mathrm{O}$ íon amônio faz uma troca com as terras raras na resina e esta em solução é complexada pelo EDTA, Eq. 3. As frações recolhidas iniciam pelas pesadas ( Ye Lu - Gd), que são separadas, terras raras médias (Ho - Sm), que são difícies de separar com este agente complexante, formando um concentrado, seguidas finalmente as leves ( $\mathrm{Eu}$ - La) que são relativamente fáceis as suas separações.

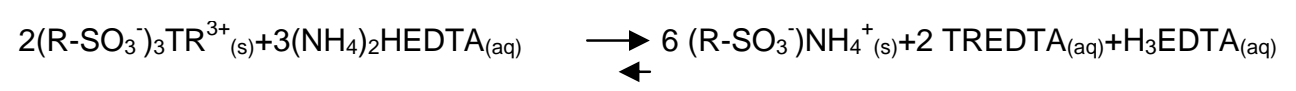

Na Figura 5 é mostrada uma unidade piloto de produção de terras raras, grau de pureza espectrográfica, sendo operada pelo grupo de terras raras do Instituto de Pesquisas Energéticas e Nucleares-CNEN/SP. 


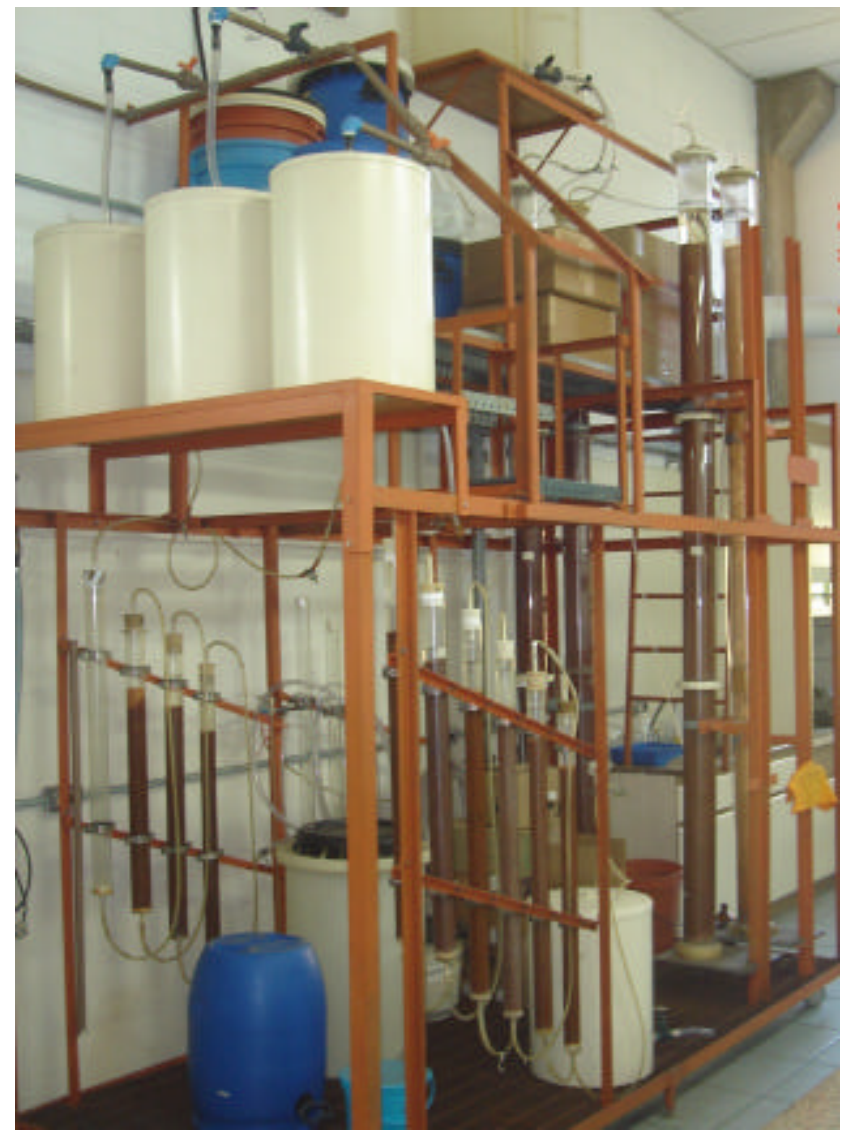

Figura 5- Unidade piloto de terras raras do IPEN-CNEN/SP

\subsubsection{Extração por solvente}

O processo de extração por solvente é baseado na transferência preferencial das terras raras da fase aquosa para fase orgânica, agente extrator, em um sistema líquido-líquido em equilíbrio.

Os principais agentes extratores são o fosfato de tri-n-butila (TBP) e o ácido di(2-etilhexil)fosfórico (DEHPA) (BROWN E SHERRINGTON, 1979; STEVENSON, 1961). O TBP mais utilizado em meio nítrico, Eq.4, e o DEHPA (H) para os meios clorídrico e sulfúrico, Eq.5.

$$
\mathrm{TR}^{3+}{ }_{(\mathrm{aq})}+3 \mathrm{NO}_{3}^{-}{ }_{(\mathrm{aq})}+3 \mathrm{TBP}_{\text {(org) }} \longrightarrow \mathrm{TR}\left(\mathrm{NO}_{3}\right)_{3} \cdot(\mathrm{TBP})_{3} \text { (org) }
$$




$$
\mathrm{TR}^{3+}{ }_{(\mathrm{aq})}+3(\mathrm{HR})_{2(\mathrm{org})} \longrightarrow \mathrm{TR}\left(\mathrm{HR}_{2}\right)_{3(\mathrm{org})}+3 \mathrm{H}^{+}{ }_{(\mathrm{aq})}
$$

O processo pode ser utilizado em colunas de extração ou em misturadores-decantadores com elevado número de estádios de equilíbrio, operando continuamente, em contra-corrente.

A técnica é muito eficiente na separação das terras raras em grupo, na purificação do európio, cério e do ítrio ( VYJAYAN et al.,1989; ZINNER, 1982; BROWN E SHERRINGTON, 1979;).

\subsubsection{Aplicações}

As terras raras são utilizadas em diversos campos, principalmente como catalisadores de petróleo, em polimentos de vidros especiais, ligas de aço, pedras de isqueiro, superligas, componentes eletrônicos, ímãs permanentes, usos em lasers, fósforos de televisão, na medicina como agentes de imagem em tomografia e com grande importância na tecnologia nuclear (ABRÃO, 1994 ; QUEIROZ, 1988; ZINNER, 1982).

\subsection{Chumbo}

O chumbo é um elemento conhecido desde a antiguidade e seu principal mineral a galena, um sulfeto de chumbo, era encontrada em grande quantidade pelo mundo antigo. A partir de 1623, Comeldon desenvolveu um processo de tratamento para a galena com redução pela hulha para obtenção de grandes quantidades de chumbo ( CALVET, 1962).

\subsubsection{Minerais de chumbo}

O mineral de chumbo é considerado raro pois, sua abundância na crosta terrestre é de $\sim 1,6 \times 10^{-3} \%$ ( MOREIRA, 1993 ), no entanto os depósitos encontrados têm elevada porcentagem em chumbo, o que viabiliza a extração mineral, além de estar, geralmente, associado à prata e zinco. 
Os minerais mais importantes do chumbo ( DANA, 1981) e seus teores médios são apresentados na Tabela 5.

Tabela 5- Pricipais Minerais de chumbo

\begin{tabular}{ccc}
\hline Composto & Fórmula & $\mathrm{PbO}(\%)$ \\
\hline Galena & $\mathrm{PbS}$ & $86,6^{(*)}$ \\
Cerussita & $\mathrm{PbCO}_{3}$ & 83,5 \\
Anglesita & $\mathrm{Pb} \mathrm{SO}_{4}$ & 73,6 \\
\hline${ }^{*}$ teor em Pb & &
\end{tabular}

\subsubsection{A Química do chumbo}

O chumbo tem sido um elemento de grande importância comercial e sua química é bem detalhada por diversos pesquisadores (BAILAR e EMELÉUS, 1973; CALVET,1962, GIBSON, 1961).

O chumbo metálico tem alta densidade, $11,34 \mathrm{~g} \cdot \mathrm{cm}^{-3}$ a $20{ }^{\circ} \mathrm{C}$, maleável, flexível, com ponto de fusão em $327^{\circ} \mathrm{C}$, ebulição $1750^{\circ} \mathrm{C}$, baixa dureza e alta resistência à corrosão de ácidos, porém, em água contendo $\mathrm{O}_{2}$, forma $\mathrm{Pb}(\mathrm{OH})_{2}$, que se dissolve lenta e parcialmente tornando-a tóxica ( CALVET, 1962).

O chumbo metálico pode ser dissolvido facilmente em ácido nítrico concentrado ( 8,0 Mol.L $\left.\mathrm{L}^{-1}\right)$, mas é resistente à ação de ácido sulfúrico nestas condições. Em ácido sulfúrico concentrado o chumbo é dissolvido. O oxigênio reage com chumbo em presença de ácidos orgânicos fracos, como ácido acético.

O chumbo forma numerosos sais, óxidos e compostos organometálicos solúveis e insolúveis bem como complexos ( GIBSON, 1961). 
Incluem-se entre os principais sais solúveis de chumbo os nitratos e nitritos, cloratos, bromatos, percloratos, ditionatos, citratos e acetatos. Os sais dos halogêneos são pouco solúveis em água gelada e sua solubilidade aumenta em meio ácidos de halogêneos, em razão da formação dos íons complexos como $\mathrm{PbCl}_{3}^{-}$.

O hidróxido de chumbo é pouco solúvel em água mas é solúvel em ácido ou soluções alcalinas. Em soluções alcalinas o nitrato básico de chumbo é precipitado, mas em presença de excesso de acetato, forma o acetato básico de chumbo solúvel que é utilizado para prevenir precipitação ou hidrólise de chumbo em meio neutro ou levemente básico.

O estado de oxidação +2 é o de maior importância em meio aquoso. Compostos do estado de oxidação +4 (íon plúmbico) são bem conhecidos, mas o íon livre é instável ou insolúvel em solução aquosa. Como o íon $\mathrm{Pb}^{2+}$ em meio aquoso torna-se predominante, as reações de oxi-redução não são importantes em separações ou determinação de chumbo. Exceção para a oxidação anódica para dióxido de chumbo e redução para o metal catodicamente ou por eletrodeposição interna.

Os principais sais insolúveis de chumbo são o brometo, carbonato, cromato, dicromato, ferrocianeto, fluoreto, hidróxido, iodato, iodeto, laurato, molibdato, oxalato, óxido, dióxido, ortofosfato, selenato, sulfato, sulfeto, tiocianato, tiosulfato, e tungstato.

O chumbo não é totalmente precipitado em solução de hidróxido de amônio, exceto na presença de Fe (III) ou Al (III). O hidróxido é anfótero sendo solúvel em soluções de alta alcalinidade devido a formação do íon plumbito, $\mathrm{HPbO}_{2}^{-}$.

$\mathrm{Na}$ presença de EDTA o chumbo por formar um complexo com boa estabilidade, não tende a co-precipitar ou precipitar em presença de hidróxido. 
A separação de bismuto do chumbo numa solução de $0,1 \mathrm{Mol}^{-L^{-1}}$ de $\mathrm{NaOH}$, contendo EDTA em excesso, tem sido usada, pois este fica na solução e o bismuto é precipitado. O chumbo então é precipitado no filtrado, rendimento $90 \%$ em menos de 15 minutos, no complexo com o bismutiol-1 (2,5-dimercapto-1,3,4 tiodiazol) (LIMA e ABRÃO, 1960),

A precipitação de cloreto de chumbo não é quantitativa, mas em alguns casos serve para retirar o excesso de massa para uma posterior separação, levemente solúvel em água fria, e solúvel em água quente ou ácido nítrico diluído a quente. Este é usado para separar chumbo de prata, pela precipitação de cloreto de prata.

As condições para um rendimento máximo de $\mathrm{PbCl}_{2}$ em meio $\mathrm{HCl}$ à temperatura ambiente está entre $\mathrm{pH} 0,5$ e pH 0,03 em soluções de acetato de chumbo. Ao acrescentar excesso de cloreto haverá a formação de complexos $\mathrm{PbCl}_{3}{ }^{-}, \mathrm{pk}=1,85$ (YATSIMIRSKII e VASIL'EV ,1960).

Utilizando excesso de EDTA em soluções de cloreto de chumbo, contendo prata e tálio, pela formação do complexo EDTA-Pb, o chumbo é solubilizado, permanecendo a prata e o tálio insolúveis, possibilitando uma a separação do chumbo. $\mathrm{O} \mathrm{Hg}_{2}{ }^{2+}$ também forma um complexo solúvel com o EDTA nestas condições, tornando-se um interferente.

A presença de citrato também evita a precipitação de chumbo em soluções diluídas de cloreto, podendo separar prata de chumbo.

A Ditizona ( difeniltiocarbazona) é um excelente reagente colorimétrico para determinação de traços de chumbo. Este reagente é seletivo, além de sua sensibilidade para o chumbo, devido à formação do complexo ditizona-chumbo que pode ser extraído em solventes orgânicos, principalmente em tetracloreto de carbono ou clorofórmio. 


\subsubsection{Troca iônica}

A adsorção de íon chumbo (II) pode ser feita em resinas aniônicas ou catiônicas (GIBSON, 1961; KRAUS e NELSON, 1956).

A adsorção do íon $\mathrm{Pb}^{2+}$, meio clorídrico diluído 0,05 Mol. $\mathrm{L}^{-1}$, em resinas aniônicas fortes é baixa ( coeficiente de distribuição $D=1$ ), atingindo um máximo em 1,5 Mol.L ${ }^{-1}(D=25)$ e decrescendo até 8,0 Mol.L ${ }^{-1}(D=<1)$. Esta variação permite que com mudanças nas condições de operação façam que, ora o chumbo saia antes do $\mathrm{Fe}^{3+}\left(\mathrm{Pb}^{2+}-8,0 \mathrm{Mol} . \mathrm{L}^{-1} \mathrm{HCL} ; \mathrm{Fe}^{3+}-0,5 \mathrm{Mol}^{-1}\right)$, ou saia depois $\left(\mathrm{Fe}^{3+}-1,0 \mathrm{Mol} . \mathrm{L}^{-1} \mathrm{HCL} ; \mathrm{Pb}^{2+}-8,0 \mathrm{Mol} . \mathrm{L}^{-1}\right)$.

O íon $\mathrm{Pb}^{2+}$ em meio nítrico tem baixa adsorção em resinas aniônicas, pois a forma complexa com o ânion $\mathrm{NO}_{3}{ }^{-}$não atinge um coeficiente de distribuição maior que 4,0, na faixa de 0,5 Mol. $\mathrm{L}^{-1}$ até 8,0 Mol.L $\mathrm{L}^{-1}$. Deve-se levar em conta que em concentrações acima de 6,0 Mol.L ${ }^{-1}$ a resina é atacada (VASCONCELLOS, 2000). Ao ser adicionado EDTA, em baixas concentrações, o comportamento é alterado e sua adsorção é elevada, produzindo um coeficiente de distribuição, em $\mathrm{pH} 4,7-5,0$, da ordem de 100.

A adsorção do íon $\mathrm{Pb}^{2+}$ em resinas catiônicas fortes, meio nítrico, também não ultrapassa o coeficiente de distribuição 5,0, com retenção entre 1,0 a $5,0 \mathrm{Mol} . \mathrm{L}^{-1}$. Em soluções de perclorato diversos íons são retidos o que possibilita a retenção em grupos, seguida de separações com eluentes apropriados.

\subsubsection{Extração por solvente}

Um dos mais conhecidos reagentes utilizados em extração por solvente é a ditizona para a remoção de chumbo, principalmente por ser um agente muito utilizado em análises colorimétricas de chumbo.

A utlização de ácido iodidríco para a remoção de chumbo seguido de extração por metil-isopropil-cetona, consiste em um sistema simples em soluções com diversos íons e $\mathrm{Pb}^{2+}$. 
Em soluções alcalinas contendo íons chumbo pode-se extrair o chumbo com ácido corboxílico dissolvido em solventes orgânicos, principlamente a metil-isobutil-cetona.

\subsubsection{Isótopos do chumbo}

Os principais isótopos do chumbo natural são ${ }^{204} \mathrm{~Pb}$ (abundância 1,40 \%) , ${ }^{206} \mathrm{~Pb}$ ( abundância 24,10 \% ), ${ }^{207} \mathrm{~Pb}$ ( abundância 22,10 \% ) e ${ }^{208} \mathrm{~Pb}$ ( abundância 52,40 \%) ( MUGHABGHAB, 1984). Os isótopos radioativos do chumbo vão de ${ }^{195} \mathrm{~Pb}$ até ${ }^{214} \mathrm{~Pb}$ ( GIBSON, 1961).

\subsubsection{Enriquecimento isotópico}

Os processos de enriquecimento isotópico foram desenvolvidos durante o século XX, principalmente no Projeto Manhattam para enriquecer o urânio em seu isótopo ${ }^{235} \mathrm{U}$.

Os principais processos são: difusão gasosa, ultracentrífuga a gás, tubo vórtex, separação por laser molecular ou atômico, químico ( diferenças no equilíbrio químico de reações de troca isotópica), separação em plasma, separação eletromagnética, difusão térmica, e bocal de separação.

Qualquer que seja o processo empregado, o efeito elementar de separação ocorre no elemento que separa o material introduzido em duas frações, uma enriquecida e outra empobrecida no isótopo desejado. Um grupo de unidades de separação ligadas em paralelo define um estágio. Quando a extensão de separação obtida na realização é pequena torna-se necessário o uso de repetição em cascata para alcançar os níveis desejados.

O trabalho de separação isotópica é extremamente difícil, e utiliza-se uma unidade prática para definir o enriquecimento isotópico, especialmente conhecido para urânio, que é a UTS ( unidade de trabalho separativo ), ou seja, 1 UTS é o trabalho separativo necessário para produzir $1,0 \mathrm{~kg}$ de urânio contendo aproximadamente o dobro da composição isotópica natural. O consumo de energia aproximado pode variar de 100 a $3500 \mathrm{kWh}$ para cada UTS. 
Este trabalho recupera o chumbo radiogênico, derivado do ${ }^{232} \mathrm{Th}$, enriquecido naturalmente, sem a utilização dos processos anteriores, evitando assim o alto consumo de energia utilizado para o seu enriquecimento.

\subsubsection{Aplicações do ${ }^{208} \mathrm{~Pb}$}

As principais aplicações do ${ }^{208} \mathrm{~Pb}$ são:

- Obtenção de novos elementos como o número atômico =108, é utilizado como alvo para a formação do elemento;

- Revestimento em detectores do tipo "Self-powered gamma detector" para medida de fluxo local em reatores nucleares;

- Refrigerante em reatores nucleares, podendo ser utilizado como liga $\mathrm{Pb}-\mathrm{Bi}$ ou $\mathrm{Pb}$.

- Marcadores de munição determinando a origem do fabricante.

- Material estratégico para uso militar.

\subsubsection{Toxicidade}

Os perigos do chumbo ( STELLMAN e DAUM,1975) estão associados aos vários processo industriais quanto em tintas de pintar ou em escapes de gases de automóveis ( especialmente em países que usam chumbo-tetraetila como anti-detonante da gasolina).

Os primeiros sintomas de intoxicação são insônia, fadiga e constipação intestinal ( prisão de ventre). O comprometimento do cérebro causa dor de cabeça, perda de apetite, fraqueza e, às vezes, dupla visão. Uma "orla saturnina" azul nas gengivas é evidência da intoxicação por chumbo. Afeta os tecidos formadores do sangue na medula óssea, produzindo anemia. Seus efeitos poderão ser sentidos ao longo dos anos, pois tem efeito cumulativo. 


\section{TROCA IÔNICA}

As resinas de troca iônica modernas (PETRONI,2004; ABRÃO, 1972) são hidrocarbonetos polimerizados, principalmente poliestireno, com ligações cruzadas de divinilbenzeno, contendo grupos ionizados. A resina está associada a um íon de carga oposta, ao grupo ionizado da resina, de livre ação para migrar para dentro e para fora da estrutura cruzada da resina sob condições de troca iônica.

A porcentagem de divinilbenzeno introduzida no polímero durante a síntese define as características de solubilidade da resina, como porosidade, inchamento e rigidez.

A estabilidade da resina está associada à ligação carbono-carbono nas resinas catiônicas, resistindo bem a ácidos, hidróxidos, agentes oxidantes e solventes orgânicos. Nas resinas aniônicas a ligação carbono-nitrogênio determina sua estabilidade, podendo ser atacada ao longo do tempo por microorganismos.

Os requisitos principais de uma resina são a insolubilidade, estabilidade química, capacidade de troca iônica e difusão.

Existem diversos tipos de resinas com diversos grupos funcionais e podem ser tipo gel ou macroreticular. Nas Figuras 6 a 11 são apresentadas as diferenças entre as resinas tipo gel e macrorreticular . 


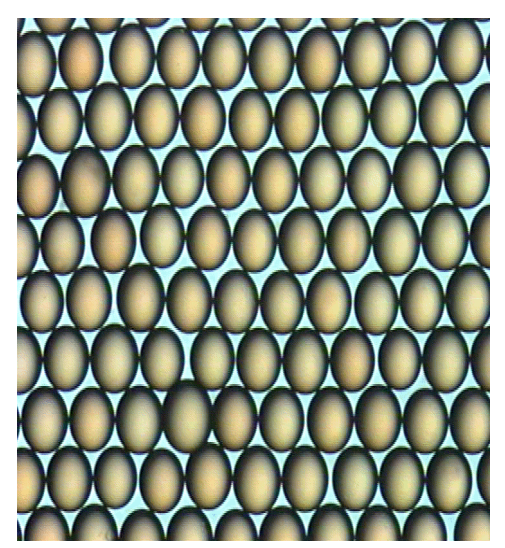

Figura 6- Resina Gel

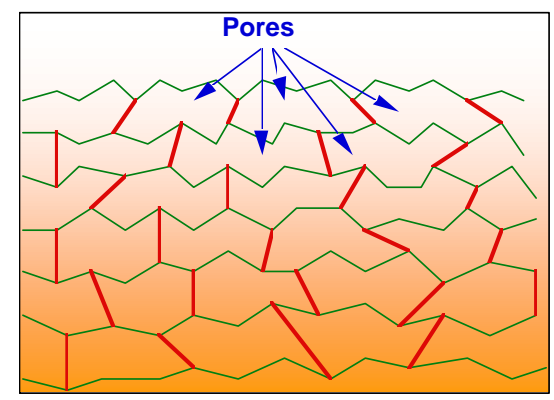

Figura 7- Poros - Gel

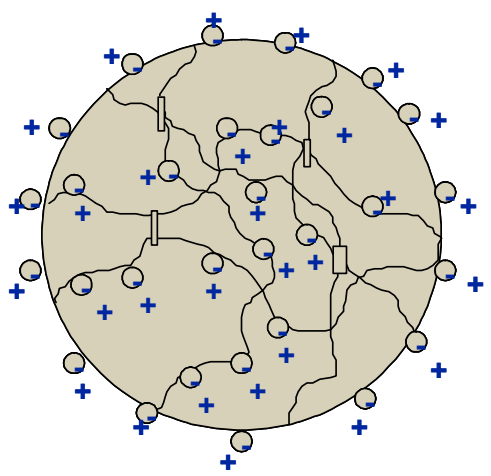

Figura 8- Estrutura Gel

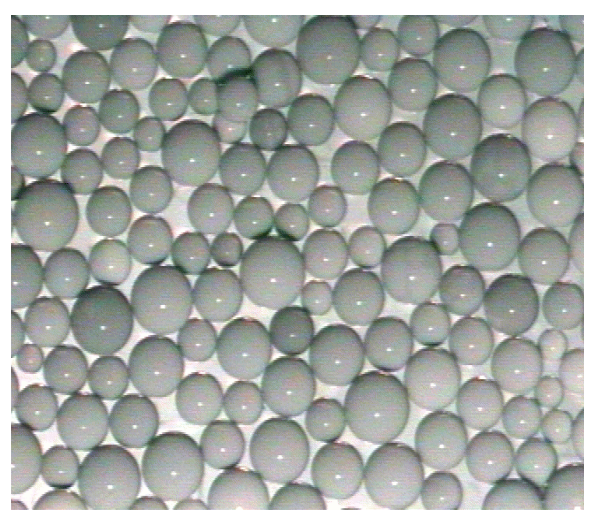

Figura 9- Resina macrorreticular

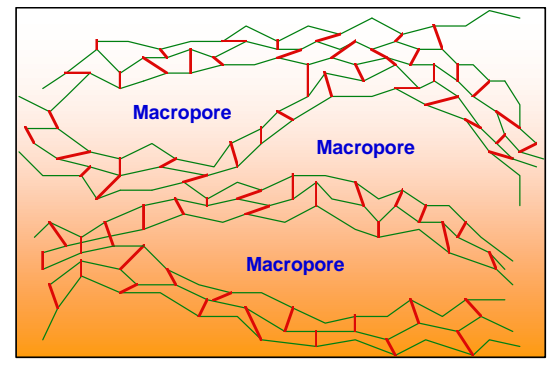

Figura10-Poros - macrorreticular

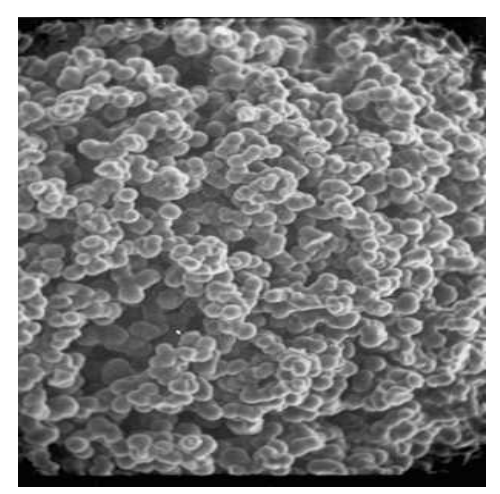

Figura 11- Estrutura macrorreticular 
As operações de troca iônica podem ser feitas na prática em bateladas ou colunas. Para esta tese foi utilizado o processo em colunas pois se obtém um grande número de equilíbrios consecutivos em um único local, ou seja, uma série de trabalhos em batelada simultaneamente, fornecendo condições contínuas para um ciclo cromatográfico de percolação, lavagem e eluição.

No processo em colunas utiliza-se curva de breakthrough (ponto de quebra), Figura 12, que é definido pelo aumento da razão entre as concentrações de efluente e influente com o movimento da zona de adsorção do íon estudado pela coluna ( C/Co X tempo ou volume de solução processado ).

O breakpoint representa o ponto da operação em que, para aplicações práticas, a coluna está em equilíbrio com a solução influente e somente uma pequena remoção adicional do soluto irá ocorrer.

A capacidade de troca da resina $\left(X_{b}\right)$, pode ser determinada pela Eq. 6 , a partir da curva de breakthrough, utilizando o volume de breakthrough ( $\left.\mathrm{V}_{\mathrm{b}}\right)$, o qual corresponde ao volume de solução efluente correspondente a C/Co igual a 0,5 :

$$
X_{b}=V_{b} \cdot C_{o} \cdot\left(?_{0} V_{\text {res }}\right)^{-1}
$$

Em que ?o representa a massa específica da resina em coluna, e $V_{\text {res }}$ o volume ocupado da resina na coluna em operação e $C_{0}$ a concentração da solução influente.

O ciclo da coluna de troca iônica segue as seguintes operações:percolação, lavagem e eluição.

A curva de breakthrough está relacionada à etapa de percolação, e para a etapa de eluição obtém-se a curva de eluição. Na Figura13 apresentase o formato típico desta curva. 
A área hachurada da integral da concentração pelo volume representa a quantidade do íon eluído $m_{a d s}$, em unidades de massa, e pode ser calculado pela Eq. 7.

$$
m_{a d s}=?_{0}^{v} \mathrm{Cdv}
$$

A partir deste valor determina-se a porcentagem de recuperação do íon adsorvido na coluna.

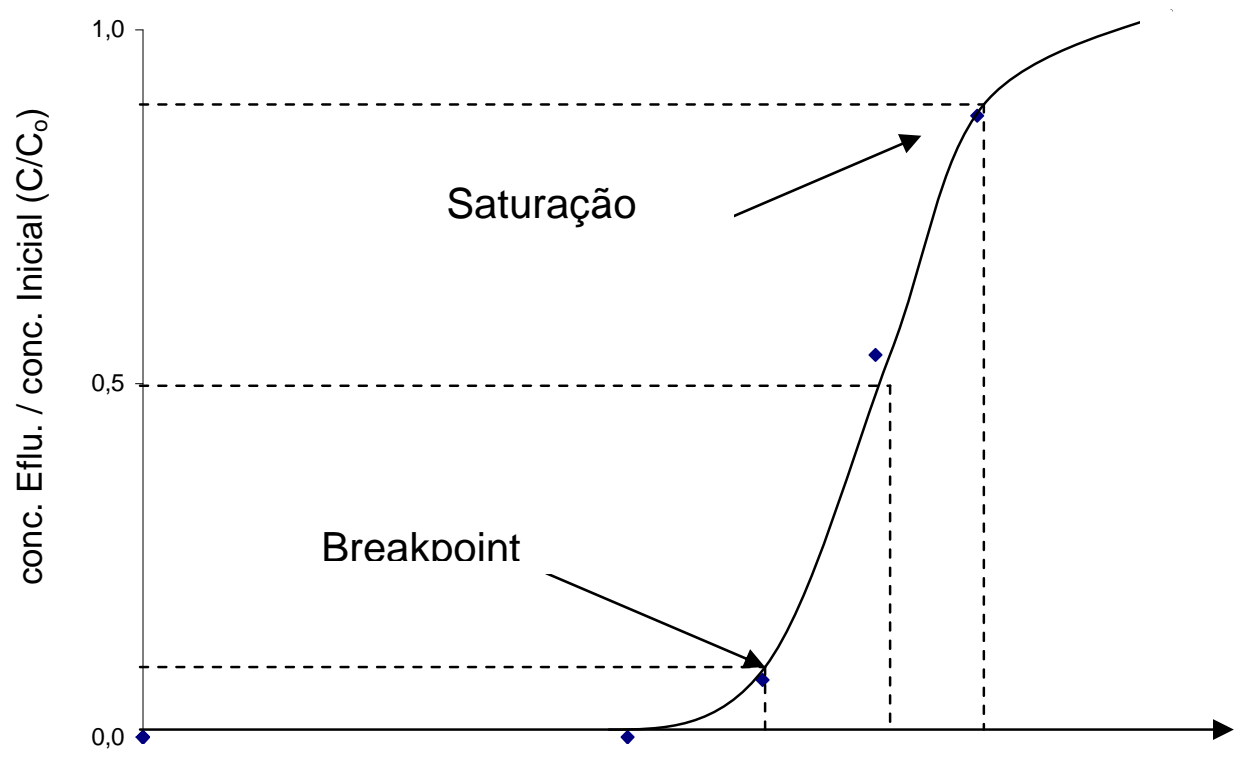

Figura 12- Curva teórica de breakthrough volume efluente $(\mathrm{mL})$

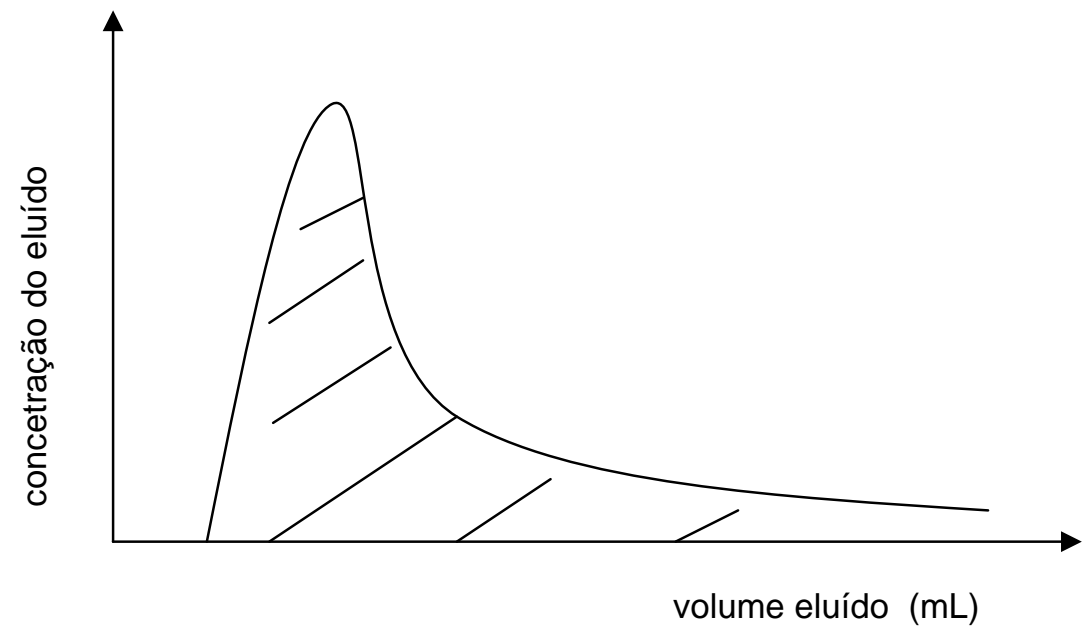

Figura13- Curva de eluição 


\section{MATERIAS E MÉTODOS}

\subsection{Materiais e Reagentes}

Todos os reagentes utilizados foram de grau analítico, Merck ou Carlo Erba, e as soluções foram preparadas usando-se água desionizada com condutividade $=1,0 \mu \mathrm{S} . \mathrm{cm}^{-1}$.

Resina tipo macrorreticular IRA-900 Cl, 16-50 mesh capacidade de troca total volumétrica (base úmida) 1,0 meq. $\mathrm{mL}^{-1}$ e resina tipo gel IRA- 458, capacidade de troca total volumétrica (base úmida) 1,25 meq. $\mathrm{mL}^{-1}$ aniônica forte, forma cloreto, da firma Rohm and Hass Brasil Ltda. Foi lavada somente com água desmineralizada para remoção dos finos. A resina assim obtida foi utilizada para a coluna cromatográfica;

Coluna de troca iônica ( Diam. Int. $14 \mathrm{~mm}$ X 7,0 mL da resina IRA-458) de poliestireno;

Coluna de troca iônica ( Diam. Int. $21 \mathrm{~mm}$ X $100 \mathrm{~mL}$ da resina IRA 458 ou IRA $900 \mathrm{Cl}$ ) de PVC;

Foram utilizados diversos materiais como vidrarias de laboratório, tais como erlenmeyer, béqueres, provetas, cadinhos de porcelana e de platina, frascos para solução de estoque, buretas, pipetas, funis de separação, tubos de ensaio, frascos de polietileno de variados tamanhos, estabelecidos quanto à necessidade do uso. 


\title{
5.2 Equipamentos
}

Os equipamentos utilizados para as análises desta tese estão nos laboratórios do Centro de Química e Meio Ambiente do IPEN-CNEN/SP, estes possuem sistema de qualidade implantado segundo a norma ABNT NBR ISSO/TEC 17025:2005. Estabelecem e mantém procedimentos documentados para controlar, calibrar e manter equipamentos de análises, medição e ensaios, incluindo software de análises, utilizados pelos laboratórios para demonstrar a conformidade do produto aos requisitos especificados, assegurando que se conheça a incerteza das medições, e que é consistente com a exatidão e as especificações requeridas. Sendo discriminados abaixo:

Reatores químicos de $4000 \mathrm{~mL}$ em Pyrex, e $1000 \mathrm{~mL}$ em Vidro, providos de agitadores, termômetros e camisas de aquecimento;

Banho termostatizado, tipo FK 4391, faixa de trabalho de $-30{ }^{\circ} \mathrm{C}$ a + $100{ }^{\circ} \mathrm{C}$, Haake;

\author{
Balança Analítica H15, Metler; \\ pHmetro modelo B371 Micronal; \\ Placa -agitador aquecedor modelo 258- Fanen; \\ Estufa, Ética Equipamentos;
}

Analisador Voltamétrico Metrohm 757 VA Computrace no modo electrodo gota pendente de mercúrio (HMDE) - (Pt A.E., Ag/AgCl Ref. System, Stirring PTFE);

Espectrômetro de Fluorescência de Raios-X - Energia Dispersiva ( EDXRF) marca Shimadzu, Modelo EDX-700; 
Espectrômetro de Fluorescência de Raios-X com dispersão de comprimento de onda ( WDXRF) marca Rigaku Denki, Modelo RIX 3000, gerador Geigerflex;

Espectrômetro de Massa de alta resolução com fonte de plasma induzido (ICPMS). Modelo Element 1 - fabricado pela Finnigam MAT;

Espectrômetro de Massa Termoiônico. Modelo 354 com sistema de software da HP- VG ISSUE fabricado pela Micromass VG Isotopes ${ }^{(*)}$.

Espectrômetro Gama de Nal ( TI ) (range 60 - 3000 kev) acoplado a um multicanal ORTEC e sistema de análises de dados por computação, marca ORTEC, fabricado nos Estados Unidos.

${ }^{(*)}$ Equipamento do Laboratório do Instituto de Geociências da Universidade de São Paulo

\subsection{Técnicas Utilizadas}

As principais técnicas utilizadas neste trabalho foram a fluorescência de Raios- X, Espectrometria de massa e Voltametria.

\subsubsection{Fluorescência de raios-X}

\subsubsection{Dispersão de comprimento de onda (WDXRF)}

A técnica de Fluorescência de Raios-X por dispersão de comprimento de onda (WDXRF) ( SCAPIN, 2003; SALVADOR, 1982) consiste em incidir um feixe de Raios-X em uma amostra e produzir radiações fluorescentes, ou seja, um elétron é removido de seu lugar ficando uma vacância que é preenchida pelo elétron mais próximo, neste processo ocorre a emissão de um fóton com energia correspondente à diferença entre os níveis do elétron vizinho até a vacância. Estas, por serem transições eletrônicas das camadas mais internas dos átomos, tornam-se características de cada elemento químico. Ao serem difratadas por um cristal analisador, segundo a Lei de Bragg, é captada por um detector. 
A técnica permite a análise quantitativa e qualitativa de elementos maiores e menores constituintes em diversos tipos de materiais.

As vantagens desta técnica são: análises instrumentais multielementares sem o uso de curvas de calibração, alta sensibilidade e metodologias não destrutivas e rápidas.

A técnica foi utilizada para a caracterização do RETOTER. As amostras sólidas de RETOTER para as análises no espectrômetro de fluorescência de raios- $X$, tinham granulometria de 200 mesh, e foram adicionadas a um porta-amostra de $40,0 \mathrm{~mm}$ e recobertas por uma fina folha de Mylar. As amostras encaminhadas eram em triplicatas.

\subsubsection{Energia dispersiva (EDXRF)}

O espectrômetro de fluorescência por energia dispersiva (EDXRF) usa o detector de Si (Li), diferente dos de dispersão por comprimento de onda que usam cintiladores e contadores proporcionais. Os detectores captam a radiação fluorescente e conseguem distinguir diferentes radiações características pelas suas energias. Assim, no EDXRF o detector capta todo o espectro simultaneamente, enquanto no WDXRF, o detector capta as linhas características que foram separadas pelo cristal analisador.

Os elementos possíveis de serem analisados no EDXRF vão desde 0 ${ }_{11} \mathrm{Na}$ até $\mathrm{O}{ }_{92} \mathrm{U}$. Com esse aparelho é possível efetuar análises em soluções e sólidos, e sua velocidade de análise pode levar em média 40 s por varredura.

A técnica foi utilizada no acompanhamento do processo de separação e recuperação de chumbo. As amostras foram encaminhadas diretamente para análises desde a solução de carga, efluentes e eluídos, para determinação dos constituintes presentes. 


\subsubsection{Espectrometria de massa}

A técnica de espectrometria de massa (VERGARA,2001; PEDREIRA $F^{\circ}$., 2000; MORAES, 1988; WILLARD et al.,1974) é empregada em medidas precisas de abundâncias isotópicas.

A determinação da composição isotópica de chumbo requer amostras com massas da ordem de dezenas de microgramas a dezenas de miligramas, dependendo do tipo de amostras, se composto puro de chumbo, ou uma matriz complexa contendo chumbo, do modo de ionização, e da precisão requerida na determinação.

A ionização térmica como fonte de ionização é geralmente preferida para amostras que necessitam de medidas de composição isotópica com grande precisão. Os espectrômetros de massa com fonte de ionização termoiônica (TIMS) produzem resultados com precisão da ordem de 0,02 \% a 0,06\% para medidas isotópicas de chumbo ( KURITANI, 2002). A boa precisão obtida está relacionada ao preparo da amostra e quantidades trabalhadas. De um modo geral, os procedimentos envolvem separação química do elemento de interesse e eliminação dos voláteis, impurezas orgânicas presentes na amostra.

A separação química geralmente é realizada em colunas de troca iônica e uma vez preparada para medida no TIMS, o próprio procedimento de análise por aquecimento gradual até atingir a temperatura de ionização do elemento de interesse promove um espectro de massas de chumbo com menos interferentes.

Medidas isotópicas de chumbo apresentam dificuldade em relação a outros elementos em se obter uma boa eficiência de ionização por medida direta de chumbo depositado no filamento de ionização. Em geral a técnica utilizada para melhorar a eficiência de ionização é a que faz a associação do chumbo com sílica gel e ácido fosfórico. 
A espectrometria de massa com fonte de ionização por plasma indutivo com detector monocoletor apresenta uma menor precisão nas medidas isotópicas do que as realizadas por TIMS. A própria natureza da forma de ionização por plasma produz muita instabilidade na ionização dos isótopos. Toda amostra introduzida em alta temperatura de ionização do plasma, cerca de $8000 \mathrm{~K}$, sofre a evaporação e ionização e recombinações com os gases do plasma que competem com a ionização do elemento de interesse.

Têm-se observado que um grande número de trabalhos vem empregando a técnica de espectrometria de massas com fonte de plasma indutivo (ICPMS), uma vez que com os novos avanços tecnológicos nesta área, as medidas de composição isotópica têm atingidos níveis de precisão comparáveis ao TIMS. Precisões melhores que 0,01 \% foram obtidas em espectrômetros de massa com fonte de plasma indutivo com detectores multicoletores ( MC-ICPMS) ( KAMENOV, 2005). Independente do tipo de ICPMS, medidas isotópicas com precisões razoáveis da ordem de $0,1 \%$ são obtidas facilmente nos ICPMS convencionais, com a vantagem de não necessitar realizar separações químicas demoradas e permitir trabalhar com amostras da ordem de microgramas.

O trabalho desenvolvido utilizou-se do teste cruzado, nas análises isotópicas de chumbo, para a obtenção de resultados com grau de certeza elevada. Analisou-se por métodos e aparelhos distintos, espectrômetro de massa (setor magnético) com fonte de plasma induzida por argônio (ICPMS) e espectrômetro de massa termoiônico (TIMS). 


\subsubsection{Voltametria}

A voltametria é uma técnica (SISTI, 2001) onde estudam-se as relações corrente-potencial quando se aplica um potencial a um eletrodo de trabalho. Na voltametria com varredura linear de potencial faz-se o registro de curvas corrente-potencial quando o potencial varia linearmente com o tempo. $O$ voltamograma fornece informações analíticas de identificação e concentração do metal por meio do potencial e altura da onda voltamétrica. As etapas de transferência de massa do reagente à superfície do eletrodo durante a eletrólise são:

- difusão, associado ao gradiente de concentração que se estabelece devido ao fenômeno de eletrólise;

- convecção , causado pela agitação mecânica da solução;

- migração, movimento ou migração dos íons.

Admitindo-se que a solução não tem agitação e as correntes de migração devido ao eletrólito suporte sejam desprezíveis, estabelece-se o mecanismo de difusão como a etapa controladora, ou lenta, do processo de transferência de massa, mas não se pode esquecer de utilizar-se de critérios de caracterização do processo de eletrodo, pois o etapa de transferência de elétron pode ser a lenta.

Neste trabalho usou-se a voltametria de redissolução anódica onde os metais são depositados no eletrodo e a sua concentração é aumentada pela acumulação na interface eletrodo-solução. Os tempos de deposição para a préconcentração são relativamente pequenos geralmente de $20-60$ segundos. Após o tempo de pré-concentração no potencial de deposição, o potencial do eletrodo é registrado na direção anódica e nos respectivos potenciais redox os metais depositados são novamente reoxidados ao seu estado iônico e redissolvidos., Os voltamogramas são registrados utilizando-se a polarografia de pulso diferencial, voltametria de onda quadrada ou outra técnica voltamétrica. $\mathrm{O}$ valor da corrente 
de pico é proporcional à concentração do metal que está sendo extraído. Como cada metal tem potencial de pico diferente, vários metais podem ser determinados simultaneamente em um único registro. Assim na varredura linear de potencial na direção anódica, que ao alcançar o potencial de oxidação do metal, no caso do chumbo em - 0,38 V, gera-se uma corrente proporcional à concentração do metal na amostra. Esta é analisada por um detector, que encaminha os sinais para um sistema de análise de dados ( computador), gerando as informações da análise.

A Eq. 8 representa o processo voltamétrico (CARVALHO, 1988) :

$$
\mathrm{Ip}=881 \cdot \mathrm{n}^{3 / 2} \cdot A D^{1 / 2} \cdot v^{1 / 2} \cdot \mathrm{C} . ? \quad\left(\mathrm{a} 25^{\circ} \mathrm{C}\right) \quad \text { ( Eq. } 8 \text { ) }
$$

em que:

Ip $=$ corrente de pico $(A) ; \quad A=$ área do eletrodo $\left(\mathrm{cm}^{2}\right)$

$C=$ concentração $\left(\right.$ Mol. $\left.L^{-1}\right) ; \quad D=$ coeficiente de difusão $\left(\mathrm{cm}^{2} \cdot \mathrm{s}^{-1}\right)$

$\mathrm{v}=$ velocidade de varredura de potencial $\left(\mathrm{V} . \mathrm{s}^{-1}\right)$

$\mathrm{n}$ = número de elétrons que participam da reação

$?=r_{o}^{-1}\left(D .(n . v)^{-1}\right)^{1 / 2}$ sendo $r_{o}$ o raio do eletrodo $(\mathrm{cm})$

O valor de Ip é diretamente proporcional à concentração das espécies eletroativas, fundamental para a análise dos elementos a serem determinados.

As amostras de chumbo, entre 150 a $250 \mu \mathrm{L}$, para as análises, foram obtidas diretamente da solução estoque, efluentes de percolação, lavagem e eluído. Avaliou-se cada amostra em triplicata. Estas são pipetadas para a célula do analisador voltamétrico com os parâmetros de medições em: 
solução eletrólito $=21 \mathrm{~mL}$ de $\mathrm{HNO}_{3} 0,005{\mathrm{Mol} . \mathrm{L}^{-1}}^{-1}$

tempo de purga com nitrogênio $=300 \mathrm{~s}$

agitação = 4000 rpm; $\quad$ tempo de pré-concentração = $20 \mathrm{~s}$

tempo de equilíbrio $=10 \mathrm{~s} ; \quad$ varredura $=5 \mathrm{mv} \cdot \mathrm{s}^{-1}$

Utilizou-se o método de adição padrão para a quantificação do chumbo, com padrões monoelementares diluídos de soluções concentradas de chumbo da Metrohm.

\section{$5.4 \quad$ Metodologia}

O processo de separação e recuperação dos metais no resíduo RETOTER iniciou-se com: obtenção do concentrado, um hidróxido, tendo como constituintes principais os metais provenientes do RETOTER, a partir da precipitação dos refugados de unidades de produção de nitrato de tório com hidróxido de sódio concentrado até pH 9,0. O precipitado foi separado por filtração e a pasta resultante estocada em tambores apropriados de PVC.

\subsubsection{Amostragem}

As amostras do material foram obtidas nos 180 tambores contendo pasta de RETOTER, peso variando de 120 a $200 \mathrm{~kg} / \mathrm{tambor}$, da seguinte forma:

Dividiu-se o lote total em 18 conjuntos de 10 tambores, sendo retirado aleatoriamente, em um tambor de cada um dos conjuntos, uma amostra com uma régua de amostragem para pasta, confeccionado no IPEN. As amostras foram obtidas em cinco pontos do tambor, sendo quatro pontos em forma de um losângulo equilátero e uma central, mostrado na Figura 14. Retiraram-se aproximadamente $50 \mathrm{~g}$ de pasta em cada ponto, numa amostragem perpendicular de cima até $5 \mathrm{~cm}$ do fundo. A pasta foi misturada e retirou-se desta 
amostra, uma parcela que foi pesada e levada para uma estufa a $110{ }^{\circ} \mathrm{C}$ por 24 horas, até peso constante, obtendo-se o teor de umidade. Misturou-se o pó am almofariz para homogeneização, fez-se o quartiamento, e da amostra retirou-se $1 / 4$, levando-se $5 \mathrm{~g}$ para análise dos elementos constituintes no composto por WDXRF (Fluorescência de Raios-X).
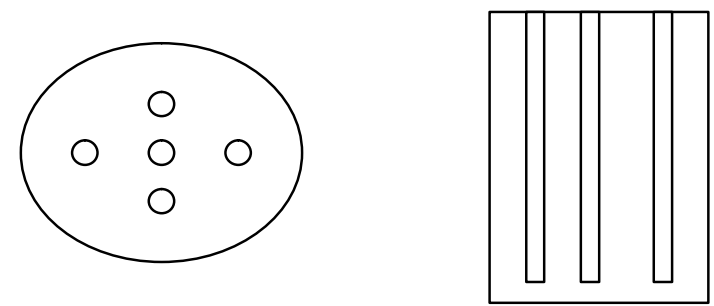

Figura 14- Amostragem no tambor de RETOTER

\subsubsection{Chumbo}

Estudos preliminares indicaram duas rotas possíveis para o processo de separação e recuperação de chumbo a partir do RETOTER:

1) Dissolução do RETOTER com ácido clorídrico seguido de separação e recuperação do chumbo, utilizando-se a técnica de troca iônica, sendo o produto obtido por concentração e precipitação ;

2) Extração seletiva do chumbo utilizando-se hidróxido de sódio para a precipitação de tório, terras raras e outros elementos que formam hidróxidos insolúveis, enquanto o chumbo é dissolvido por complexação com o próprio hidróxido de sódio.

No diagrama de blocos da Figura 15 apresentam-se os procedimentos necessários para a obtenção óxido de chumbo. 


\subsubsection{Dissolução ácida}

$\mathrm{Na}$ dissolução do RETOTER foram estudadas as variáveis: Razão HCl:RETOTER, intervalo 1:1 - 5:1 (v/m); Agitação da solução, intervalo 100- 500 rpm; Temperatura de digestão, intervalo $25-85{ }^{\circ} \mathrm{C}$; Tempo de dissolução, intervalo $15-60 \mathrm{~min}$.
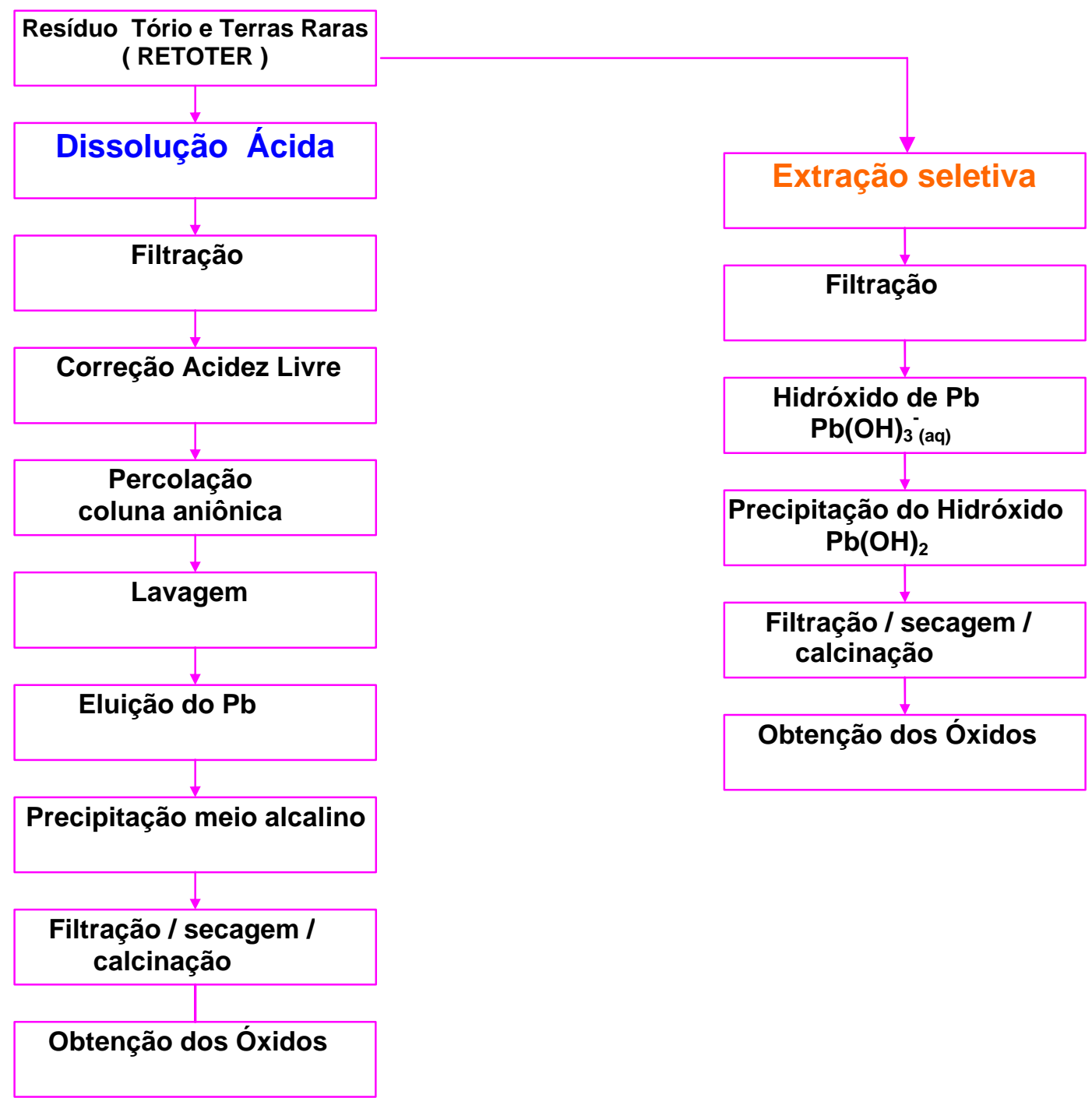

Figura 15- Diagrama de blocos do processo para obtenção do óxido de chumbo por troca iônica e por complexação com $\mathrm{NaOH}$. 
Escolheu-se nesta tese o ácido clorídrico, pois trabalhos em meio nítrico para a dissolução do RETOTER já foram realizados (BRANDÃO,1992 ; IKUTA,1977 ). O meio clorídrico proporciona a melhor retenção em resina aniônica. Para a dissolução pesam-se $50 \mathrm{~g}$ de RETOTER, Figura 16, transferindo-o para um reator de dissolução com camisa de aquecimento, Figura 17, em Pyrex, contendo $50 \mathrm{~mL}$ de ácido clorídrico concentrado, Inicia-se a agitação do meio e o aquecimento até $85{ }^{\circ} \mathrm{C}$ por uma hora. Após resfriamento, filtra-se a solução para eliminar os insolúveis, principalmente composta de sílica.

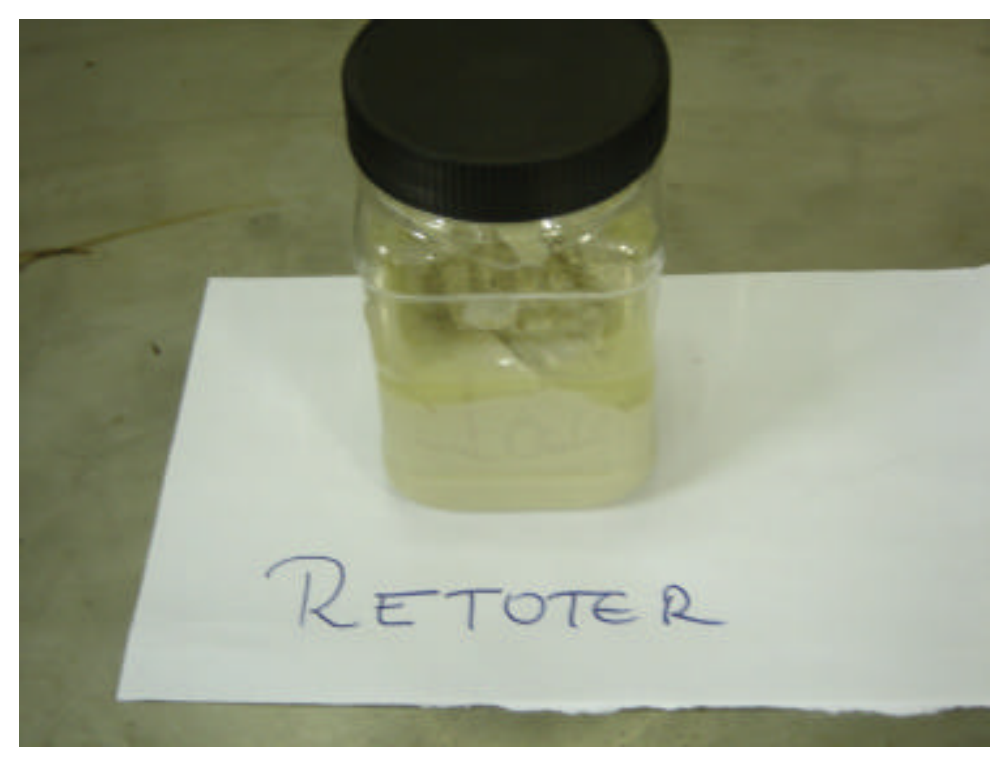

Figura 16 - Pasta de RETOTER

A dissolução ácida do RETOTER produz uma solução de cloretos metálicos, proveniente da reação do meio com os hidróxidos metálicos, Eq. 9.

$$
\begin{gathered}
x \mathrm{HCl}_{(\mathrm{aq})}+\mathrm{Me}(\mathrm{OH})_{\times(\mathrm{s})} ? \mathrm{Me}(\mathrm{Cl})_{\times(\mathrm{aq})}+\mathrm{H}_{2} \mathrm{O}(\mathrm{aq}) \\
\text { em que x é o número de oxidação do metal }
\end{gathered}
$$


Corrige-se a concentração para $\sim 10 \mathrm{~g} \cdot \mathrm{L}^{-1}$ do metal contido no RETOTER, solução estoque, e estuda-se a acidez livre no intervalo de 0,5 a 3,0 Mol. $L^{-1}$, para o iniciar o ciclo cromatográfico. Na Tabela 6 apresenta-se a composição química da solução estoque, na Figura 18 é mostrado o espectro de fluorescência de Raios-X por energia dispersiva - EDXRF, e Figura 19 a solução estoque.

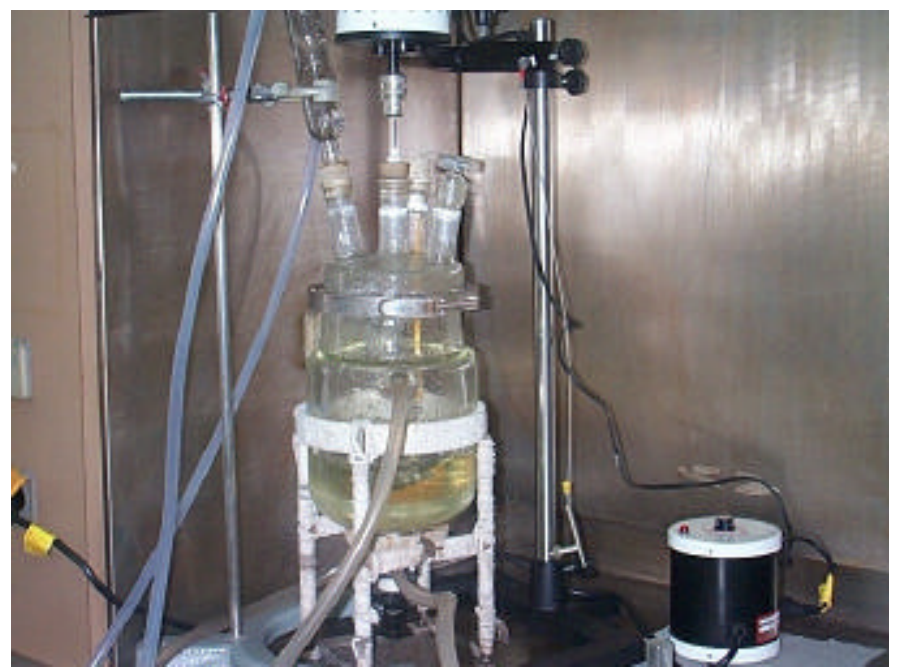

Figura 17- Reator de Dissolução do RETOTER 

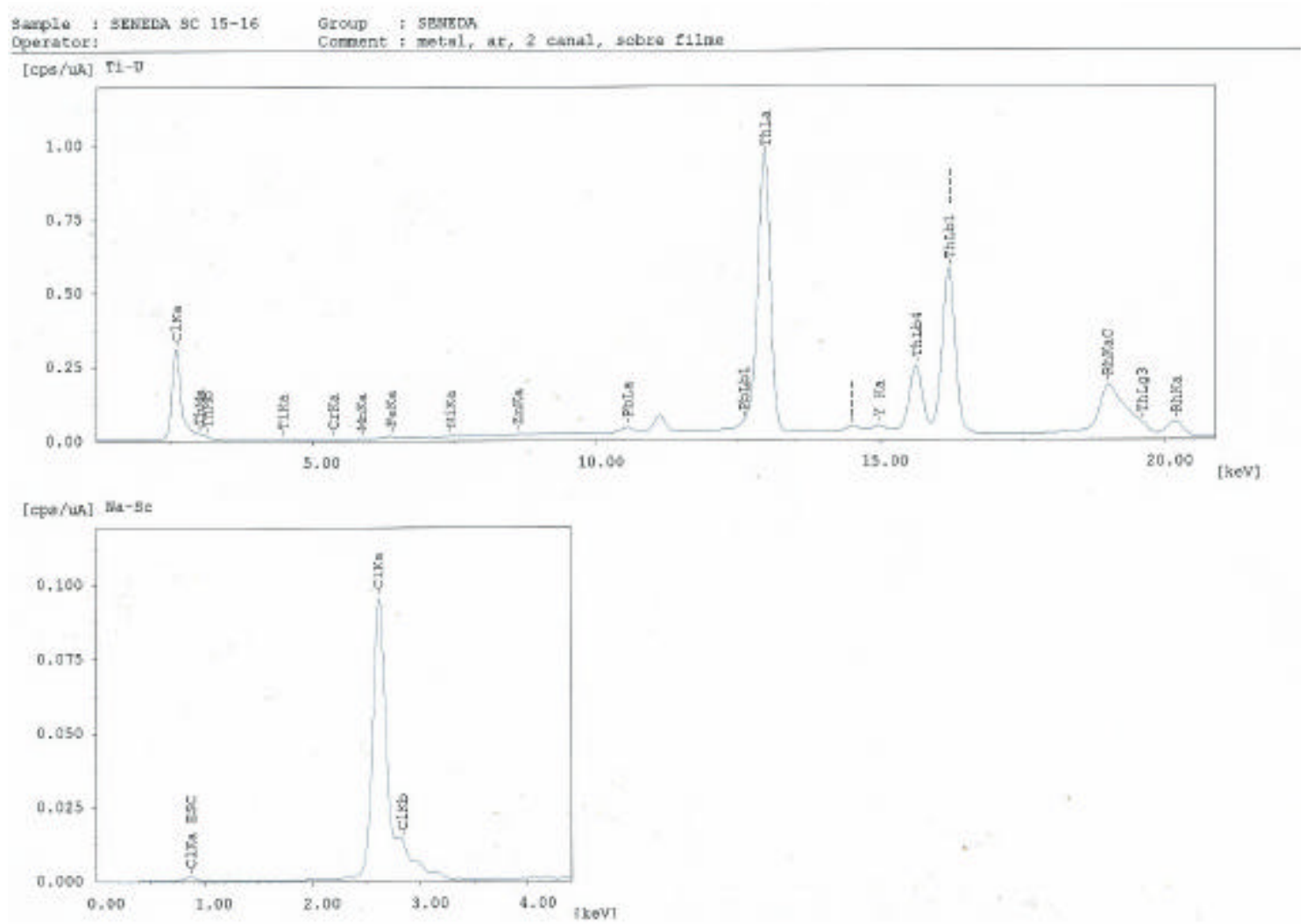

Figura 18- Espectro EDXRF da solução estoque

Tabela 6- Composição Química da solução estoque

\begin{tabular}{ccc}
\hline Constituinte & $\% \cdot 10^{-3}\left(^{*}\right)$ & $\mu \mathrm{g} \cdot \mathrm{mL}^{-1}\left({ }^{(\prime)}\right.$ \\
\hline $\mathrm{Th}$ & $460,0+/-23,0$ & \\
$\mathrm{Fe}$ & $6,0+/-0,3$ & \\
$\mathrm{Cr}$ & $4,0+/-0,2$ & \\
$\mathrm{Ni}$ & $3,0+/-0,2$ & \\
$\mathrm{Zn}$ & $3,0+/-0,2$ & $170+/-8$ \\
$\mathrm{Mn}$ & $4,0+/-0,2$ & \\
$\mathrm{~Pb}$ & $55,0+/-1,0$ & \\
$\mathrm{Ti}$ & $11,0+/-0,6$ & \\
$\mathrm{Cl}$ & $9.523+/-476$ & \\
$\mathrm{H}$ & $89.657+/-4.480$ & \\
\hline
\end{tabular}

$\left(^{*}\right)$ análise por EDXRF

$\left(^{* \star}\right)$ ánalise por voltametria 


\subsubsection{Ciclo cromatográfico}

Os estudos em coluna cromatográfica, Figura 20, foram realizados à temperatura ambiente. O ciclo é aniônico, em resinas tipo gel - IRA 458 e macroreticular - IRA $900 \mathrm{Cl}$. Inicialmente foram realizadas em coluna de poliestireno, sendo otimizada na coluna de cloreto de polivinila -PVC transparente.

Foram estudadas as variáveis: tipo de resina: gel ou macroreticular; acidez livre da solução de carga no intervalo: 0,5 - 3,0 Mol.. ${ }^{-1}$; fluxo da solução nas etapas de percolação, lavagem e eluição no intervalo $0,3-2,0$ mL.min ${ }^{-}$ ${ }^{1} \mathrm{~cm}^{-2}$; solução de lavagem e eluição.

A solução de carga, volume de $1000 \mathrm{~mL}$, é percolada em resina aniônica - ciclo cloreto com fluxo entre 1,0 a 2,0 mL. $\mathrm{min}^{-1} 1 \mathrm{~cm}^{-2}$, recolhendo-se o efluente em recipientes apropriados, pois contém elevado teor de materiais radioativos, principalmente tório. A seguir lava-se a coluna com 2,5 vezes o volume do leito com ácido clorídrico 2,0 Mol.L $\mathrm{L}^{-1}$ para eliminar a solução residual além dos íons ocluídos nos interstícios da resina, recolhendo-se o efluente em recipientes apropriados.

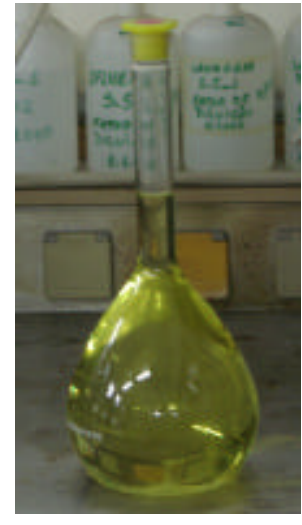

Figura 19- Solução estoque

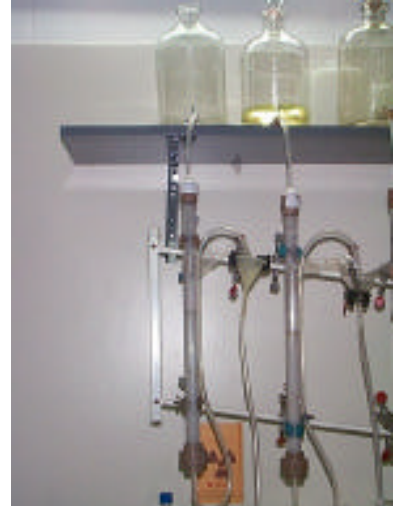

Figura 20- Coluna cromatográfica 
A eluição do chumbo foi feita com água desmineralizada, volume de 250 $\mathrm{mL}$, recolhendo o eluído em frascos de polipropileno. A seguir, são retiradas amostras da solução e levadas para análise isotópica em espectrometria de massa ICPMS e TIMS, e a pureza química em fluorêscencia de Raios- X (EDFRX) e voltametria. Transfere-se o restante da solução para um béquer de $5,0 \mathrm{~L}$ concentrando-a em chapa aquecedora sob agitação até redução do volume em 10 vezes. Após resfriamento precipita-se o chumbo com hidróxido de amônio. Filtra-se a vácuo, seca-se a $110{ }^{\circ} \mathrm{C}$ em estufa e calcina-se a $500{ }^{\circ} \mathrm{C}$ em mufla.

\subsubsection{Extração seletiva}

Escolheu-se o estudo da extração seletiva do chumbo no resíduo, utilizando-se hidróxido de sódio, pela possibilidade de solubilização do chumbo devido a formação de seu complexo solúvel, Eq. 10.

$$
\mathrm{Pb}(\mathrm{OH})_{2(\mathrm{~s})}+\mathrm{OH}^{-}{ }_{(\mathrm{aq})} \rightleftarrows \mathrm{H}_{2} \mathrm{O}_{(\mathrm{l})}+\mathrm{HPbO}_{2}^{-} \rightleftarrows \mathrm{Pb}(\mathrm{OH})_{3}^{-} \text {(aq) }
$$

Foram mantidos parâmetros constantes :

- massa do RETOTER (pasta) $250 \mathrm{~g} /$ experimento;

- solução de extração: hidróxido de sódio;

- ordem de adição: retoter sobre o hidróxido de sódio e

- razão: RETOTER: hidróxido de sódio (1:2) (m/v).

$\mathrm{Na}$ extração seletiva de chumbo no RETOTER foram estudadas as variáveis definidas pelos levantamentos preliminares de literatura e testes experimentais, sendo estas a concentração da solução de extração, intervalo 0,53,0 Mol.L ${ }^{-1}$; temperatura da solução de extração, intervalo de $25-70{ }^{\circ} \mathrm{C}$, agitação da mistura, intervalo 100- 400 rpm e tempo de extração, intervalo 30 $60 \mathrm{~min}$. 
Iniciaram-se os estudos em batelada, pela transferência de $250 \mathrm{~g}$ de RETOTER a um reator de extração contendo $500 \mathrm{~mL}$ de hidróxido de sódio 3,0 Mol. $\mathrm{L}^{-1}$, agitando-se a mistura a $400 \mathrm{rpm}$ aumentando-se 0 aquecimento lentamente até $70{ }^{\circ} \mathrm{C}$ por 1 hora. Finalizando-se a extração, separa-se a fração solúvel por filtração, a seguir analisa-se o teor de chumbo.

O acompanhamento analítico foi realizado na fração solúvel, analisando-se a concentração de chumbo, pela análise por titulação complexiométrica com EDTA -via direta (indicador eriocromo black T) para concentrações acima de mg. $\mathrm{L}^{-1}$ ou por voltametria para concentrações da ordem de $\mu g \cdot L^{-1}$.

\subsection{Tório e Terras raras}

Neste processo utilizou a técnica de troca iônica, meio clorídrico, facilitando o trablho pois se torna seqüencial à recuperação de chumbo, utilizando as soluções efluentes de percolação e lavagem. Isto levaria a um tempo de manipulação mínimo para correções da solução, pois esta é uma solução radioativa, necessitando apenas de ajustes de $\mathrm{pH}$, e acrescentaria informações sobre a tecnologia de resíduos do tório. Na Figura 21 apresentam-se os procedimentos necessários para a recuperação do tório e da terras raras.

A separação e recuperação do tório e terras raras foram feitas com 500 $\mathrm{mL}$ de uma solução estoque homogeneizada, do efluente com soluções de lavagem, proveniente da coluna aniônica da recuperação do chumbo. Antes de ser transferida para a coluna catiônica, Figura 22, é necessário a correção do pH entre 1,0 a 2,0. A correção foi feita com hidróxido de amônio/ tamponado. $O$ coeficiente de distribuição do tório é superior a 1000, nesta faixa de $\mathrm{pH}$, além de evitar a precipitação do tório ou das terras raras.

Estudos preliminares das seguintes variáveis foram elaborados: fluxo da solução de carga, lavagem e eluição, intervalo $0,5-2,0 \mathrm{~mL} \cdot \mathrm{min}^{-1} \cdot \mathrm{cm}^{-2}$ e a solução de eluição. 
Inicia-se o ciclo cromatográfico, percolação, lavagem e eluição, variando-se o fluxo, em um conjunto de 2 colunas, volume resina $100 \mathrm{~mL}$ cada, separadas por um desnível de $10 \mathrm{~cm}$, para manter o fluxo contínuo, contendo resina catiônica forte, S100 Bayer, forma amônio, Figura 23.

O acompanhamento do processo é feito pela concentração do íon Th (IV) no efluente, utilizando-se de detecção com ácido oxálico e/ou detector Gama a cada $1000 \mathrm{~mL}$ de efluente.

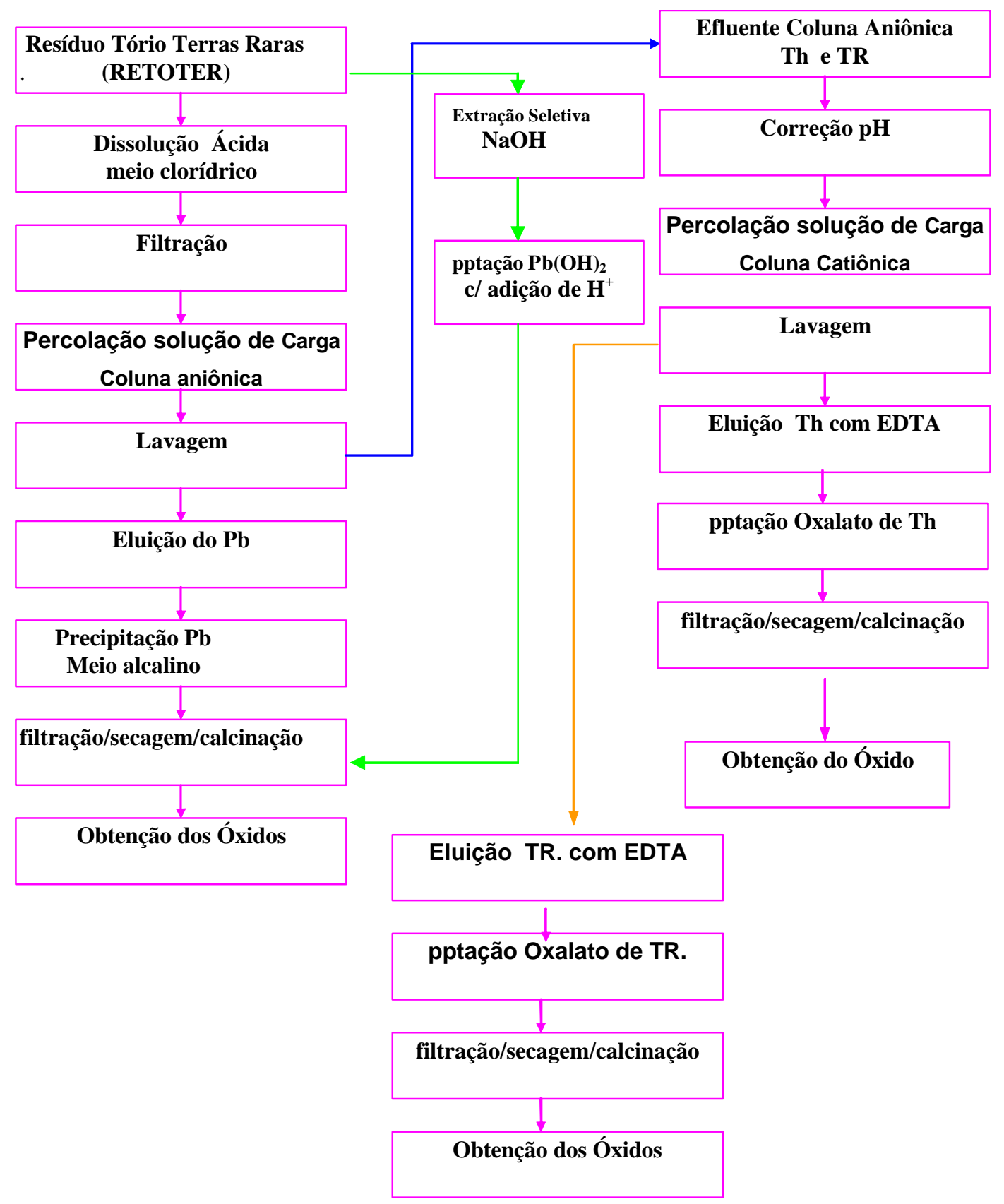

Figura 21- Diagrama de blocos do processo de obtenção de tório e terras raras 
A separação e recuperação das terras raras são a simples cromatografia entre o tório e as terras raras, de maneira que os parâmetros para a separação do tório serão idênticos para as terras raras.

O efluente resultante foi encaminhado para análises de elementos no laboratório de radioproteção ambiental, possibilitando o possível descarte ao meio ambiente, após constatar-se que estão dentro das Normas Ambientais e de Radioproteção.

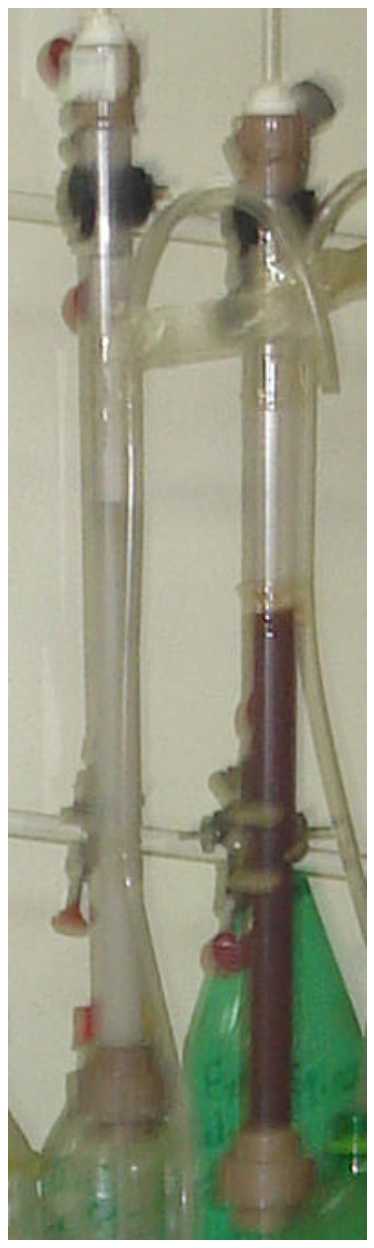

Figura22-Colunas cromatográficas

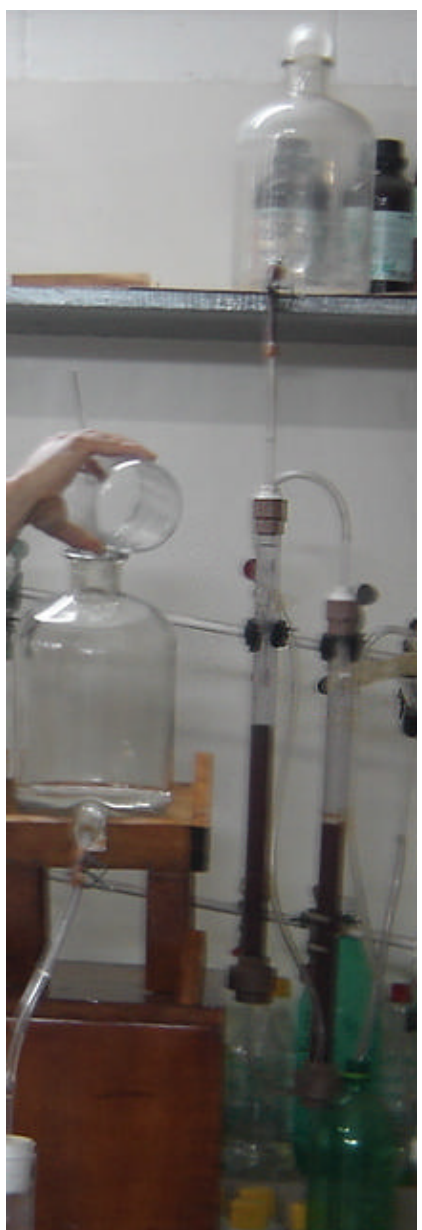

Figura 23- Colunas Catiônicas 


\section{$6 \quad$ RESULTADOS E DISCUSSÕES}

\subsection{Dissolução do RETOTER}

Foram realizados os experimentos de dissolução objetivando estudos para o estabelecimento da faixa operacional das variáveis: ordem de adição dos reagentes, agitação da mistura, tempo de adição e digestão, temperatura de digestão e razão RETOTER:HCl, procurando verificar como estas interferiam na filtração.

\subsubsection{Adição e agitação dos reagentes}

A adição dos reagentes na dissolução foi adotada em RETOTER sobre o ácido clorídrico, manualmente, e tomando-se o cuidado para evitar perdas do material.

A agitação dos reagentes foi realizada em 400 rpm, pois rotações inferiores, devido a falta de torque do agitador, não permitiram que a mistura RETOTER-ácido fosse agitada suficientemente, para uma boa distribuição da mistura, diminuindo assim o contato entre os componentes. Agitações superiores ocasionavam perdas do material.

\subsubsection{Efeito do tempo de adição e digestão}

Estabeleceu-se no estudo do tempo de adição e digestão da suspensão, que eram executadas seqüencialmente numa mesma operação, mantendo-se constantes as outras variáveis do sistema, que tempos de digestão superiores a 15 minutos teve rendimento de dissolução superior a $90 \%$. Na Tabela 7 são apresentados os resultados. Recomenda-se a faixa de 15 a 60 minutos de digestão para o processo. 


\subsubsection{Efeito da temperatura}

Fez-se a leitura conjunta das temperaturas de adição e digestão e observou-se nos experimentos, Tabela 8, que a adição do RETOTER ao ácido à temperatura ambiente resultava em aquecimento por ser uma reação exotérmica ácido - base.

Em temperaturas inferiores a $70{ }^{\circ} \mathrm{C} \circ$ material não era dissolvido completamente, formando ainda uma mistura heterogênea, apesar de os resultados apresentarem rendimento acima de $90 \%$ de dissolução.

O estudo do material não dissolvido não foi feito, pois ao ser resfriado o material, este começava a apresentar nova composição em razão da agregação a outros compostos formados no meio, dificultando uma análise precisa do composto resultante.

$\mathrm{Em}$ temperaturas superiores a $70{ }^{\circ} \mathrm{C}$ os hidróxidos contidos do RETOTER eram totalmente dissolvidos, formando uma mistura homogênea. Recomenda-se a faixa de temperatura entre $70-85^{\circ} \mathrm{C}$ para ser a utilizada para a dissolução.

Em temperaturas acima de $85{ }^{\circ} \mathrm{C}$, a perda de ácido clorídrico por evaporação se torna um fator relevante, apesar de o reator possuir um sistema para refluxo dos gases.

A temperatura acaba exercendo um efeito predominante na fase de dissolução do RETOTER. 


\subsubsection{Estudo da razão RETOTER:HCl}

Em uma série de experimentos foi determinada a quantidade mínima de ácido necessário para dissolver $50 \mathrm{~g}$ de RETOTER pasta ( base úmida ). Fez-se esta determinação por meio da adição do concentrado a quantidades diferentes do ácido clorídrico, digerindo a mistura por 1 hora, a $85^{\circ} \mathrm{C}$.

Na Tabela 9 apresentam-se os resultados, verificando-se que a razão RETOTER: $\mathrm{HCl}$ concentrado ( $1: 1$ ) ( $\mathrm{m} / \mathrm{v}$ ) produz uma dissolução com rendimento acima de 97 \%. Evitou-se a diluição da solução para as etapas seguintes de separação, recuperação do chumbo por troca iônica.

As razões superiores também forneceram resultados no rendimento acima de $97 \%$, mas foram evitadas, pois aumentavam a acidez livre para a etapa de troca iônica, necessitando de maiores correções na solução de percolação. Este fato definiu a escolha pela razão RETOTER:HCl (1:1), evitando-se as outras razões.

Tabela 7- Efeito do tempo de digestão na dissolução do RETOTER

\begin{tabular}{|c|c|c|c|}
\hline Exp. & $\min \left({ }^{*}\right)$ & Insolúveis (g) & \% Dissolução \\
\hline 1 & 15 & 2,74 & 94,5 \\
\hline 2 & 30 & 2,22 & 95,7 \\
\hline 3 & 40 & 3,08 & 93,9 \\
\hline 4 & 50 & 2,54 & 94,9 \\
\hline 5 & 60 & 2,85 & 94,3 \\
\hline
\end{tabular}


Tabela 8- Efeito da temperatura na dissolução do RETOTER

\begin{tabular}{cccc}
\hline Exp. & ${ }^{\circ} \mathrm{C}$ & Insolúveis $(\mathrm{g})$ & \% Dissolução \\
\hline 1 & 85 & 1,86 & 96,3 \\
2 & 70 & 2,57 & 94,9 \\
3 & 55 & 2,24 & 95,5 \\
4 & 40 & 3,93 & 92,1 \\
5 & 25 & 3,75 & 92,5
\end{tabular}

Massa inicial $=50,00 \mathrm{~g}$ RETOTER pasta, tempo dissolução $=60 \mathrm{~min}$.

Agitação= 400 rpm, razão (RETOTER:HCl) 1:1 (m/v)

Tabela 9- Efeito da razão RETOTER:HCl conc. na dissolução do RETOTER

\begin{tabular}{cccc}
\hline Exp. & $\begin{array}{c}\text { RETOTER } \\
: \mathrm{HCl}\end{array}$ & Insolúveis $(\mathrm{g})$ & \% Dissolução \\
\hline 1 & $1: 1$ & 1,01 & 98,0 \\
2 & $1: 2$ & 0,79 & 98,4 \\
3 & $1: 3$ & 0,99 & 98,0 \\
4 & $1: 4$ & 1,18 & 97,6 \\
5 & $1: 5$ & 0,88 & 98,2 \\
\hline
\end{tabular}

Massa inicial= 50,00 g RETOTER pasta;temp.dissolução= $85^{\circ} \mathrm{C}$;

tempo dissolução= 60 min; agitação=400 rpm, 


\subsubsection{Rendimento de dissolução}

O rendimento de dissolução foi estabelecido em $98,0+/-0,3 \%$, e tempo de filtração da solução de 20 minutos.

A solubilização do chumbo determinou-se pela diferença entre a massa inicial para dissolução e a massa solúvel no filtrado da dissolução do RETOTER. Uma quantidade correspondente a $21,5 \%$ do chumbo inicial, ficou associada ao resíduo, concluindo-se que o rendimento da dissolução para o chumbo atingiu $78,5 \%$. Este rendimento, deve ser analisado como o mais adequado, pois a quantidade presente de chumbo é relativamente pequena, e evitou-se uma redissolução do resíduo, devido a condições adversas como radioatividade do material.

\subsection{Estudo do Sistema Resina-Cloreto-Metal}

\subsubsection{Chumbo}

O íon chumbo ao ser dissolvido pelo ácido clorídrico forma um complexo, o íon $\mathrm{PbCl}_{3}^{-}$, em concentrações de $\mathrm{HCl}$ acima de 0,5 $\mathrm{Mol}^{-1}{ }^{-1}$ (KRAUS, et al. , 1956; YATSIMIRSKII, et al., 1960). Ao percolar este numa coluna contendo resina aniônica - forma cloreto, a troca dos íons realizar-se-á até o equilíbrio ser atingido. Este processo conhecido como sorção e desorção é realizado em cinco etapas (ABRÃO, 1972):

1- Transporte dos íons através da solução para a superfície da resina (difusão de partícula ou filme ou difusão externa);

2- Difusão dos íons através da resina para os pontos de troca, sítios ativos ou grupos funcionais (transferência de massa);

3- A reação química entre os íons na posição dos pontos de troca dentro da resina; 
4- A difusão dos íons trocados dentro da resina até a superfície , reverso da etapa 2;

5- O transporte do íon da superfície da resina até o interior da solução reverso da etapa 1.

\subsubsection{Separação e retenção}

A capacidade para retenção de chumbo na resina aniônica indica que a principal espécie de chumbo é a forma aniônica, $\mathrm{PbCl}_{3}{ }^{-}$, Para o carregamento do chumbo, a retenção na forma aniônica tem enorme importância. O complexo pode ser usado para a retenção de baixos níveis do íon $\mathrm{Pb}^{2+}$.

\subsection{Efeito da acidez livre}

A acidez livre ou íons $\mathrm{H}^{+}$livres por estarem diretamente associados ao íon cloreto dissociado, favorecem a formação do complexo $\mathrm{PbCl}_{3}{ }^{-}$.

Os experimentos das curvas de quebra são apresentados nas Tabela 10 e Figura 24, e fornecem a influência da variável acidez livre na retenção de chumbo.

Os resultados apresentados recomendam um carregamento na faixa de 0,5 - 3,0 Mol.L $\mathrm{L}^{-1}$. A faixa de trabalho recomendada é 1,75 - 2,0 Mol. L $\mathrm{L}^{-1}$. Em molaridades menores do que $0,5 \mathrm{MoL}^{-1} \mathrm{~L}^{-1}$, o chumbo não é retido pela não formação do complexo aniônico, $\mathrm{PbCl}_{3}{ }^{-}$, continuando como composto catiônico, não retido à resina aniônica. Em altas concentrações de $\mathrm{HCl}$, acima de 3,0 Mol.L' ${ }^{1}$, o composto aniônico de chumbo acaba diminuindo sua retenção na resina pela competição com o íon cloreto, facilmente verificado pelo aumento da inclinação da curva de breaktrough, o que ocasiona a total perda do íon em estudo. 


\subsection{Efeito do fluxo de solução}

O fluxo de uma solução por uma coluna está diretamente relacionado à cinética da reação química, delimitando a faixa experimental para valores menores que 2,0 mL. $\min ^{-1} \cdot \mathrm{cm}^{-2}$.

A influência do fluxo na retenção do chumbo foi obtida após vários experimentos na faixa de $0,3-2,0 \mathrm{~mL} \cdot \mathrm{min}^{-1} \cdot \mathrm{cm}^{-2}$, vazão de $0,5-3,0 \mathrm{~mL} \cdot \mathrm{min}^{-1}$, mantendo-se a acidez livre em 1,75 Mol.L ${ }^{-1}$. Nas Tabela 11 e Figura 25 são apresentadas as curvas de quebra.

Em fluxos inferiores a $0,3 \mathrm{~mL} \cdot \mathrm{min}^{-1} \cdot \mathrm{cm}^{-2}$ o chumbo tende a reversibilidade diminuindo sua retenção na resina, Eq. 11. Para fluxos acima de 2,0 $\mathrm{mL} \cdot \mathrm{min}^{-1} \cdot \mathrm{cm}^{-2}$ o chumbo não é adsorvido pela baixa atração eletrostática exercida pela resina, ou seja, cinética de retenção não é alcançada.

$$
\mathrm{R}-\mathrm{PbCl}_{3}+\mathrm{Cl}^{-} \rightarrow \mathrm{PbCl}_{3}^{-}+\mathrm{R}-\mathrm{Cl}
$$

Recomenda-se um fluxo de solução de percolação entre 0,3 - 2,0 $\mathrm{mL} \cdot \mathrm{min}^{-1} \cdot \mathrm{cm}^{-2}$. Resultados obtidos da curva de breaktrought. A operação pode ser efetuada em 0,3 ou 1,0 mL. $\mathrm{min}^{-1} \cdot \mathrm{cm}^{-2}$, pois o volume de breaktrough $\left(V_{b}\right)$ é semelhante para ambos, e a escolha recai sobre o fluxo maior, permitindo diminuir o tempo do processo em cerca de 1/3, permitindo uma evidente melhora na relação custo/benifício do processo. 
Tabela 10 - Efeito da acidez livre na retenção do chumbo

\begin{tabular}{ccccccc}
\hline & \multicolumn{2}{c}{$3,00 \mathrm{Mol} \cdot \mathrm{L}^{-1}$} & \multicolumn{2}{c}{$1,75 \mathrm{Mol}^{-1}$} & \multicolumn{2}{c}{$0,50 \mathrm{Mol} \cdot \mathrm{L}^{-1}$} \\
Volume efluente $(\mathrm{mL})$ & $\mathrm{mg} . \mathrm{L}^{-1} \mathrm{~Pb}$ & $\mathrm{C} / \mathrm{Co}$ & $\mathrm{mg} . \mathrm{L}^{-1} \mathrm{~Pb}$ & $\mathrm{C} / \mathrm{Co}$ & $\mathrm{mg} \cdot \mathrm{L}^{-1} \mathrm{~Pb}$ & $\mathrm{C} / \mathrm{Co}$ \\
\hline 0 & 0 & 0,0 & 0 & 0,0 & 0 & 0,0 \\
10 & 15 & 0,1 & 8 & 0,1 & 5 & 0,0 \\
20 & 75 & 0,5 & 60 & 0,4 & 46 & 0,3 \\
30 & 80 & 0,6 & 84 & 0,6 & 89 & 0,6 \\
40 & 90 & 0,6 & 110 & 0,8 & 139 & 1,0 \\
50 & 104 & 0,7 & 112 & 0,8 & 118 & 0,8 \\
60 & 110 & 0,8 & 122 & 0,8 & 130 & 0,9 \\
70 & 145 & 1,0 & 130 & 0,9 & 134 & 0,9 \\
80 & 130 & 0,9 & 133 & 0,9 & 140 & 1,0 \\
90 & 135 & 1,0 & 142 & 1,0 & 138 & 1,0 \\
100 & 115 & 0,8 & 138 & 1,0 & 142 & 1,0 \\
\hline
\end{tabular}

Vol. Resin= 7,0 mL; Diam. Col. $=14 \mathrm{~mm}$, fluxo $=2,0 \mathrm{~mL} \cdot \mathrm{min}^{-1} \cdot \mathrm{cm}^{-2}$

$\mathrm{C} / \mathrm{C}_{0}=$ razão das concentrações efluente e influente

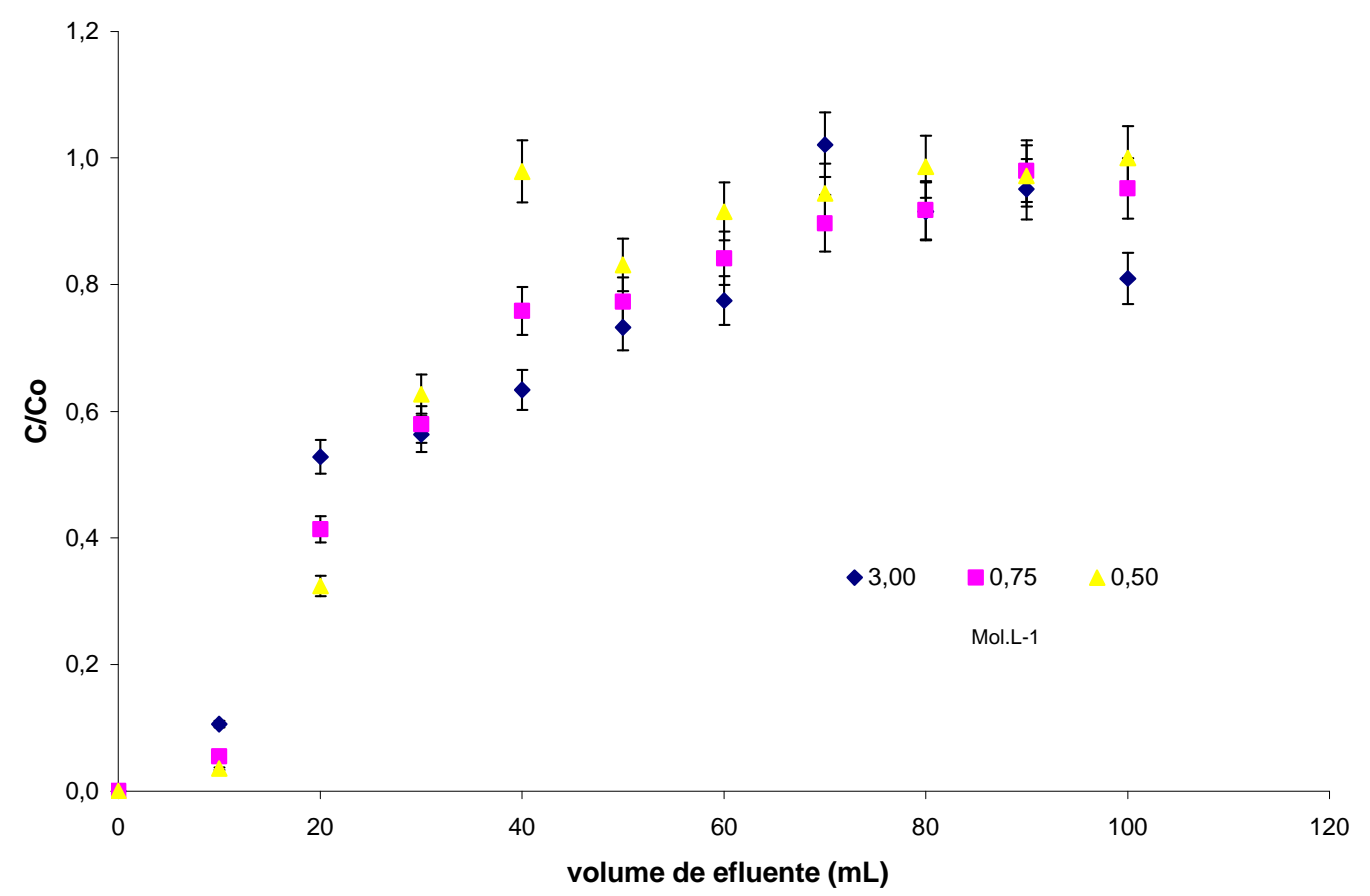

Figura 24- Infuência da acidez livre na retenção de chumbo 
Tabela 11 - Efeito do fluxo de solução na retenção do chumbo

\begin{tabular}{ccccccc}
\hline & $2,0 \mathrm{~mL} \cdot \mathrm{min}^{-1} \cdot \mathrm{cm}^{-2}$ & \multicolumn{2}{c}{$1,0 \mathrm{~mL} \cdot \mathrm{min}^{-1} \cdot \mathrm{cm}^{-2}$} & \multicolumn{2}{c}{$0,3 \mathrm{~mL} \cdot \mathrm{min}^{-1} \cdot \mathrm{cm}^{-2}$} \\
Volume efluente $(\mathrm{mL})$ & $\mathrm{mg} \cdot \mathrm{L}^{-1} \mathrm{~Pb}$ & $\mathrm{C} / \mathrm{Co}$ & $\mathrm{mg} \cdot \mathrm{L}^{-1} \mathrm{~Pb}$ & $\mathrm{C} / \mathrm{Co}$ & $\mathrm{mg} \cdot \mathrm{L}^{-1} \mathrm{~Pb}$ & $\mathrm{C} / \mathrm{Co}$ \\
\hline 0 & 0 & 0,0 & 0 & 0,0 & 0 & 0,0 \\
10 & 15 & 0,1 & 6 & 0,0 & 2 & 0,0 \\
20 & 75 & 0,5 & 65 & 0,5 & 50 & 0,4 \\
30 & 80 & 0,6 & 102 & 0,7 & 125 & 0,9 \\
40 & 90 & 0,6 & 110 & 0,8 & 140 & 1,0 \\
50 & 104 & 0,7 & 123 & 0,9 & 153 & 1,1 \\
60 & 110 & 0,8 & 130 & 0,9 & 155 & 1,1 \\
70 & 145 & 1,0 & 135 & 1,0 & 152 & 1,1 \\
80 & 130 & 0,9 & 140 & 1,0 & 150 & 1,1 \\
90 & 135 & 1,0 & 145 & 1,0 & 148 & 1,0 \\
100 & 115 & 0,8 & 138 & 1,0 & 152 & 1,1 \\
\hline
\end{tabular}

Vol. Resin= 7,0 mL; Diam. Col. $=14 \mathrm{~mm}$, Acidez livre $=1,75 \mathrm{Mol}^{-\mathrm{L}^{-1}}$

$\mathrm{C} / \mathrm{C}_{0}=$ razão das concentrações efluente e influente

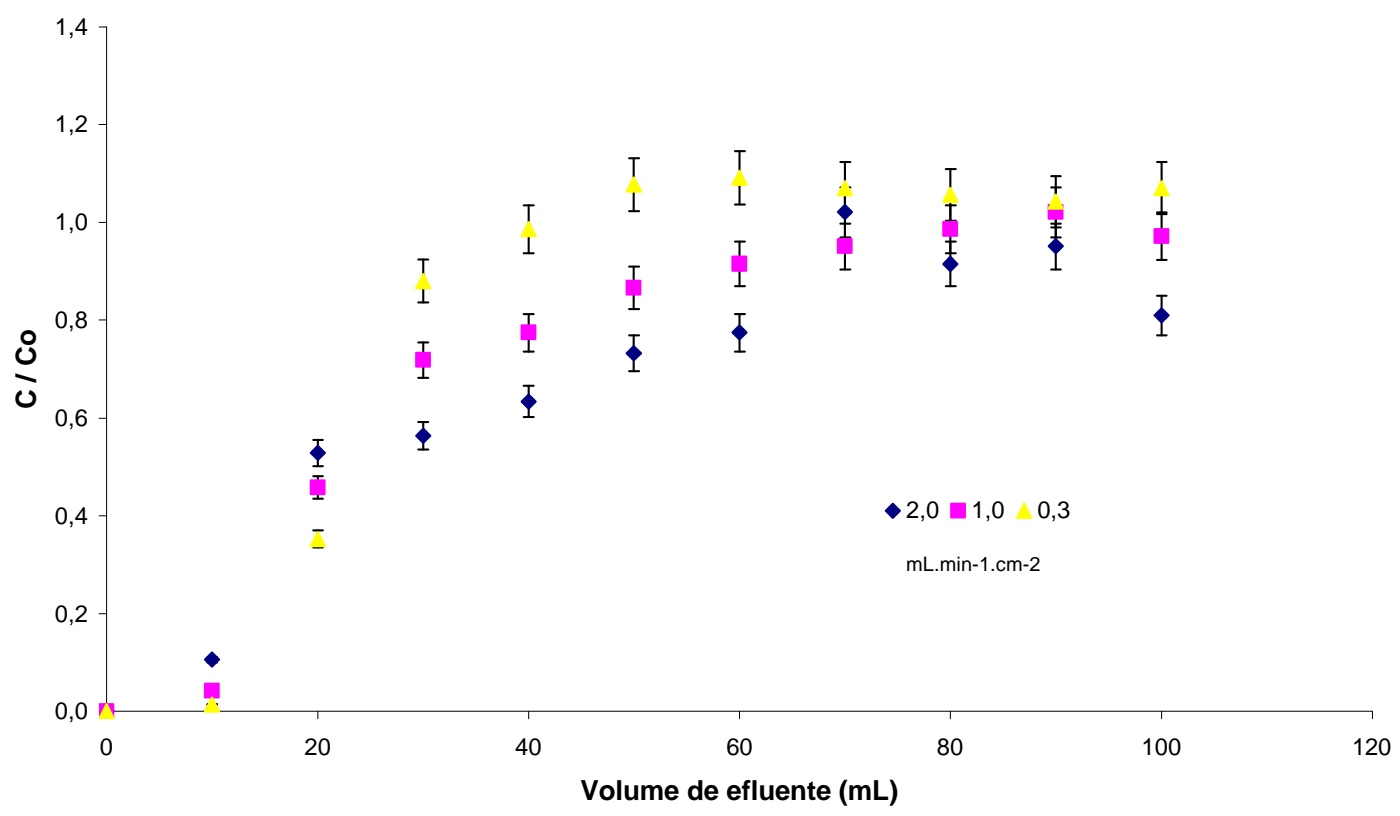

Figura 25- Influência do fluxo na retenção do chumbo 


\subsection{Lavagem e eluição}

A etapa de lavagem para o ciclo cromatográfico cumpre importante função na eliminação dos íons ocluídos e deixa a resina em condição apropriada para receber o eluente, buscando-se efetivamente evitar a eliminação dos íons retidos. Esta, porém, no sistema estabelecido apresentou influências de eliminação do íon ora estudado, $\mathrm{PbCl}_{3}{ }^{-}$.

Verificou-se que ácidos diluídos ou mesmo água quebram a estabilidade do complexo $\mathrm{PbCl}_{3}$. Optou-se pela solução de ácido clorídrico 2,0 Mol.L ${ }^{-1}$, na mesma vazão e acidez livre determinados pelos estudos de separação e retenção, como a mais indicada, possibilitando a retirada dos íons ocluídos e solução residual com um mínimo de arraste e perda do material, além de evitar a contaminação do eluído.

Na presença de ácido clorídrico $1,75 \mathrm{Mol} . \mathrm{L}^{-1}$ ainda foram eliminados 18 $\%$ do chumbo nesta etapa. Esta porcentagem pode ser considerada alta, porém, como se trata de teores da ordem de $\mathrm{mg}^{-\mathrm{L}^{-1}}$, isto representa uma parcela do íon chumbo $\mathrm{Pb}^{2+}$ da reação de equilíbrio.

Evitou-se o uso de reagentes orgânicos pois seriam introduzidas etapas de eliminação destes, ocasionando maior tempo de manipulação, o que está se evitando neste processo. Também, as bases não foram utilizadas pois a reação ácido-base são exortérmicas e influenciariam na estabilidade da resina, iniciando o rompendo das ligações vinil-benzeno da estrutura da resina, que tem limitações de temperatura em torno de $50{ }^{\circ} \mathrm{C}$.

Após a operação de carga e separação do chumbo pela formação do complexo retido à resina, passou-se a procurar o eluente adequado para 0 chumbo. 
Eluiu-se facilmente o chumbo retido na resina, cerca de $33,4 \%$ do inicial, com água desmineralizada, aproveitando a ruptura do complexo $\mathrm{PbCl}_{3}$ pela diluição do eletrólito, de $\mathrm{HCl}$, formando o íon $\mathrm{Pb}^{2+}$ hidratado.

A água desmineralizada, o eluente escolhido, proporciona a diminuição de íons interferentes que poderiam ser incluídos na solução eluente, além de proporcionar custos operacionais menores.

\subsection{Tipo de resina}

A escolha da resina a ser utilizada num processo não pode ser aleatória, é algo determinado pela condição de formação do íon a ser retido e eliminação dos interferentes. A escolha pela resina aniônica deveu-se a formação do ânion $\mathrm{PbCl}_{3}$, tipo forte, por causa da faixa de acidez utilizada nas soluções estoque e eluente. Faltava determinar se na forma Gel ou macrorreticular definada nesta etapa.

Os experimentos para a determinação da escolha pela resina, aniônica tipo Gel (IRA 458) ou macroreticular (IRA $900 \mathrm{Cl}$ ), foram realizados, a partir dos parâmetros já otimizados das variáveis anteriormente estudadas.

Nas Tabela 12 e 13 são apresentados os resultados das soluções eluídas das colunas aniônicas.

Tabela 12 - Eluído da coluna aniônica - tipo macroreticular (IRA $900 \mathrm{Cl}$ )

\begin{tabular}{ccc}
\hline Constituinte & $\% \cdot 10^{-3}$ & $\mu \mathrm{g} \cdot \mathrm{mL}^{-1}{ }^{(*)}$ \\
\hline $\mathrm{Pb}$ & $17,0+/-0,9$ & $218+/-8$ \\
$\mathrm{Zn}$ & $5,0+/-0,2$ & \\
$\mathrm{Cr}$ & $4,0+/-0,2$ & \\
$\mathrm{Th}$ & $3,0+/-0,2$ & \\
$\mathrm{Mn}$ & $3,0+/-0,2$ & \\
$\mathrm{Cl}$ & $4.023+/-201$ & \\
$\mathrm{H}_{2} \mathrm{O}$ & $95.945+/-4.797$ & \\
\hline
\end{tabular}


Tabela 13 - Eluído da coluna aniônica - tipo Gel ( IRA 458 )

\begin{tabular}{ccc}
\hline Constituinte & $\% \cdot 10^{-3}$ & $\mu \mathrm{g} \cdot \mathrm{mL}^{-1}\left(^{*}\right)$ \\
\hline $\mathrm{Pb}$ & $10,0+/-0,5$ & $95+/-2$ \\
$\mathrm{Zn}$ & $4,0+/-0,2$ & \\
$\mathrm{Cr}$ & $4,0+/-0,2$ & \\
$\mathrm{Th}$ & $8,0+/-0,4$ & \\
$\mathrm{Mn}$ & $3,0+/-0,1$ & \\
$\mathrm{Cl}$ & $4.174,0+/-208,7$ & \\
$\mathrm{H}_{2} \mathrm{O}$ & $95.798,0+/-4.789,9$ & \\
\hline
\end{tabular}

Análises efetuadas por EDXRF ; $\left(^{*}\right)$ análise por voltametria

Verifica-se que a eluição do chumbo, nestas condições, permite a sua separação de vários elementos, inclusive o ferro, um interferente de difícil separação. Nas Figuras 26 e 27 são mostradas esta eliminação comparando-se com a solução carga - estoque. Há também um alto fator de descontaminação do tório.
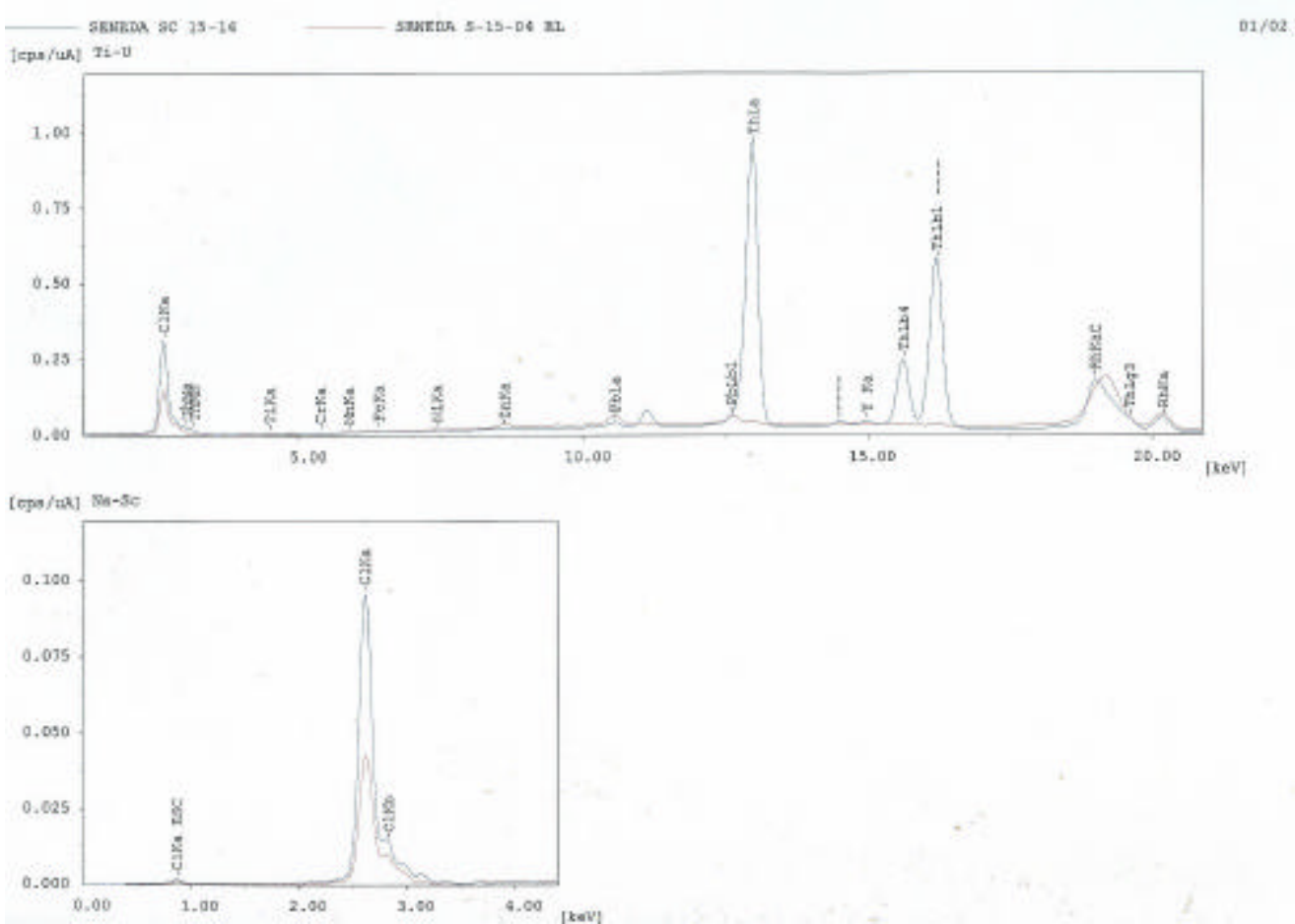

Figura 26 - Espectro EDXRF do eluído em Resina Macrorreticular - IRA $900 \mathrm{CI}$ 


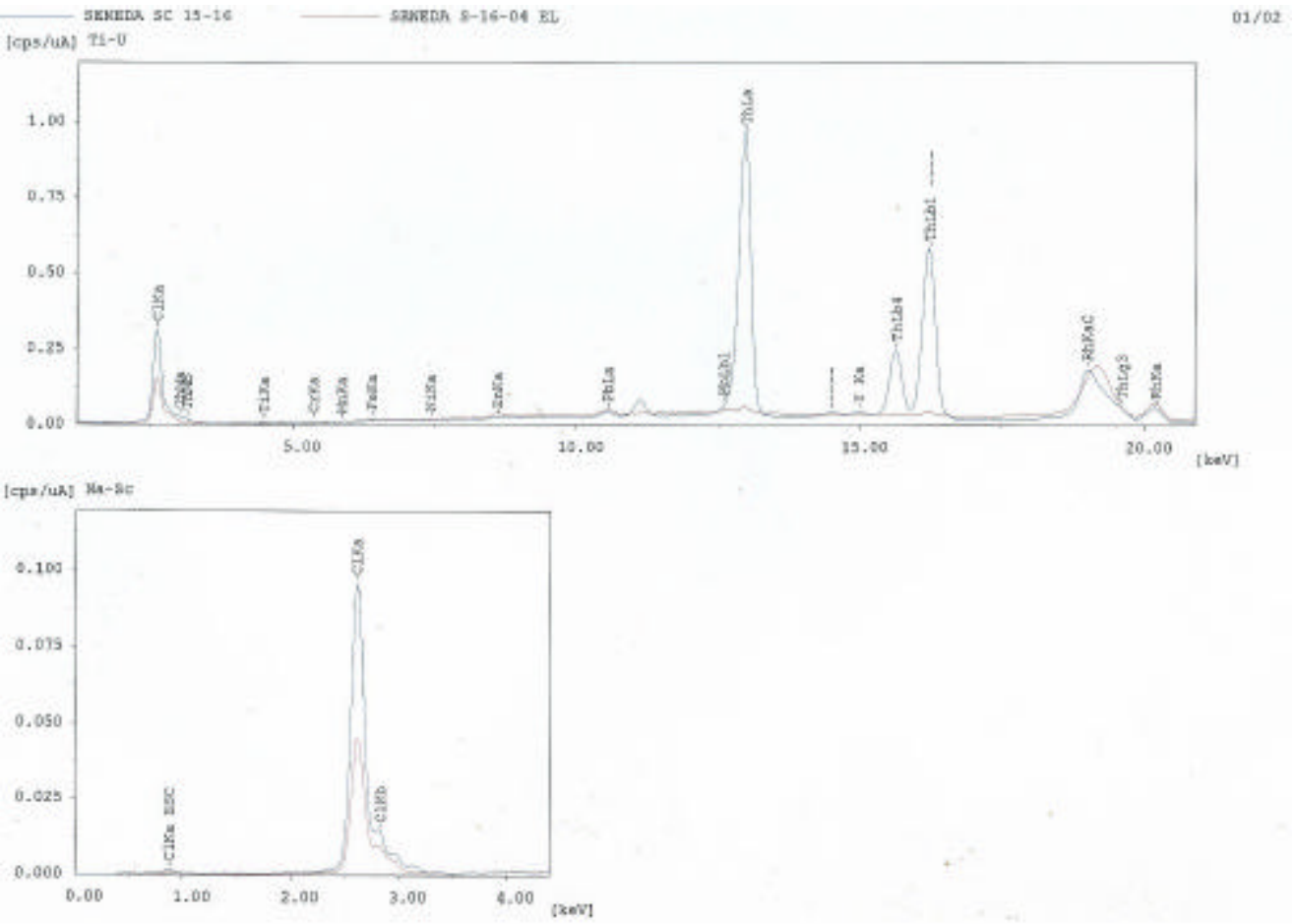

Figura 27- Espectro de EDXRF do eluído em Resina Gel - IRA 458

A resina macrorreticular apresentou uma eficiência de $100 \%$ em relação à resina Gel para a retenção do chumbo, pois seus macroporos facilitam a permeação dos íons não retidos, principalmente os catiônicos advindos da matriz, possibilitando a melhor retenção do complexo de chumbo.

$\mathrm{Na}$ Tabela 14 são apresentados os resultados das análises dos efluentes de percolação e lavagem e no eluído para um ciclo completo de separação, retenção e eluição de uma solução de RETOTER nas resinas macroreticular e Gel.

Tabela 14 - Comparação das resinas Macrorreticular e Gel para o chumbo.

\begin{tabular}{ccc}
\hline $\begin{array}{c}\text { Ciclo cromatográfico } \\
-\end{array}$ & Macrorreticular & Gel \\
\hline & $\mathrm{mg}^{-L^{-1}}$ & $\mathrm{mg} \cdot \mathrm{L}^{-1}$ \\
Efluente Percolação & $66,5+/-1,3$ & $105,0+/-1,8$ \\
Lavagem & $135,2+/-3,2$ & $143,2+/-4,0$ \\
Eluição & $200,8+/-8,2$ & $85,6+/-1,9$
\end{tabular}

Solução de carga $=1000 \mathrm{~mL}\left(162,7 \mathrm{mg} \cdot \mathrm{L}^{-1}\right.$ em Pb) ; Lavagem $=250 \mathrm{~mL}$; Eluição $=250 \mathrm{~mL}$ Vol resina $=100 \mathrm{~mL}$; técnica: voltametria por HMDE 
Na Figura 28 são mostrados os espectros dos eluídos nas colunas macrorreticular e gel. Verifica-se facilmente que na energia 11,5 kev o chumbo eluído em resina macrorreticular é o dobro da resina gel, detalhe $\mathrm{A}$.

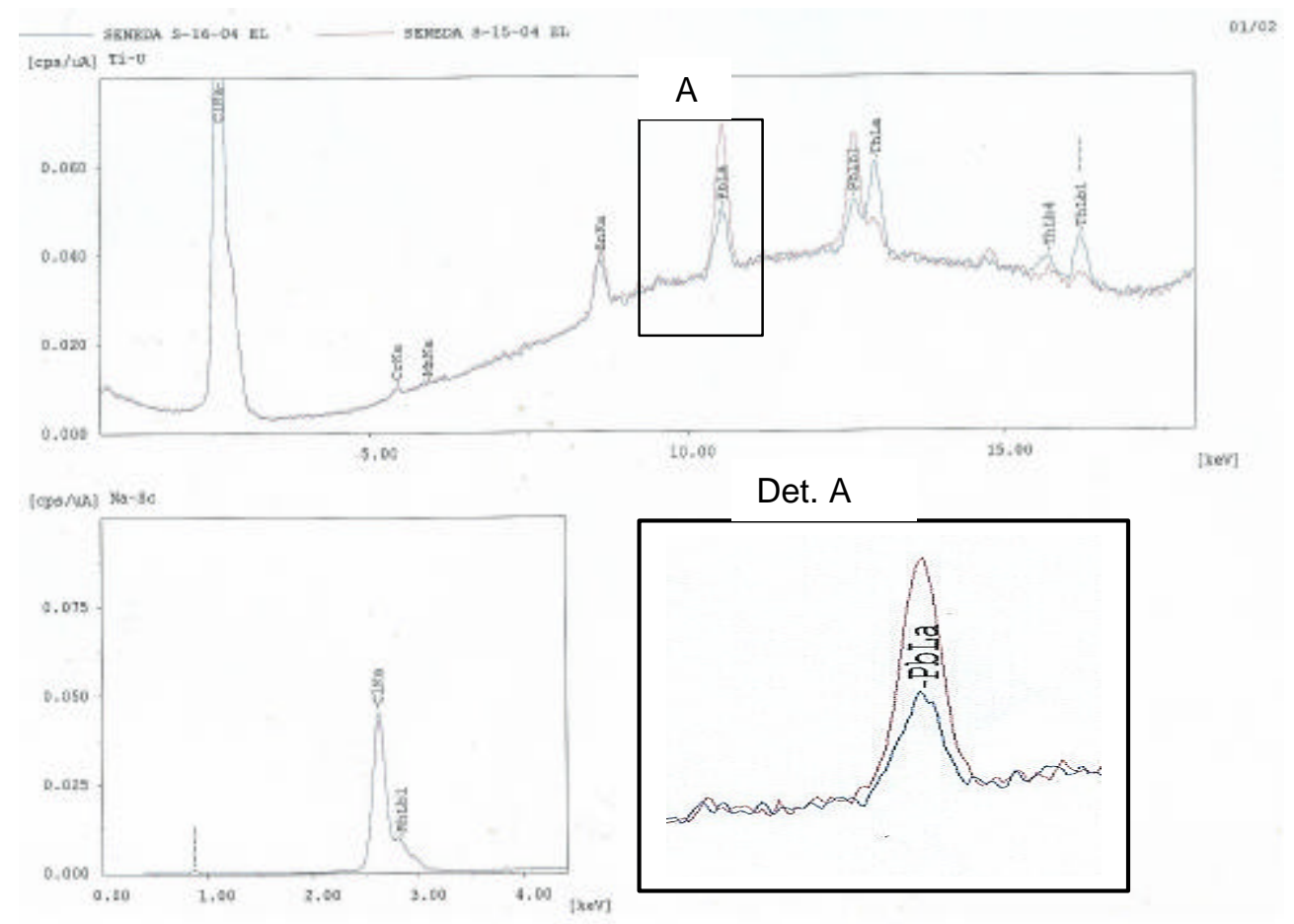

Figura 28 - Espectro dos eluídos em resina macrorreticular e gel

\subsubsection{Tório e terras raras}

O efluente obtido na percolação mais a lavagem da solução de separação do chumbo foram misturados para obtenção de uma solução homogênea para ser utilizada na separação do tório e terras raras. Após correção do seu $\mathrm{pH}$ para 2,0, foi percolada em colunas catiônicas para a retenção do íons $\mathrm{Th}^{4+} \mathrm{e} \mathrm{TR}^{3+}$ (terras raras), fluxo de 2,0 $\mathrm{mL} \cdot \mathrm{min}^{-1} \cdot \mathrm{cm}^{-2}$, a seguir, as colunas foram lavadas com água desmineralizada até pH 5,0. A eluição de tório e terras raras foi com solução de EDTA 0,005 Mol..-1 ajustado o pH para 3,5, mantendo-se o mesmo fluxo inicial. 
Verificou-se que entre 0,5 até 8,0 litros o tório saiu totalmente. $\mathrm{Na}$ Figura 29 é mostrado a curva de eluição do Th. A presença de terras raras não foi detectada. Este fato é evidente pois a presença de $\mathrm{TR}^{3+}$ já não foi detectada a partir da solução estoque. Isto ocorreu devido à cristalização com íons cloreto na etapa de dissolução. A pequena quantidade presente, na solução estoque, não foi detectada pelas análises efetuadas.

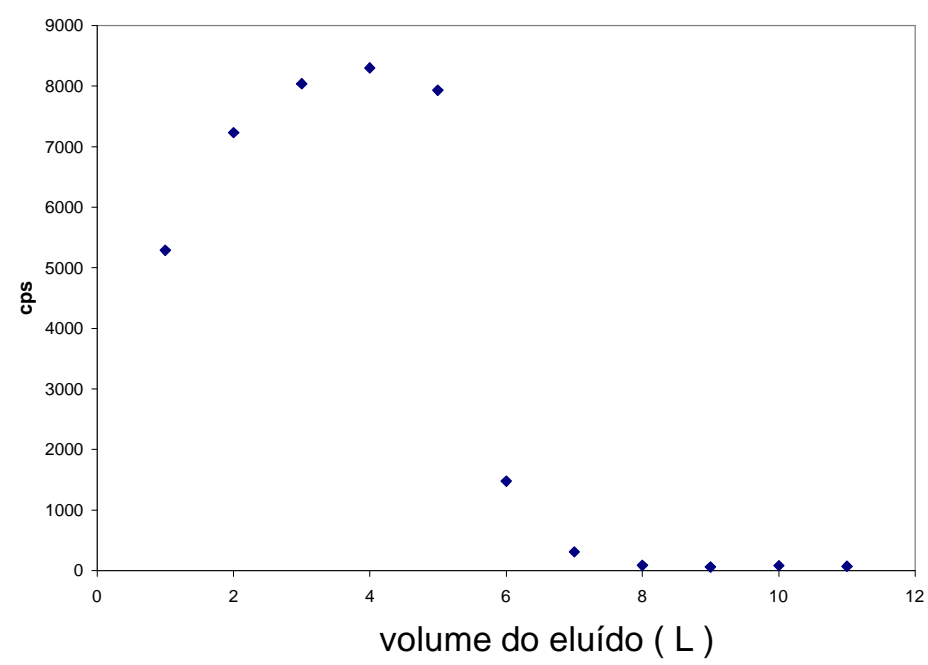

Figura 29- Curva de Eluição do tório

\subsection{Cálculo da Secção de Choque de Captura para Nêutrons Térmicos do Chumbo}

Uma amostra da solução eluída, proveniente da separação do chumbo pela resina macroreticular, é encaminhada para análise isotópica nos aparelhos HR - ICPMS e TIMS para quantificar o teor de chumbo-208. O restante do material eluído é evaporado em até 100 vezes o seu volume inicial. Precipita-se depois o chumbo com hidróxido de amônio, filtra-se e seca-se a $110^{\circ} \mathrm{C}$ em estufa. O hidróxido formado é guardado em frascos de polipropileno.

A partir da abundância isotópica dos isótopos do $\mathrm{Pb}$ natural e do $\mathrm{Pb}$ pesado obtidos neste trabalho por espectrometria de massa TIMS e ICPMS, calculou-se a secção de choque de captura para nêutrons térmicos, Eq. 12. 


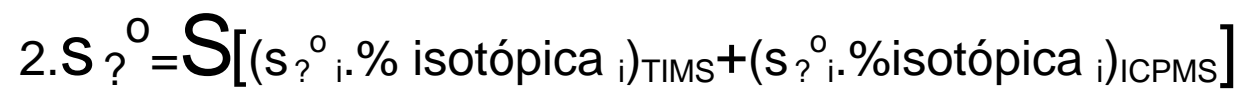

( Eq. 12 )

$$
\mathrm{i}=204
$$

A secção de choque para captura de nêutrons térmicos ( $\left.s^{0}{ }^{0}\right)$ do chumbo pesado foi obtida utilizando-se o valor da secção de choque dos isótopos ${ }^{204} \mathrm{~Pb},{ }^{206} \mathrm{~Pb},{ }^{207} \mathrm{~Pb}$ e ${ }^{208} \mathrm{~Pb}$ em literatura (Mughabhab, 1984).

Nas Tabelas 15 e 16 e Figura 30 são apresentados os resultados de análise isotópica do chumbo natural e do chumbo obtido por este processo e seu espectro por ICPMS, respectivamente. Em anexos são apresentados os resultados completos das análises em espectrometria por TIMS e ICPMS.

Tabela 15 - Razão isotópica do chumbo Natural

\begin{tabular}{cccc}
\hline & Razão & Isótopo de Pb & $\%$ atômica \\
\hline $204 / 208$ & 0,026718 & 204 & 1,40 \\
$206 / 208$ & 0,459924 & 206 & 24,10 \\
$207 / 208$ & 0,421756 & 207 & 22,10 \\
$208 / 208$ & 1 & 208 & 52,40 \\
\hline
\end{tabular}

Tabela 16- Razão Isotópica do chumbo proveniente do RETOTER

\begin{tabular}{cccc}
\hline & Razão & Isótopo de Pb & $\%$ atômica \\
\hline $204 / 208$ & 0,005 & 204 & 0,44 \\
$206 / 208$ & 0,1128 & 206 & 9,97 \\
$207 / 208$ & 0,0134 & 207 & 1,18 \\
$208 / 208$ & 1 & 208 & 88,40 \\
\hline
\end{tabular}




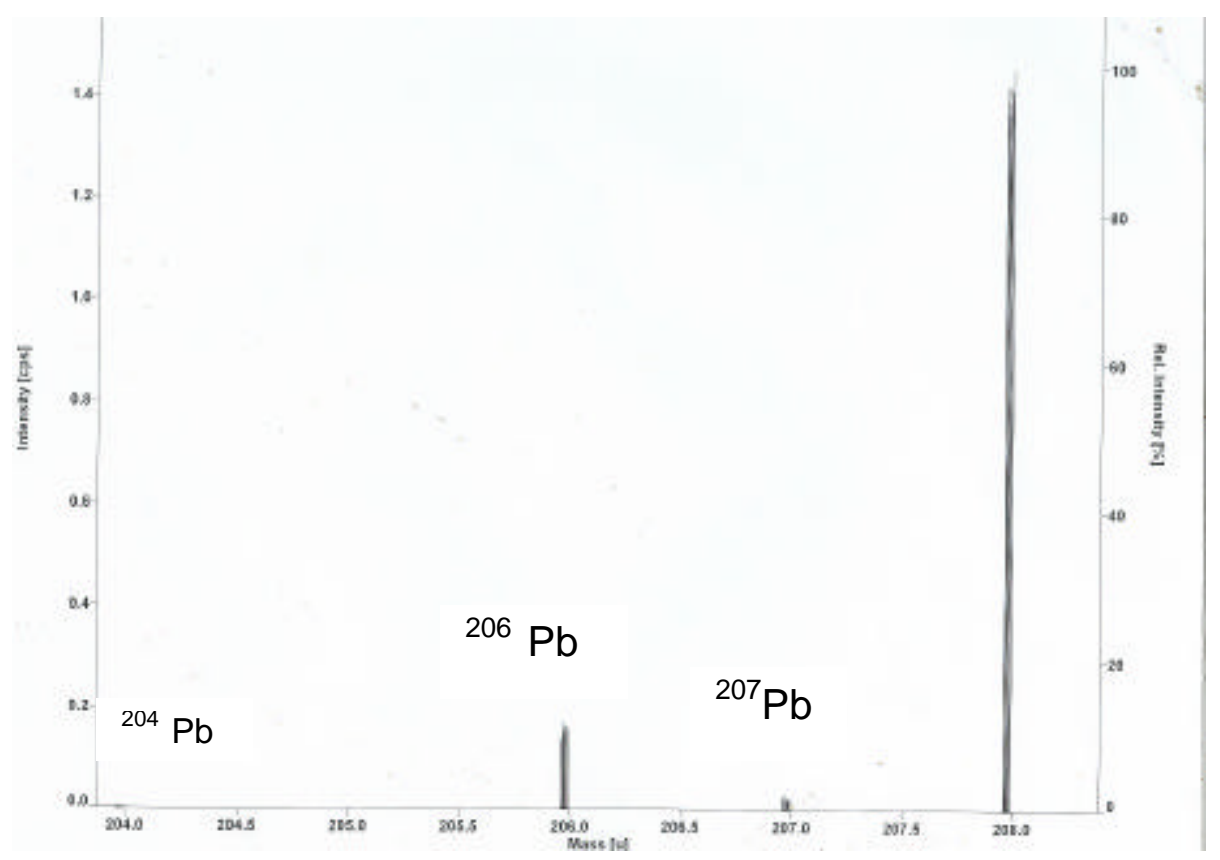

Figura 30 - Espectro dos isótopos de chumbo - Pb pesado (HR-ICPMS)

$\mathrm{Na}$ Tabela 17 são apresentados os dados, média das análises com TIMS e HR-ICPMS, referentes à secção de choque de captura para nêutrons térmicos do chumbo, obtido por meio do processo descrito nesta tese, o chumbo pesado $\left({ }^{*}\right)$, comparando-o ao chumbo natural.

Os resultados apresentam um valor correspondente para o $\mathrm{Pb}$ pesado, contendo o chumbo radiogênico $\left({ }^{208} \mathrm{~Pb}\right)$, de $8,5 \%$ quando comparado ao $\mathrm{Pb}$ natural. Isto pode ser explicado porque $0{ }^{208} \mathrm{~Pb}$ tem uma menor secção de choque de captura entre os isótopos de $\mathrm{Pb}$, e no $\mathrm{Pb}$ pesado, sua porcentagem atômica, abundância isotópica, é alta. 


\begin{tabular}{|c|c|c|c|c|}
\hline \multicolumn{3}{|c|}{ Pb Natural } & \multicolumn{2}{|r|}{ Pb pesado } \\
\hline IIńton & $\%$ & $\mathrm{~S} ?^{\mathrm{O}\left({ }^{*}\right)}$ & $\%$ & $\mathrm{~S} ?^{\mathrm{O}\left({ }^{\star}\right)}$ \\
\hline 然 & Atômica & $\mathrm{mb}$ & Atômica & $\mathrm{mb}$ \\
\hline 204 & 1,40 & $661,+/-70$ & 0,25 & $661,+/-70$ \\
\hline 206 & 24,10 & $30,6+/-0,8$ & 10,09 & $30,6+/-0,8$ \\
\hline 207 & 22,10 & $712,+/-10$ & 1,32 & $712,+/-10$ \\
\hline 208 & 52,40 & $0,49+/-0,03$ & 88,34 & $0,49+/-0,03$ \\
\hline & $\mathbf{S} ?^{\circ} \mathrm{Pb}$ Nat. & $174,2+/-7,0 \mathrm{mb}$ & $\mathrm{S}$ ? $\mathrm{Pb}$ pesado & $14,6+/-0,7 \mathrm{mb}$ \\
\hline
\end{tabular}

$\left(^{\star}\right)$ O autor desta tese recomenda o termo chumbo pesado ao elemento chumbo que contém, em seu conjunto de isótopos, uma porcentagem maior de $80 \%$ em seu isótopo estável chumbo-208, considerando que este não foi obtido por processos físicos como enriquecimentos isotópicos.

\subsection{Extração Seletiva do Chumbo}

O processo de extração seletiva consiste na remoção, sob a forma de solução, de uma fração solúvel associada a uma fase sólida permeável e insolúvel. O mecanismo envolve uma dissolução física por meio de reação química, neste caso a do chumbo no RETOTER com hidróxido de sódio.

Ao serem estudadas as variáveis: concentração de solução alcalina, agitação, temperatura e tempo de extração constatou-se que foi extraído uma quantidade mínima de chumbo do composto, Tabelas 18 a 20. 
Uma possível explicação é que a difusão do íon hidroxila pela pasta úmida, para possibilitar a formação do complexo solúvel de tetrahidroxiplumbito, não atingia camadas inferiores da pasta, somente as superficiais, impossibilitando a formação do complexo, mesmo para valores de concentração de $\mathrm{NaOH}$ 3,0 Mol.L $L^{-1}$.

Estabeleceu-se que a extração seletiva seria evitada passando a priorizar o processo por dissolução clorídrica, pois este permitiria estudos tanto do chumbo quanto dos outros elementos, como o tório e a terras raras.

Tabela 18- Efeito de $\mathrm{NaOH}$ na extração do $\mathrm{Pb}$

\begin{tabular}{ccc}
\hline $\mathrm{NaOH} \mathrm{Mol. \textrm {L } ^ { - 1 }}$ & $\mathrm{mg} \mathrm{Pb}$ & $\% \mathrm{~Pb}$ Extraído \\
\hline 0,5 & $0,7+/-0,1$ & 0,2 \\
1,0 & $1,5+/-0,1$ & 0,4 \\
1,5 & $1,9+/-0,1$ & 0,5 \\
2,0 & $2,6+/-0,1$ & 0,7 \\
2,5 & $3,3+/-0,2$ & 0,9 \\
3,0 & $3,7+/-0,2$ & 1,0
\end{tabular}

Massa Retoter = 250,00 g; volume de $\mathrm{NaOH}=500 \mathrm{~mL}$; tempo extração = $30 \mathrm{~min}$; agitação $=400 \mathrm{rpm}$; temperatura de extração $=70^{\circ} \mathrm{C}$

Tabela 19- Efeito Temperatura na extração do Pb

\begin{tabular}{ccc}
\hline${ }^{\circ} \mathrm{C}$ & $\mathrm{mg} \mathrm{Pb}$ & \% Pb Extraído \\
\hline 25 & $0,9+/-0,1$ & 0,3 \\
35 & $2,2+/-0,1$ & 0,6 \\
45 & $2,8+/-0,1$ & 0,8 \\
55 & $3,3+/-0,2$ & 0,9 \\
70 & $4,4+/-0,2$ & 1,2 \\
\hline
\end{tabular}

Massa Retoter $=250,00 \mathrm{~g}$; volume de $\mathrm{NaOH}=500 \mathrm{~mL}$; tempo extração $=30 \mathrm{~min}$; agitação $=400 \mathrm{rpm} ; \mathrm{NaOH}=3,0 \mathrm{Mol} \cdot \mathrm{L}^{-1}$ 
Tabela 20 - Efeito tempo de extração

\begin{tabular}{ccc}
\hline minutos & mg Pb & \% Pb Extraído \\
\hline 30 & $0,7+/-0,1$ & 0,2 \\
40 & $2,2+/-0,1$ & 0,6 \\
50 & $3,3+/-0,2$ & 0,9 \\
60 & $4,4+/-0,2$ & 1,2 \\
\hline
\end{tabular}

Massa Retoter $=250,00 \mathrm{~g}$; volume de $\mathrm{NaOH}=500 \mathrm{~mL} ; \mathrm{NaOH}=3,0 \mathrm{Mol}^{-\mathrm{L}^{-1}}$; agitação $=400 \mathrm{rpm}$; temperatura de extração $=70^{\circ} \mathrm{C}$ 


\section{UNIDADE DE PROCESSAMENTO PARA RECUPERAÇÃO DE ${ }^{208}$ PB}

Os estudos obtidos neste trabalho permitiram elaborar o fluxograma conceitual para uma unidade de processamento para recuperação do ${ }^{208} \mathrm{~Pb}$. Mostra-se na Figura 31 as principais operações unitárias, dissolução e filtração do RETOTER, sorção, lavagem e eluição do chumbo em colunas de troca aniônica.

Recomenda-se que os parâmetros a serem utilizados para a unidade industrial devem ser obtidos em uma unidade piloto.

Este processo químico não deve apresentar grande variação ao ser transposto para unidade maiores, pois os estudos iniciados nesta tese mostram que não haverá condições críticas, desde que se mantenham os devidos cuidados relativos a qualquer processo químico e de proteção radiológica.

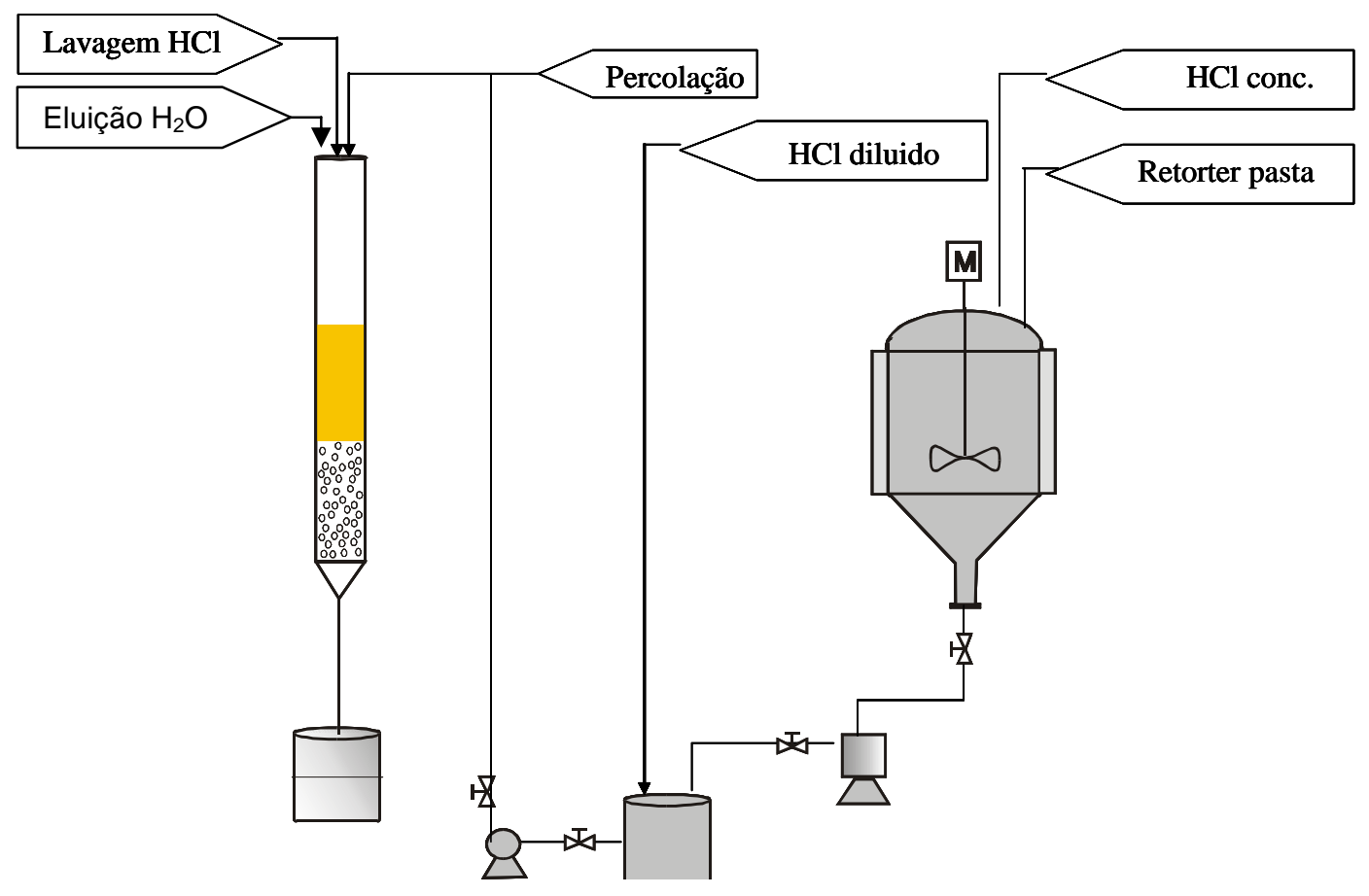

Figura 31- Fluxograma de obtenção de ${ }^{208} \mathrm{~Pb}$ 
Partindo-se do fluxograma conceitual, foi construída uma unidade de bancada para recuperação de ${ }^{208} \mathrm{~Pb}$. O reator de dissolução do RETOTER e as colunas cromatográficas são mostrados nas Figuras 32 e 33.

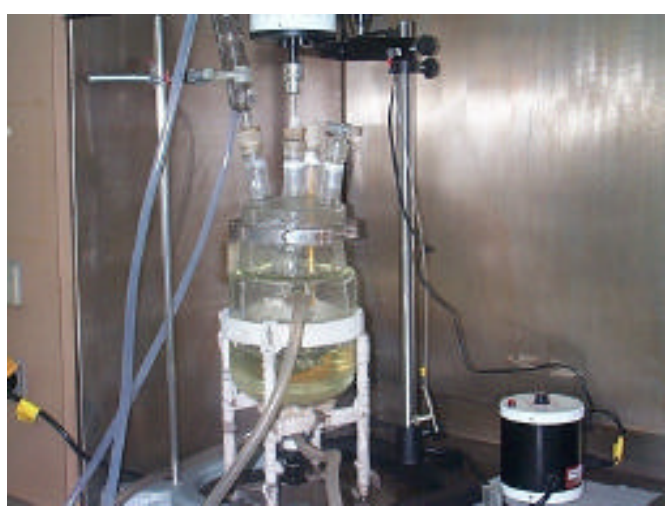

Figura 32 - Reator de dissolução

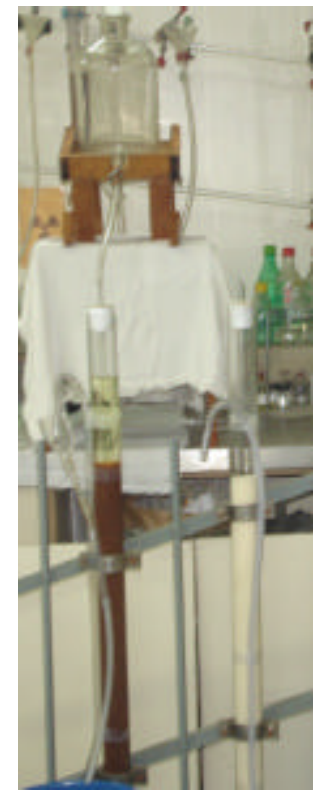

Figura 33 - Colunas Cromatográficas

Esta unidade de bancada em acrílico, volume de resina IRA $900 \mathrm{Cl}$ de $1000 \mathrm{~mL}$ e diâmetro interno de $4,2 \mathrm{~cm}$, permite separar e recuperar 1,0 Mol de chumbo-208 por batelada. 


\section{CONCLUSÃO}

Neste trabalho foi desenvolvida a tecnologia para separação e recuperação do chumbo-208, de um resíduo proveniente de unidade piloto de purificação de tório, o RETOTER.

Nos estudos realizados foram estabelecidas as condições para a separação e recuperação dos valores no RETOTER, o chumbo contendo ${ }^{208} \mathrm{~Pb}$. Inicia-se pela dissolução do RETOTER com ácido clorídrico obtendo-se a melhor dissolução nos seguintes parâmetros: adição de RETOTER sobre ácido, razão RETOTER:HCl (1:1) $(\mathrm{m} / \mathrm{v})$, temperatura de digestão $85^{\circ} \mathrm{C}$, tempo de dissolução 60 minutos e agitação em 400 rpm.

A seguir, foram estabelecidos os principais parâmetros para o ciclo cromatográfico sendo escolhida a resina: aniônica para a retenção do chumbo, em seguida a catiônica para a retenção de tório e terras raras.

O processo estabelecido nesta seqüência de resinas, aniônica e posteriormente catiônica foi importante, pois evitou operações de ajustes da concentração de acidez necessárias para a retenção do tório na coluna catiônica, o que é evitado na retenção do chumbo na coluna aniônica.

A escolha pela resina macrorreticular aniônica IRA $900 \mathrm{Cl}$, para a retenção do chumbo, estabeleceu um incremento considerável no rendimento, nas condições pré-estabelecidas de acidez livre de solução de carga em 1,75 mol.L ${ }^{-1}$ e fluxo de solução de carga, lavagem e eluição em $1,0 \mathrm{~mL} \cdot \mathrm{min}^{-1} \cdot \mathrm{cm}^{-2}$.

O rendimento global de recuperação para o chumbo foi de $33,4 \%$, em razão de se estabelecer uma estratégia para trabalhar com um determinado meio, no caso o ácido clorídrico, sem retirar a matriz, o tório, para estudar as dificuldades existentes do processo, e por se tratar de um material com baixa concentração do chumbo no resíduo. 
A formação do íon complexo cloro-chumbo aniônico, o íon $\mathrm{PbCl}_{3}{ }^{-}$, foi definitivo para a sua retenção e separação dos íons interferentes, utilizando-se da coluna aniônica.

O processo para extração seletiva, com solução alcalina, do chumbo deve ser melhor avaliado, devido aos resultados existentes necessitarem de estudos mais aprofundados, pois os resultados indicaram baixa reprodutibilidade.

As informações obtidas pelas análises isotópicas do chumbo, ora denominado como chumbo pesado, determinou uma razão isotópica diferente daquela do chumbo natural, sendo o seu enriquecimento em ${ }^{208} \mathrm{~Pb}$ por meio de decaimento do ${ }^{232} \mathrm{Th}$, estabelecendo uma abundância isotópica, porcentagem atômica, em $88,34 \%$ de ${ }^{208} \mathrm{~Pb}$.

A partir dos resultados obtidos de abundância isotópica foi calculada a secção de choque para captura de nêutrons térmicos do chumbo pesado, obtendo-se $s ?^{0}=14,6+/-0,7 \mathrm{mb}$. Este resultado bem inferior ao do chumbo natural possibilita seu uso no campo de estudos nucleares, especialmente naqueles que necessitem de um elemento que possua a propriedade nuclear de minimizar a captura de nêutrons térmicos e simultaneamente blinde a radiação gama.

Estabeleceu-se um fluxograma conceitual e construída uma unidade de bancada para estudos preliminares da separação e recuperação do chumbo-208.

Este processo pode contribuir para solucionar o passivo proveniente da unidade piloto de purificação de nitrato de tório do IPEN-CNEN/SP, além de indicar possíveis valores comerciais "escondidos" em resíduos nucleares considerados erroneamente de baixo potencial comercial. 


\section{TRABALHOS FUTUROS}

O processo estudado estabeleceu parâmetros em condições favoráveis, podendo ser estabelecidas novas rotas, como a retirada da matriz, o tório e terras raras, inicialmente por meio da extração por solventes, aproveitando estudos já realizados, de maneira a proporcionar uma concentração mais baixa dos interferentes.

Buscar melhorias no rendimento do processo para recuperação do chumbo pesado, estudando a retirada da matriz, utilizando-se a técnica de extração por solventes, ou mesmo troca iônica.

Estabelecer parâmetros operacionais de separação e recuperação do tório e terras raras.

Estabelecer parcerias nas áreas de física nuclear para iniciar estudos de aplicações para o chumbo pesado.

Estudar a purificação do chumbo-208 obtido por este processo, utilizando-se de processos eletroquímicos. 


\section{ANEXO A - RESULTADOS DO ESPECTRÔMETRO DE MASSA - ICPMS}

Os resultados para a razão isotópica $(\boldsymbol{r})$, do chumbo natural e chumbo proveniente do RETOTER, foram obtidos no espectrômetro de massa (ICPMS) do IPEN-CNEN/SP .

Os resultados de \% atômica para cada isótopo de chumbo (Pbı) são obtidos pela equação:

$$
\text { \% Atômica Pb } i=\frac{r(P b i / P b 208)}{\sum_{i=204}^{208} r(P b i / P b 208)} * 100
$$

$\begin{array}{rrrr} & \text { Razao isotopo } & \text { \%atomica } \\ & & & \\ 204 / 208 & 0,026718 & 204 & 1,40 \\ 206 / 208 & 0,459924 & 206 & 24,10 \\ 207 / 208 & 0,421756 & 207 & 22,10 \\ 208 / 208 & 1 & 208 & 52,40\end{array}$

$\mathrm{Pb}$ medido

\begin{tabular}{rrrr} 
& \multicolumn{1}{c}{ Razao } & isotopo & \%atomica \\
$204 / 208$ & 0,005 & 204 & 0,44 \\
$206 / 208$ & 0,1128 & 206 & 9,97 \\
$207 / 208$ & 0,0134 & 207 & 1,18 \\
$208 / 208$ & 1 & 208 & 88,4 C
\end{tabular}


Analysis Date

Sample Name :

Tune Parameters:

Method File :

Runs/Passes (Meas.):

Res. Switch Delay [s]

Washtime [min]

Take-up Time [min]:

Deadtimo [ns] :

C:-lelementuseruma uricioldataiPbRetoter_050903in_10ppbadat

Fri, 05-Sep-2003 16:18:26

Cilelementuserimauriciolidscl2003.tpt

C:lelementusertmauricioidesciln_controle.met

$10 * 2+0 * 0+0 * 0$

2

0.0

0.0

I Evaluation Parameters

I Standard File:

Int. Standard File:

Elank File:

Runs/Passes (Eval.)

Quantification Type:

Calibration File :

Response Flie:

Dilution Factor:

Sample Amount

Spike Amount

Final Volume:

Int. Std. active:

is before BS:

No

$10 * 2+0 * 0+0 * 0$

Intensitles

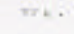

Isotope Error

Error [ops]
[or

Ratio AVG Ratio RSD

intensity RSD

Intensity $\mathrm{B}$ cor AVG

870723.0

[\%]

[\%]

[cps]

in115/LR]

1.44

870723.0 


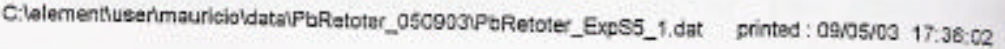

-Aciquisition Parameters

Doto File:

-4ralyais Date

Sample Name

- Tune Parameters :

Wethed Fie

eas)

Res. Bmiten Deisy [s]

Washtime [min]

Take-up Time [s]

Evaluation Parametera

Btandard File :

int. Stondard File

Blank File:

puantitioation Type

Callbration File:

Response File

Plution Facter:

Spike Amount :

Final Volume:

int. Std. active

IS before BS:

I lsotope

Fo202(LR)

Pt204(LR)

b200E(LR)

Pb207(LR)

SL208(LR)

HP200(LR)

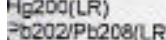

O202/PB208(LR)

PD206/PL20Q(LR)

DD207/Fb208(LR)

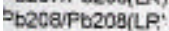

C.lelementlusermauricioldataVoRototer_0509031PbRetoter_ExpS5_1, dat

C: ielementusentmaunciolidsclav03.tpf

C.lelementhuserhnauricioldescipbRetoter_050903.met

$50 \cdot 2+0 \cdot 0+0 * 0$

2.0

25

C.lelementluserimauricioldata PbRetotor_050903MBrancoGeral_Exp5_1. dat int $2+0=0+0$

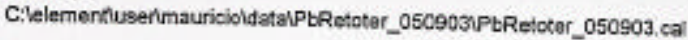

No
Yos

Intensity B oar RSO Conoertratian AVG Concantration STO

[\%]

24.65

21.09

2.09

3.75
1.65

1.63
2301 


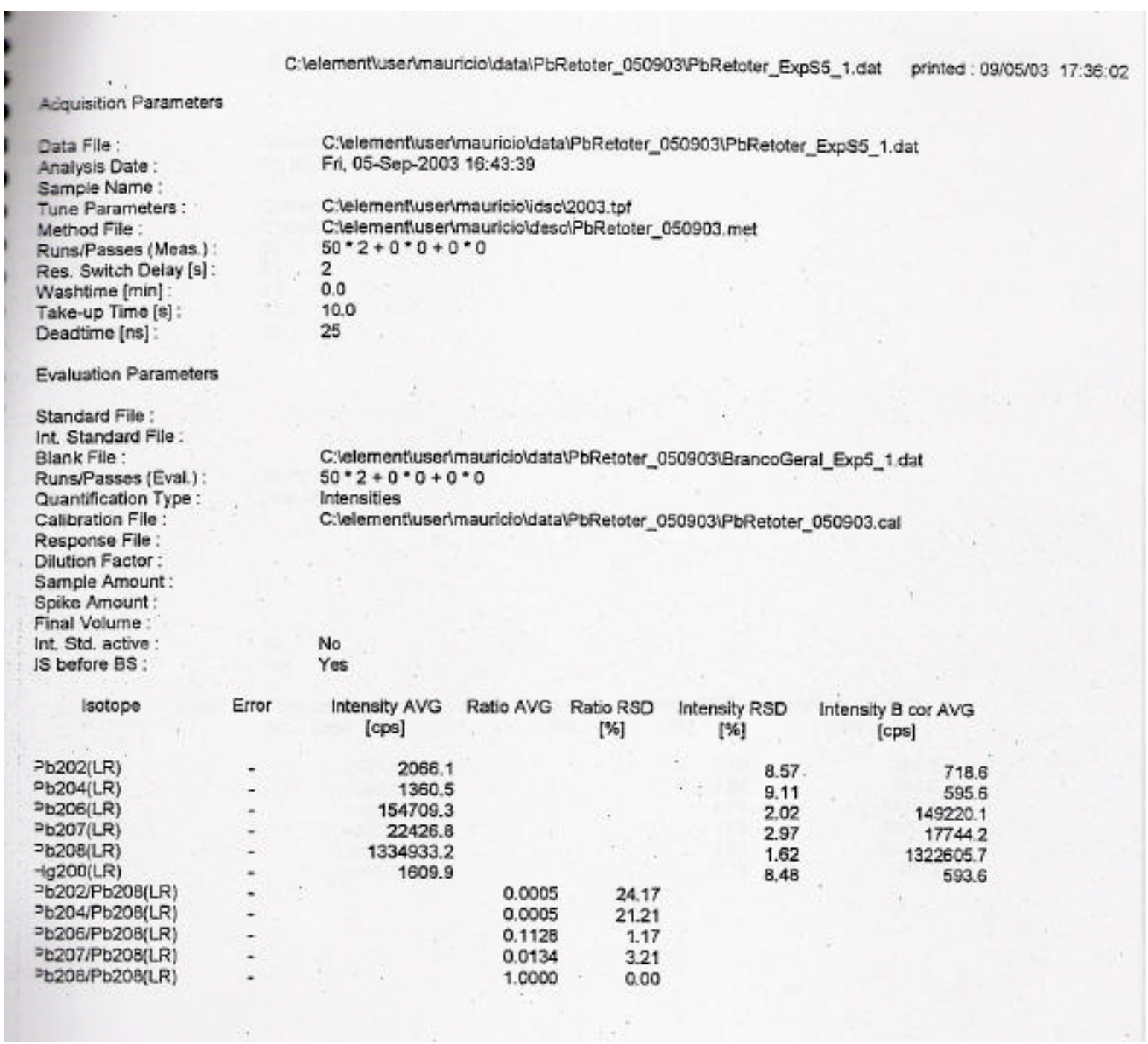




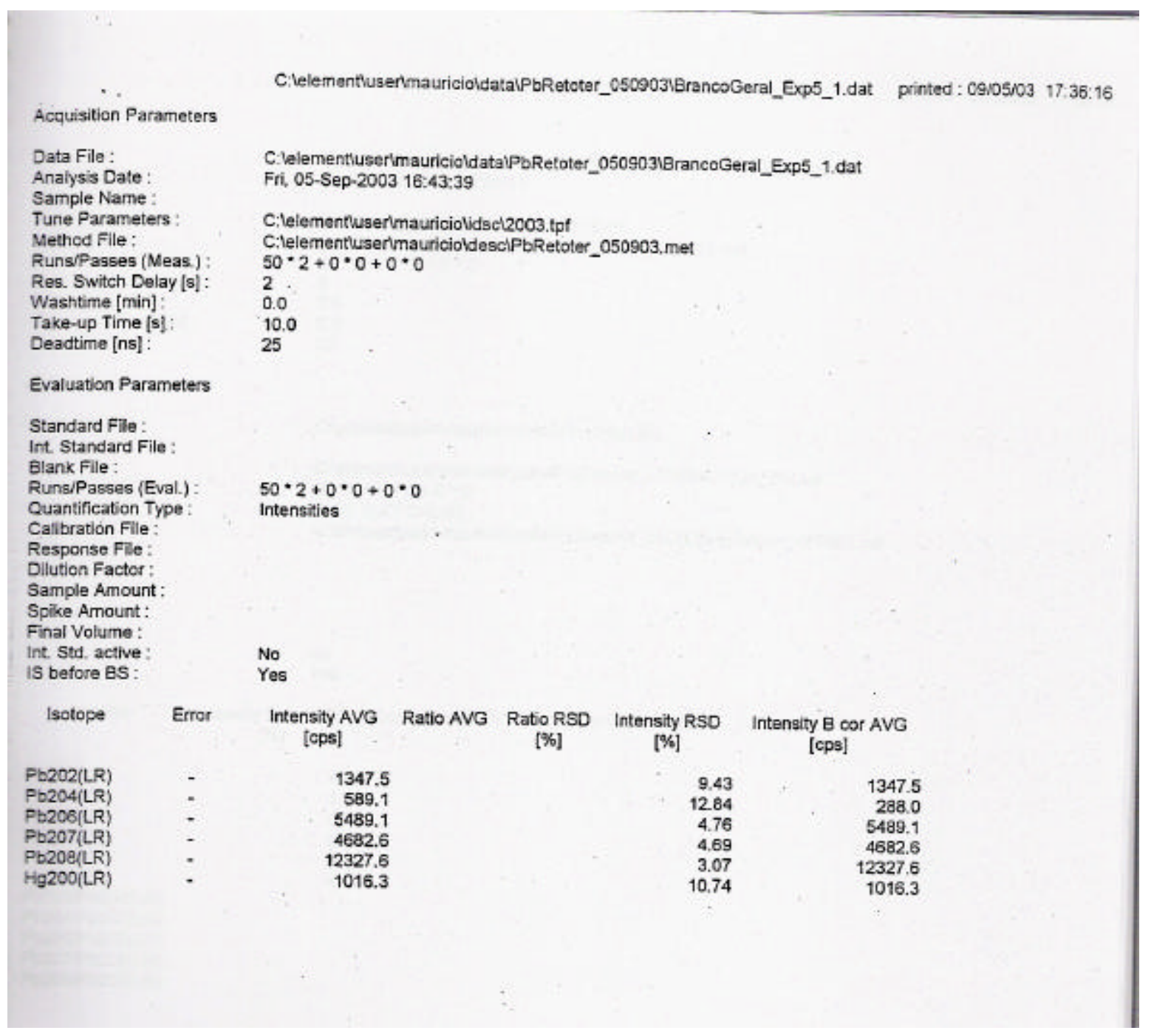


Acquisition Parameters

Data File:

Analysis Date:

Sample Name :

Tune Parameters :

Method File:

Runs/Passes (Meas.)

Res, Switch Delay [s]:

Washtime [min] :

Take-up Time [min] :

Deadtime [ns] :

C:lelementuser/mauricioldatalPbRetoter_050903\%pb_10ppb.dat Fri, 05-Sep-2003 16:28:53

C-lelementuservmauniciolidscl2003.tpf

C-lelementiuser/mauricioldesciPbRetoter_050903.met

$50 * 2+0 * 0+0 * 0$

2

0.

0,0

25

Evaluation Parameters

Standard File :

int. Standard File

Elank File:

Runs/Passes (Eval.):

Quantification Type:

Calloration File

Response File:

Dilution Factor:

Sample Amount :

Spike Amount :

Final Votume :

Int. Std. active :

is before BS

C.lelementluserimauricioldescipb10ppb.std

C:lelementluserimauricioldatalPbRetoter_0509034HO3_2\%.dat $50 * 2+0 * 0+0 * 0$

Calib (EXT CALIB)

C:VelementluserimauricioidatalPbRetoter_050903vPbRetoter_050903.cal

No

Yes

Isotope

Intensity $\mathrm{B}$ cor RSD

[\%]

$\mathrm{Pb202}$ (LR)

Pb204(LR)

Pb206(LR)

Pb207(LR)

$\mathrm{Pb20B(LR)}$

$\mathrm{Hg} 200$ (LR)

Pb202/Pb208(LR)

Pb204/Pb208(LR)

Pb206/Pb208(LR)

Pb207/Pb208(LR)

Pb208/Pb208(LR)
4.24

1.89

0.80

0.99

0.91

4.83 
Acquisition Parameters

C:leiementusermauricioldatalPbRetoter_0509031Pb_10ppb.dat

Data File:

Analysis Date :

Sample Name :

Tune Parameters :

Wetnod File

Runs/Passes (Meas.):

Res. Switch Delay [s]:

Washtime [min] :

Take-up Timo [min]:

Deadtime [ns] :

$\mathrm{Frn}, 05-$ Sep-2003 16:28.53

\section{C:Leiementiusertmauriciolids 12003 tof}

Cileiementuser/mauricioidescipbRetoter_050903.met

$50 * 2+0 * 0+0 * 0$

2

0.0

0.0

Evaluation Parameters

Standard File :

it Standard File:

Jlank File:

Rune/Passes (Eval,):

Quantification Type :

Callbration File :

Response File:

Olution Factor:

Sample Amount:

Soike Amount:

Final Volume :

int Std. active

is before BS

No

Isotope

Enror

Intensity AVG Ratio AVG Ratio RSD Intensity RSD Intensity B oor AVG

[cps]

11998.5

597053

1068723.2

896917.4

2219985.9

9247.2
$[\%]$

[\%]

3.67 .

1068598

896801.2

$0.91 \quad 2219731.0$

$\begin{array}{rr}4.19 & 8026.9\end{array}$

$=0202 / P D 208(L R)$

=b204/Pb208(LR)

b206/Pb200(LR)

-b207/PL208(LR)

=b200/Pb20B(LR)

0.0000 not def

0.0000 not def.

0.0000 not def.

0.0000 not def.

0.0000 not def. 


\section{Acquisition Parameters}

Data File :

Analysis Date :

Sample Name :

Tune Parameters :

Method File :

Runs/Paeses (Meas.):

Res Switch Delay [s] :

Washtime [min] :

Take-up Time [min]:

Deadtime [ns] :

C:lelementuserimauricioldatalPbRetoter_050903Un_10ppb.dat Fn, 05-Sep-2003 16:18:26

C:lelementuserlmauriciolidsel2003.tpf

Cilelementluservmauricioldescilin_controle. met

$10 * 2+0 * 0+0 * 0$

2 .

0.0

0.0

25

Evaluation Parameters

Standard File :

Int. Standard File:

Biank File :

Runs/Passes (Eval.):

Quantification Type :

$10 * 2+0 * 0+0 * 0$

Intensifies

Calibration File:

Response File:

Dilution Factor:

Sample Amount :

Spike Amount :

Final Volume:

Int. Std. active:

No

iS before $\mathrm{BS}$ :

Isotope

Intensity $\mathrm{B}$ cor RSD Concentration AVG Concentration STD [\%]

In115(LR)

1.44 


\section{ANEXO B - RESULTADOS DO ESPECTRÔMETRO DE MASSA - TIMS}

Os resultados para a razão isotópica $(\boldsymbol{r})$, do chumbo natural e chumbo proveniente do RETOTER, foram obtidos no espectrômetro de massa (TIMS) do Instituto de Geociências da Universidade de São Paulo.

Os resultados de \% atômica para cada isótopo de chumbo (Pbi) são obtidos pela equação:

$$
\text { \% Atômica } \mathrm{Pb} i=\frac{r(P b i / P b 206)}{\sum_{i=204}^{208} r(P b i / P b 206)} * 100
$$

$\mathrm{Pb}$ RETOTER

$\begin{array}{cccc} & \text { Razão } & \text { Isótopo } & \% \text { Atômica } \\ 204 / 206 & 0,005827 & 204 & 0,05947 \\ 206 / 206 & 1,000000 & 206 & 10,206 \\ 207 / 206 & 0,14319 & 207 & 1,4614 \\ 208 / 206 & 8,6489 & 208 & 88,273\end{array}$




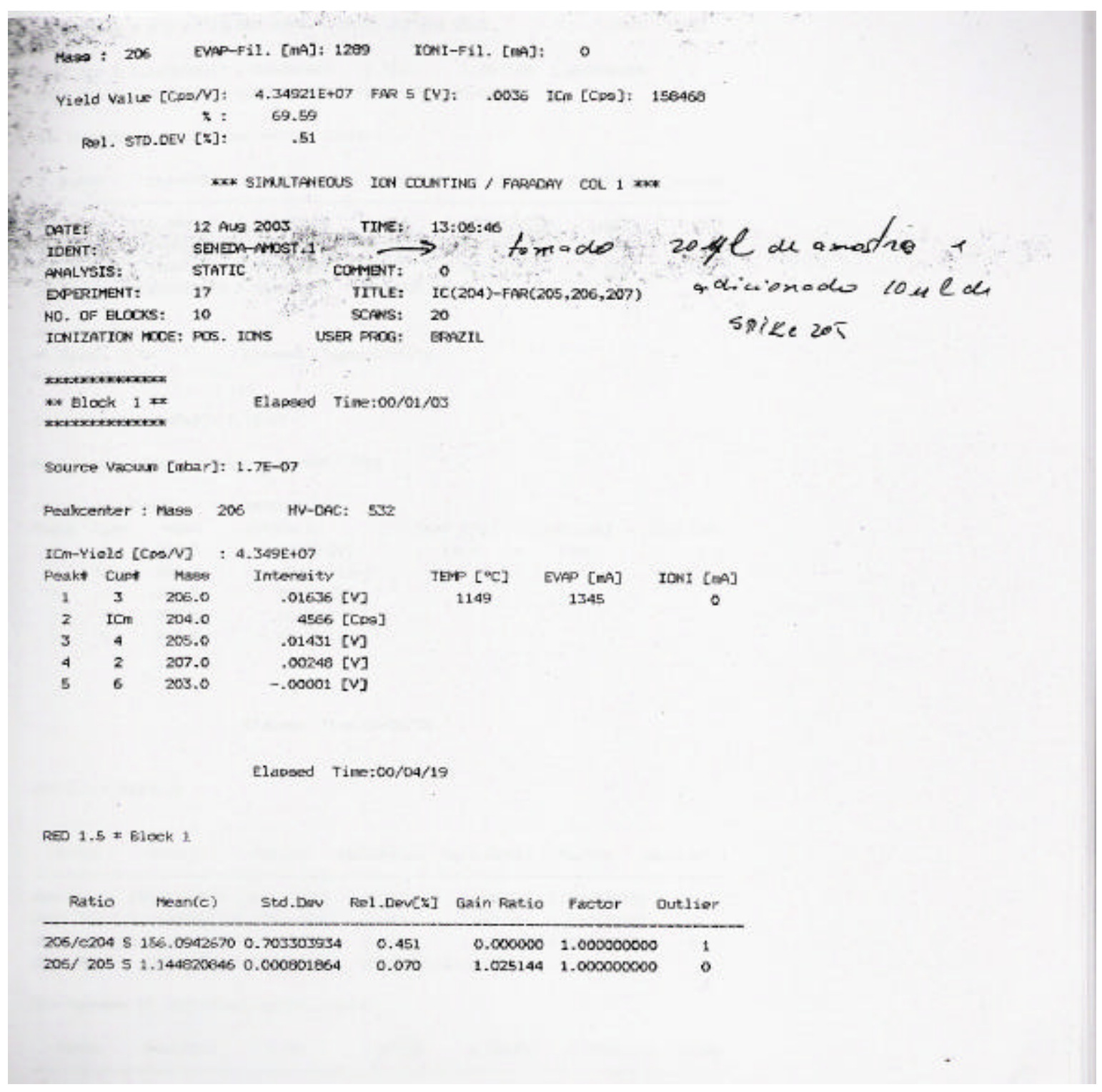


Relense 4.8.2 of 15 MaY 1958 DATE: 12 AUE 2003 PPGE 29690

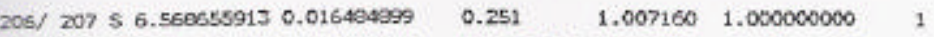
$203 / 205 \$-, 0002170950.000632206$ ERR $-290,143400315$

RUN SUMMPY OF INDTVIDUAL RATIOS (Red15)

\begin{tabular}{|c|c|c|c|c|c|c|}
\hline Ratio & $\operatorname{Mean}(R S)$ & 150 & $1 \sec [x]$ & $2 \operatorname{se}(M)$ & $2 \operatorname{se}(\mathrm{M})[\mathrm{x}]$ & values \\
\hline $206 / 6204$ & 156.0942670 & 0.703303934 & 0.451 & 0.3226979764 & 0.207 & 19 \\
\hline $206 / 205$ & 1.144820e45 & 0.000001864 & 0.070 & 0.0003585046 & 0.051 & 20 \\
\hline $206 / 207$ & 6.568655913 & 0.016404099 & 0.251 & 0.0075537906 & 0.115 & 19 \\
\hline $203 / 205$ & -.000217095 & 0.000632200 & EPR -99 & 9999 & & \\
\hline
\end{tabular}

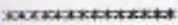

AF Block 2 nes Elapoed Tine:co/05/10

Source Vacuin [mber]: 1,7E-0?

Peakconter: Maso $206 \quad$ MV-DnC: 532

ICn-Yield [CparN] : 4.TA9E+07

Peakt Cupk Hase

$1306.0 \quad 02006[\mathrm{~V}]$

TEMP [ $\left.{ }^{\circ} \mathrm{C}\right]$ EVP $[\mathrm{ma}]$ IONI [MA]

ICm $204.0 \quad 7025$ [Cpses]

$.0245 z[V]$

$\infty 427[V]$

Elapoed Time:00/0e/3J

RED $1.5 *$ Blook 2

Ratio Han(c) Std.Dev Rel.Dev[x] Gain Ratio Factor Dutlier

$206 / 02045155.55176890 .510701750 \quad 0.327 \quad 0.000000 \quad 1.000000000$

$206 / 205 \$ 1.144969671 \quad 0.000831032 \quad 0.073 \quad 1.025144 \quad 1.0000000000$

$206 / 207 \$ 6.558642260 \quad 0.019759215 \quad 0.301 \quad 1.007160-1.000000000 \quad 0$

$203 / 205$ \$ $-.000196756 \quad 0.000639519 \quad$ ERP -325.031815947

RUN SUMARY of INDIVIDUAL RATIOS (Red15)

\begin{tabular}{|c|c|c|c|c|c|c|}
\hline Ratio & $\operatorname{Moan}(125)$ & 150 & $1 \mathrm{SD}[\%]$ & $2 \operatorname{SE}(M)$ & $2 \operatorname{se}(M)[\pi]$ & values \\
\hline 205 & 156.02268100 & 0.510542137 & 0.391 & 0.1980857017 & 0.127 & 30 \\
\hline $206 / 205$ & 1.144065259 & 0.000607295 & 0.071 & 0.0002552392 & 0.022 & $\infty$ \\
\hline $206 / 207$ & 5. 563749006 & 0.018672130 & 0.294 & 0.0059796673 & 0.091 & 39 \\
\hline
\end{tabular}




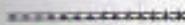 \\ $=$ Block 3 xo:

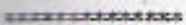

Elapsed Tine:00/09/32

Soures Vacuun $[\mathrm{mbar}]: 1,7 \in-07$

Prakesenter : Hase 206 HV-DEC: 532

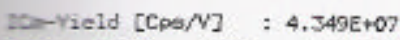

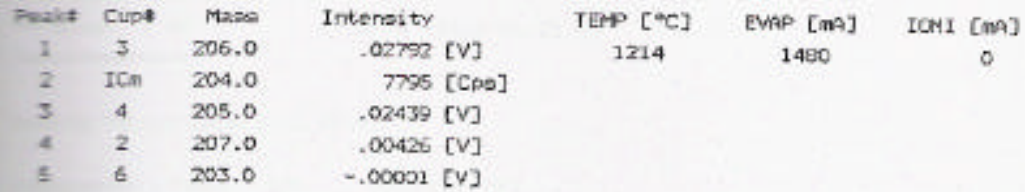

Elapsed Yins: $00 / 12 / 46$

Ne $1.5 \times$ Block 3

Ratio Mean(e) Std.Den Rol.Dev[r] Gzin Ratio Factor outlier

$206 / 1204$ S 155.67090290 .294437730

20E/ $205 \leqslant 1.1442181020 .000641240$

$206 / 20756.5653416520 .021620043$

$\begin{array}{llll}0.189 & 0.000000 & 1.000000000 & 3 \\ 0.056 & 1.025144 & 1.000000000 & 1 \\ 0.320 & 1.007160 & 1.000000000 & 0 \\ 02.66 & 0.599221 & 1.0000000000 & 2\end{array}$

2012050.0004512020 .000372956

EN SUTARY OF INDTVTOUAL RATIOS (REd1S)

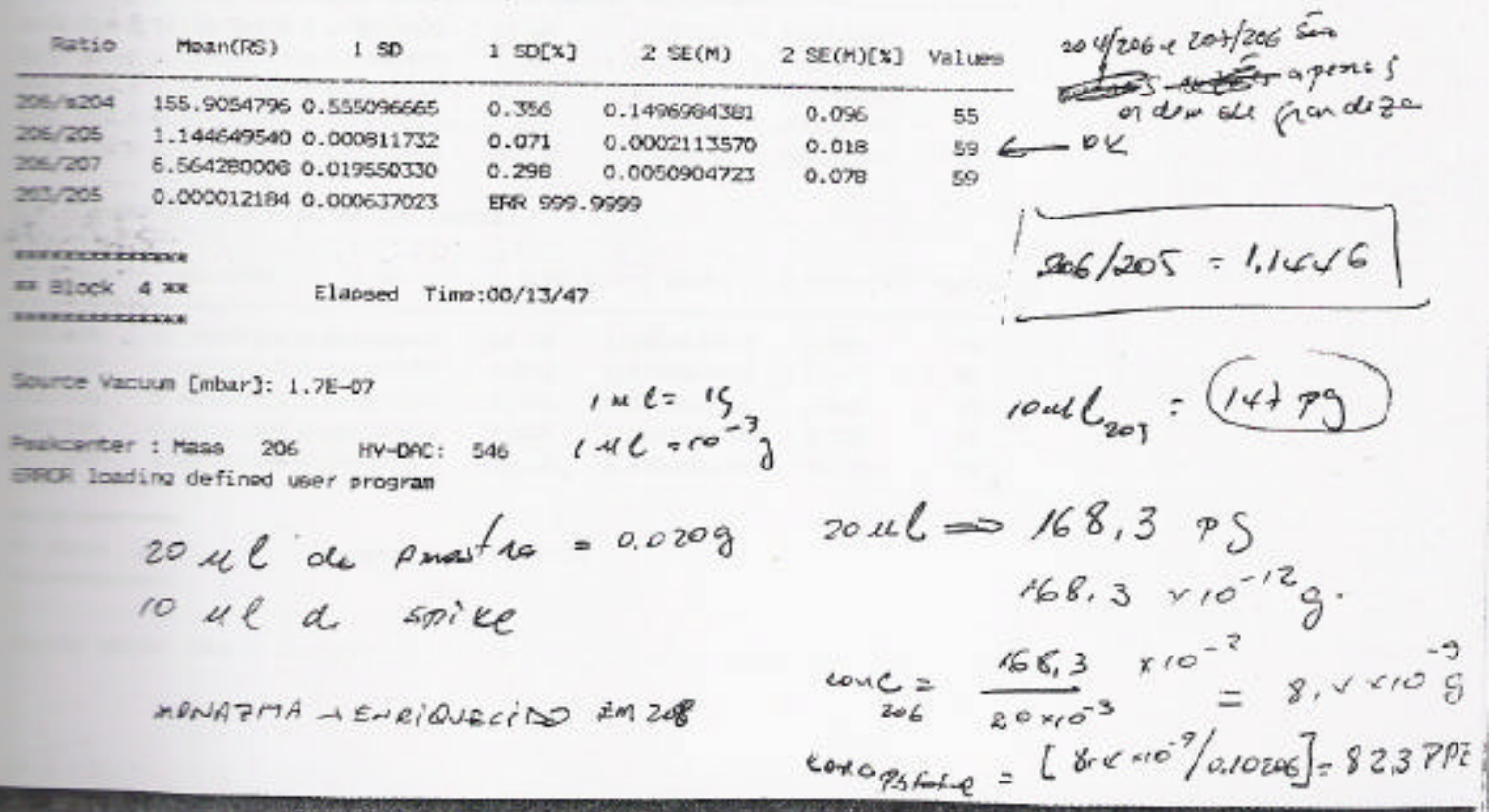


Relesse 4.8.2 of 15 May 1996 DATE: 12 AUg 2003 PAGE 20692

*W* SIMULTANEOUS DATA ACOUISITICN FABAOAY COL 5 W:KK

DATE:

DATE:

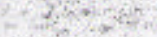

12 Avg 2003 SENEDA-ERANCO

ANALYSIS: STATIC

ME: $14: 57: 04$

EXPERTMENT

COMENT: 0

NO. OF BLOCKS: 5

IONIZATION MOOE: POS. ICNS

TITLE: PB STATIC FAR $20 \mathrm{~S}$

SCANS: 20

USER PROG: BRAZIL

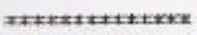

If Block 1 wer

Elapsed Time:00/01/05

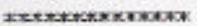

Source Vacum [nbar]: 1.9E-07

\begin{tabular}{|c|c|c|c|c|c|c|c|}
\hline Peakf & Cupt & Mase & Intensity $[\mathrm{V}]$ & $\operatorname{TEM}\left[{ }^{\circ} \mathrm{C}\right]$ & EWPS [MA] & IONI & [ma] \\
\hline 1 & 4 & 206.0 & .00084 & 1278 & 1506 & & 0 \\
\hline 2 & 3 & 207.0 & .00070 & & & & \\
\hline 3 & 2 & 200.0 & .00169 & & & & \\
\hline 4 & 5 & 205.0 & .01210 & & & & \\
\hline 5 & 6 & 204.0 & .00007 & & & & \\
\hline 6 & 7 & 203.0 & -.00001 & & & & \\
\hline
\end{tabular}

Elapsed Time:00/04/19

RED 1.5 * Block

Ratio Hean(e) Stid.Dew Rel-Deu[\%] Gain Ratio Factor Dutlier

$205 / 204518.706963503 .009318400$

$206 / 20751.1865851130 .031497479$

16.09

$1.000790 \quad 1.000000000$

$0.975473 \quad 1.000000000$

$206 / 2065$ 0.485490926 0.010217344

.654

$0.962457 \quad 1.000000000$

2.105

$0.993057 \quad 1.000000000$

$206 / 205 \$ 0.0685512000 .001097512$

0.9995221 .000000000

RLN SUTYPFY OF INDIVIDUAL RATIOS (FEOT15)

\begin{tabular}{|c|c|c|c|c|c|c|}
\hline Ratio & Fean(RS) & 150 & $15 D[x]$ & $2 \operatorname{SE}(M)$ & $2 \operatorname{SE}(M)[*]$ & Values \\
\hline $206 / 204$ & 16. 70699350 & 3.009318400 & 16.09 & 1.30076997es & 7.381 & 19 \\
\hline $206 / 207$ & 1.106585113 & 0.031497479 & 2.654 & 0.0140851010 & 1.187 & 20 \\
\hline $206 / 208$ & 0.485490925 & 0.010217344 & 2.105 & 0.0045695351 & 0.941 & 20 \\
\hline $206 / 205$ & 0.068551200 & 0.001097612 & 1.601 & 0.0005036180 & 0.735 & 19 \\
\hline $203 / 205$ & 0.000505507 & 0.001020203 & 201.8 & 0.0004562486 & 90.25 & 20 \\
\hline
\end{tabular}

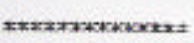

tw Block 2 wer. Elapsed Tumz:00/05/24

$x= \pm x+1+1: x \times x \times x=:$

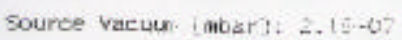




\begin{tabular}{|c|c|c|c|c|c|c|c|}
\hline Peakt & Cupt & Mass & Intensity $[\mathrm{V}]$ & TEMP $\left[{ }^{\circ} \mathrm{C}\right]$ & EVAP $[\mathrm{mA}]$ & IOWI & {$[m \in]$} \\
\hline 1 & 4 & 206.0 & .00076 & 1279 & 1500 & & 6 \\
\hline 2 & 3 & 207.0 & $.0005 A$ & & & & \\
\hline 3 & 2 & 208.0 & .0015 .5 & & & & \\
\hline 4 & 5 & 205.0 & .21105 & & & & \\
\hline 5 & 6 & 204.0 & .00004 & & & & \\
\hline 6 & 7 & 203.0 & .00001 & & & & \\
\hline
\end{tabular}

RED $1.5 *$ 8lock 2

\begin{tabular}{|c|c|c|c|c|c|c|}
\hline Ratio & Mean(c) & Ste.Det & Rol.Dev[ $[x]$ & Gain Ratio & Factor & out.lier \\
\hline $206 / 2045$ & 23.93563407 & 8.069956570 & 37.06 & 1.000780 & 1.000000000 & 2 \\
\hline $206 / 2075$ & 1.202298376 & 0.020506150 & 1. 706 & 0.975473 & 1.000000000 & 1 \\
\hline $206 / 2085$ & 0.486713603 & 0.006303103 & 1.711 & 0.932457 & 1. 000000000 & 1 \\
\hline $206 / 2055$ & 0.068443272 & 0.001329067 & 1.942 & 0.993057 & 1.000000000 & 0 \\
\hline $203 / 2055$ & 0.001063145 & 0.001132511 & 104,6 & 0.999322 & 1.000000000 & 0 \\
\hline
\end{tabular}

RUIN SUMMAFY OF INDTVIDUAL RATIOS (REd1S)

\begin{tabular}{|c|c|c|c|c|c|c|}
\hline Ratio & $\operatorname{Mean}($ RS) & $1 S D$ & $1 S O[x]$ & $2 \operatorname{SE}(M)$ & $2 \operatorname{SE}(M)[\pi]$ & Val wes \\
\hline $206 / 204$ & 21.32030879 & 6.978523617 & 32.73 & 2.2945244309 & 10.76 & 37 \\
\hline $206 / 207$ & 1.194441744 & 0.027542366 & 2.306 & 0.0086206163 & 0.738 & 39 \\
\hline $206 / 208$ & 0.485102265 & 0.009243056 & 1.901 & 0.0025601470 & 0.609 & 39 \\
\hline $206 / 205$ & 0.063497235 & 0.001207009 & 1.762 & 0.0003955522 & 0.564 & 39 \\
\hline $203 / 205$ & 0.000794326 & 0.001103380 & 138.9 & 0.0203489220 & 43.93 & 40 \\
\hline
\end{tabular}

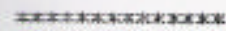

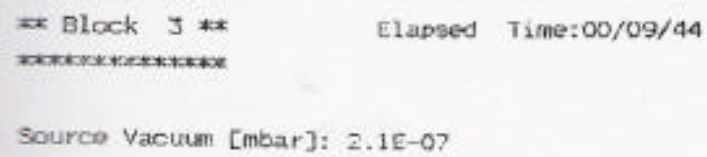


Ratio Man(c) Std.Dev Fol.Dov[z] Gain Ratio Factor outlier

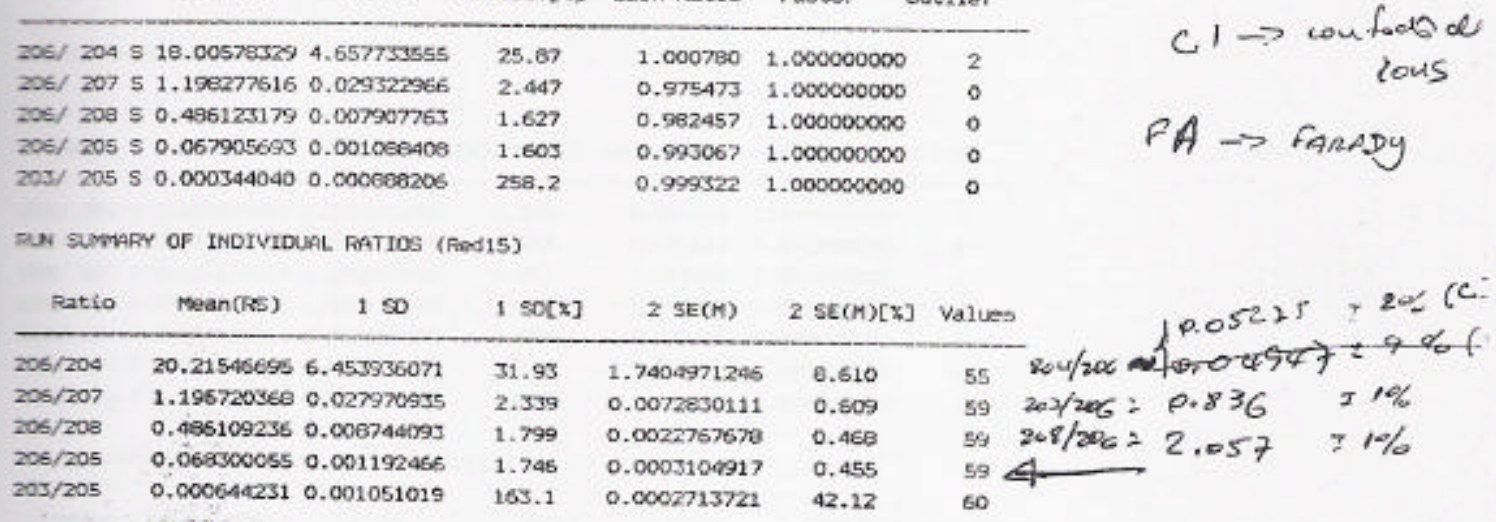

EReCR loadima defined user progran

tes

$$
\begin{aligned}
& \text { in } l \text { ar surco } \\
& 206 / 205=0,068388 \quad \Rightarrow 206=5,020 \times 10^{-12} \mathrm{~g} / .
\end{aligned}
$$

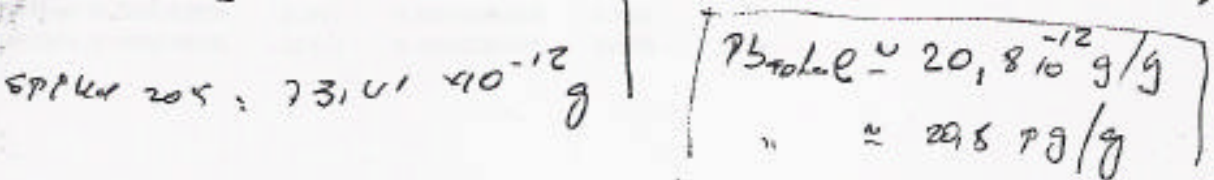


Felease 4.8 .2 of 15 May 1998 DATE: 12 Aus $z 003$

*Ee SINULTANEDUS DATA ACQUISITICN FARPDAY COL 5 **2.

DATE:

12 Aug 2003

TIME: $\quad 15: 16: 23$

roent:

SEMEDA-AODST. 1

AWALYSIS: STATIC

EPERTMET:

NO. Of BLocks: 10

IOWYZATICN MODE: POS. IONS

CONIIENT: 0

TITLE: PE STATIC FNR 208

SCANS: 20

USER FROL: BRAZI

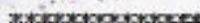

* Block 1 ow Elapsed Time:00/01/05

xaromonis

Source Vacuun [mbar]: 1,ee-07

Poukcenter : hase 208 HV-OAC: 525

Peak Cupot Mase Jntemoity [V]

200.0

Irrtenoity [V]

TEP $\left[{ }^{\circ} \mathrm{C}\right]$

EVPP [IIA]

IOWI [MA]

$\begin{array}{llll}2 & 3 & 207.0 & .02186\end{array}$

3. $4.206 .0 \quad .15264$

$\begin{array}{llll}4 & 5 & 205.0 & .00002\end{array}$

$\begin{array}{llll}5 & 6 & 204.0 & .00090\end{array}$

$1226 \quad 1411$

Elapsed Timo:c0/04/19

RED $1.5 \div 810 \mathrm{ck}$

\begin{tabular}{|c|c|c|c|c|c|c|}
\hline Ratio & Mean(c) & Std.Dev & Rel.Dev[\%] & Gain Ratio & Factor & Outlier \\
\hline $204 / 2065$ & 0.005863969 & 0.000063096 & 1.076 & 0.999221 & 1.000000000 & 0 \\
\hline $207 / 2065$ & 0.143073615 & 0.000104559 & 0.073 & 1.025144 & 1.000000000 & 0 \\
\hline $200 / 2065$ & 8. 624310553 & 0.000962508 & 0.011 & 1.017856 & 1.000000000 & 1 \\
\hline $205 / 204 \mathrm{~s}$ & 170.5547135 & 1.843127673 & 1.081 & 1.000780 & 1.000000000 & 0 \\
\hline $206 / 207$ s & 6.909412466 & 0.005109483 & 0.073 & 0.575473 & 1.000000000 & 0 \\
\hline $206 / 200 \mathrm{~s}$ & 0.115951299 & 0.000013034 & 0.011 & 0.952457 & 1.000000000 & 2. \\
\hline $205 / 2055$ & 0.000045071 & 0.000074091 & 164.3 & 1.006982 & 1.000000000 & 1 \\
\hline
\end{tabular}

FUW SURMEY OF INDIVIDUAL RATIOS (REd15)

\begin{tabular}{|c|c|c|c|c|c|c|}
\hline Ratio & Mean(RS) & 150 & $1 \mathrm{so}[\chi]$ & $2 \operatorname{SE}(M)$ & $2 \operatorname{se}(M)[x]$ & Values \\
\hline $204 / 206$ & $0 . \cos 253 a 59$ & 0.000053096 & 1.076 & 0.0000282173 & 0.481 & 20 \\
\hline $207 / 206$ & 0.1435073615 & 0.000104559 & 0.073 & 0.0000467604 & 0.033 & 20 \\
\hline $208 / 206$ & 0.624310553 & 0.000959500 & 0.011 & 0.0004448410 & 0.005 & 19 \\
\hline $206 / 204$ & 170.5547135 & 1.843127673 & 1.081 & 0.8242717537 & 0.483 & 20 \\
\hline $206 / 207$ & 6.989412466 & 0.005109483 & 0.073 & 0.0022850301 & 0.033 & 20 \\
\hline $206 / 208$ & 0.115951299 & 0.000013034 & 0.011 & 0.0000059004 & 0.005 & 19 \\
\hline $205 / 206$ & 0.000045071 & 0.000074041 & 164.3 & 0.0000339723 & 75.38 & 19 \\
\hline
\end{tabular}




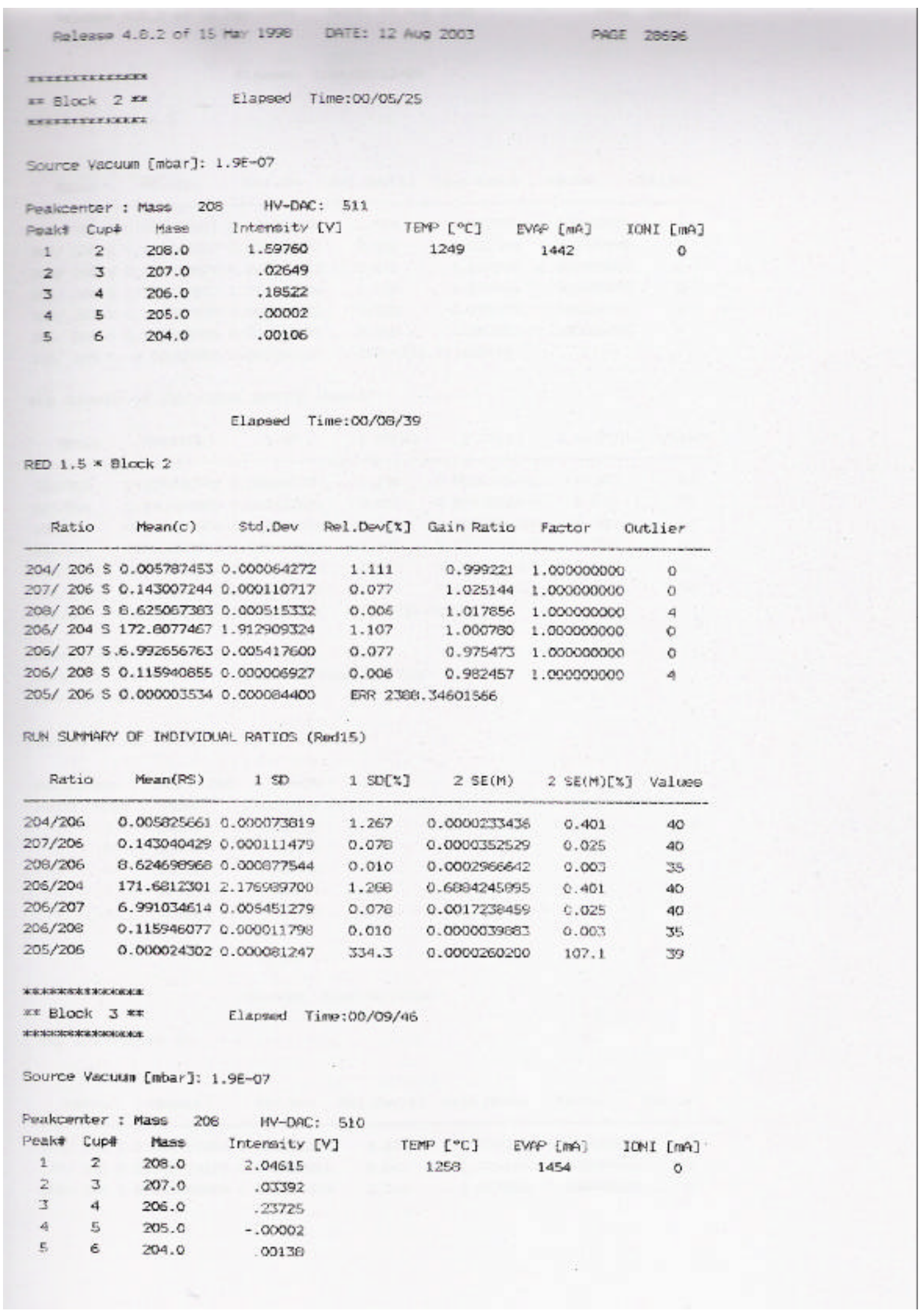


Release 4.8 .2 of 15 Way 1996

DATE: 12 AUg 2003

PACE 28697

\section{Elapsed Time:00/13/00}

RED $1.5 \times$ Block 3

\begin{tabular}{|c|c|c|c|c|c|c|}
\hline Ratio & Meran(c) & Stat. Der & Fel_-Dev[x] & Gain Ratio & Factor & Outlier \\
\hline $4 / 2065$ & 0.005840911 & 0.000000050 & 1.028 & 0.955221 & 2.000000000 & 0 \\
\hline $207 / 206 \mathrm{~s}$ & 0.142563207 & 0.000055038 & 0.039 & 1.025144 & 1.000000000 & 1 \\
\hline $200 / 2065$ & 8.524719678 & 0.000677413 & 0.010 & 1.017855 & 1.000000000 & 1 \\
\hline $205 / 2045$ & 171.2232937 & $1.75-4743686$ & 1.025 & 1. 0007780 & 1.000000000 & 0 \\
\hline $206 / 2075$ & 6.994007699 & 0.002692723 & 0.039 & 0.975473 & 1.000000000 & 1 \\
\hline $205 / 2085$ & 0.125945796 & 0.000011795 & 0.010 & 0.982457 & 1.000000000 & 1 \\
\hline
\end{tabular}

RUN SUMARY OF INDIVIDUAL PATICS (Red15)

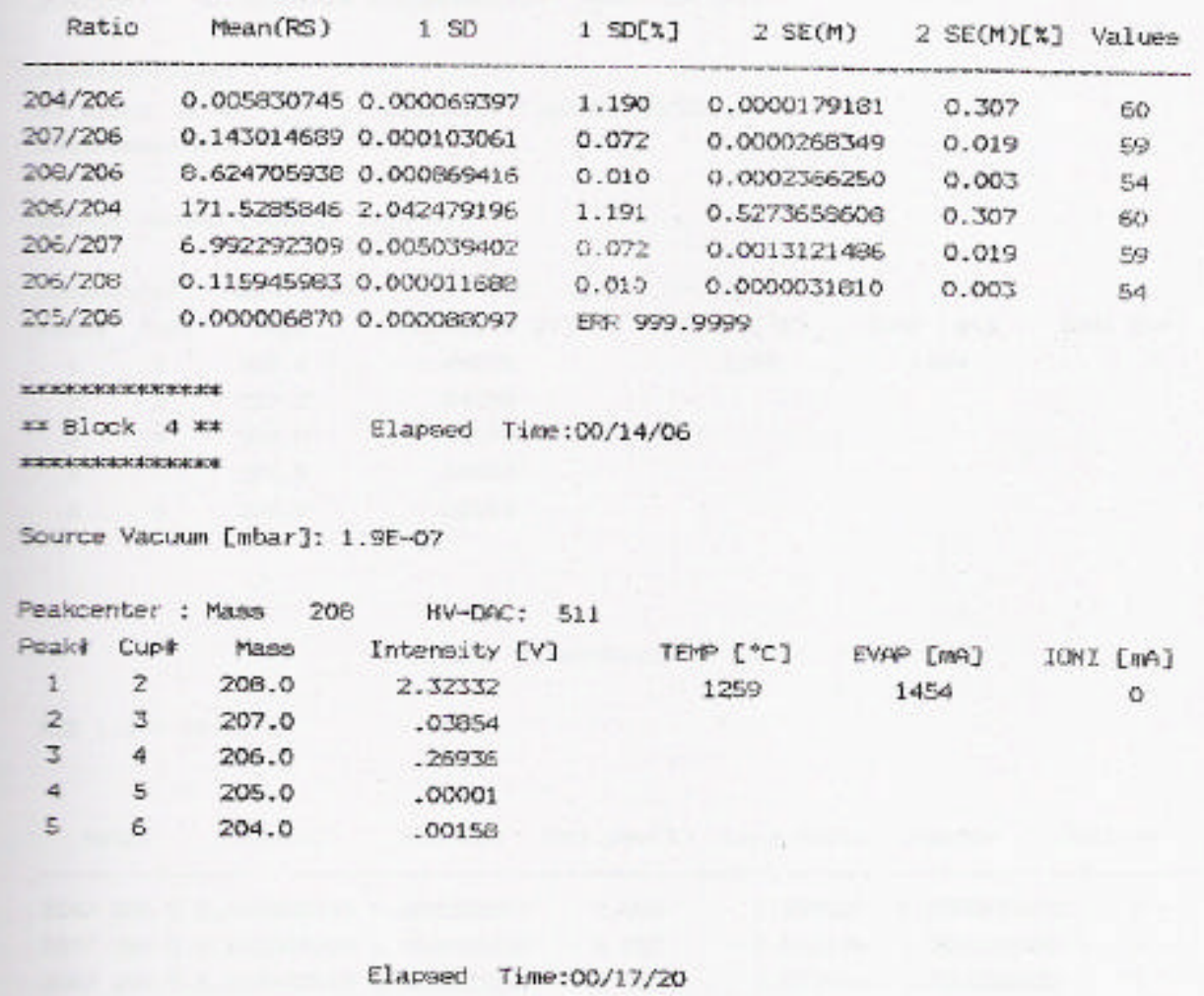

Red $1.5 *$ Block 4

\begin{tabular}{ccccccc} 
Ratio Moan(c) & Std.Dev Rel.Dev[y] & Gain Ratio & Factor Outlier \\
\hline $204 / 20650.005827454$ & 0.000025272 & 0.434 & 0.999221 & 1.000000000 & 2 \\
$207 / 20650.143024182$ & 0.000058516 & 0.041 & 1.025144 & 1.000000000 & 0 \\
$208 / 20558.625462984$ & 0.000055979 & 0.010 & 1.017856 & 1.000000000 & 0
\end{tabular}


Relezae 4.9 .2 of 15 MaY 1998 DATE: 12 AUg 2003

PAGE 29698

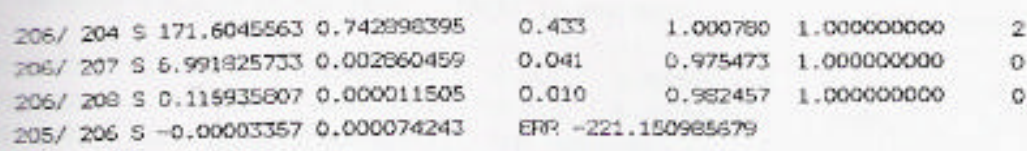

RUN SUNWAFY OF INDYVIOUAL RATIOS (BRd15)

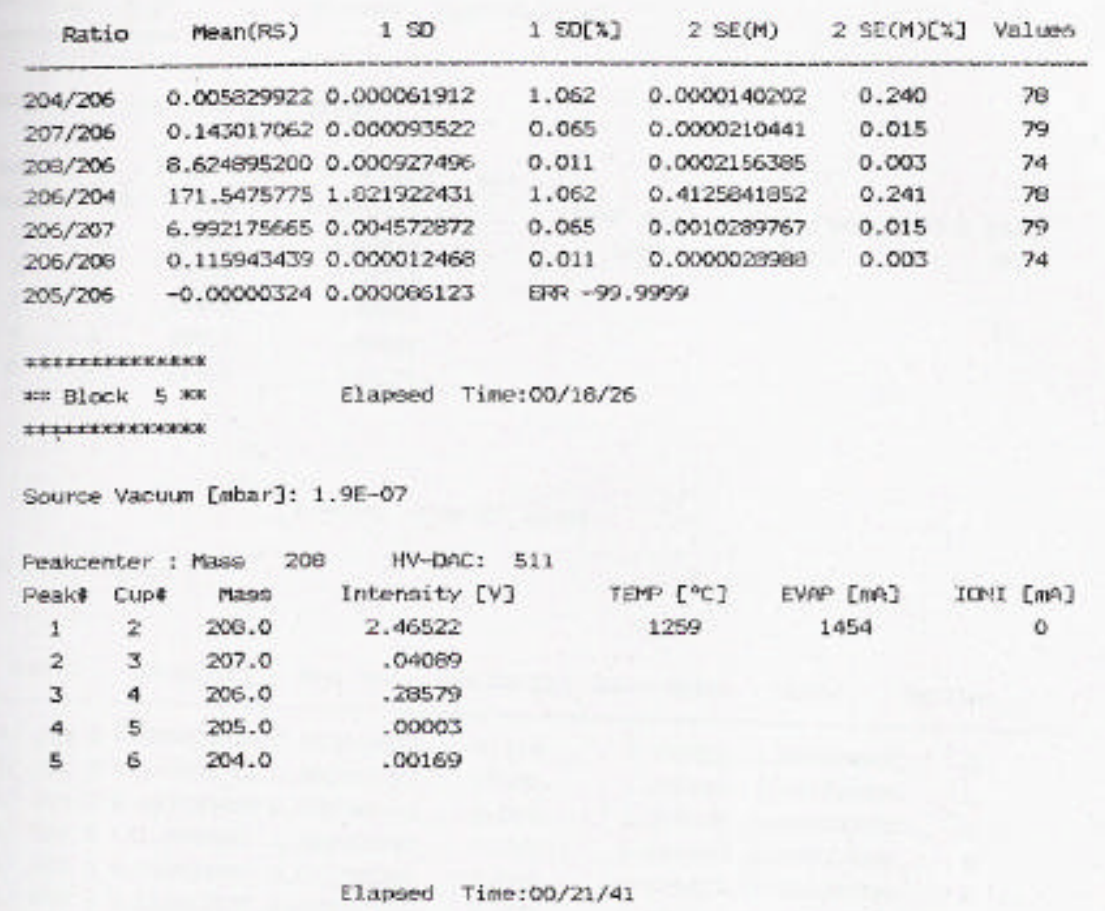

FED $1.5 \times$ Block 5

Ratio Mean(c) Sto.Dev Rel.Dev[\%] Gain Ratio factor Outlier

$204 / 20650.0059563950 .000058002 \quad 0.990 \quad 0.999221 \quad 1.0000000000$

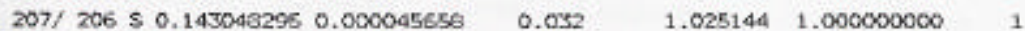

$200 / 20553.5264406190 .000623242 \quad 0.010 \quad 1.017856 \quad 1.000006000 \quad 1$

$206 / 204 \$ 170.76945701 .694326862 \quad 0.992 \quad 1.0007901 .000000000 \quad 0$

$206 / 207 \$ 6.9906467340 .003231106 \quad 0.032 \quad 0.975473 \quad 1.000000000 \quad 1$

$\begin{array}{lllllll}206 / 208 & 50.115922668 & 0.000011062 & 0.010 & 0.962457 & 1.000000000 & 1\end{array}$

$205 / 206$ \& 0.0000083630 .000091876 ERR 1096.6340793

RUN SUMTNEY OF INOIVIDUAL FATIOS (REA15)

\begin{tabular}{ccccccc} 
Ratio & Mean(RS) & $1 S D$ & 1 SD[\%] & 2 SE(M) & 2 SE(M)[X] & Values \\
\hline $204 / 206$ & 0.005035217 & 0.000061775 & 1.053 & 0.0000124805 & 0.214 & 98 \\
$207 / 206$ & 0.1430233093 & 0.000086909 & $0.06:$ & 0.0000175745 & 0.012 & 90 \\
$208 / 206$ & 8.625204203 & 0.001090902 & 0.013 & 0.0002279163 & 0.003 & 93 \\
$206 / 204$ & 171.3919536 & 1.815573092 & 1.059 & 0.3668011556 & 0.214 & 98
\end{tabular}


Releage 4.8 .2 of 15 may 1958

DATE: 12 Aug 2003

PACE 28690

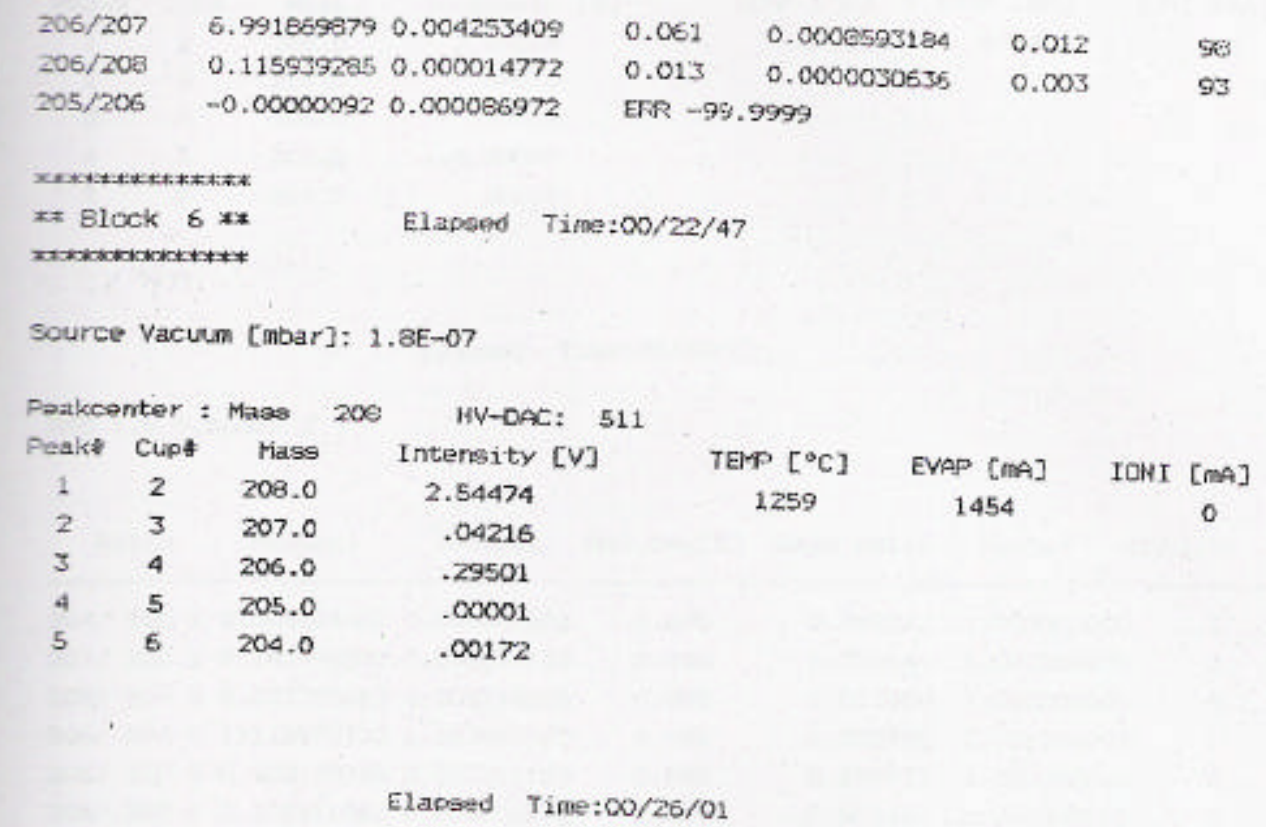

$0.061 \quad 0.0000593134$

$0.013 \quad 0.00000305 \pi 5$

0.012

0.003

$5 \%$

EFR -99.9999

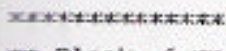

$x=$ Block $6 \%$

Elapsed Time:00/22/47

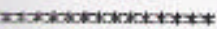

Source Vacuum [mbar]: $1.8 \mathrm{E}-07$

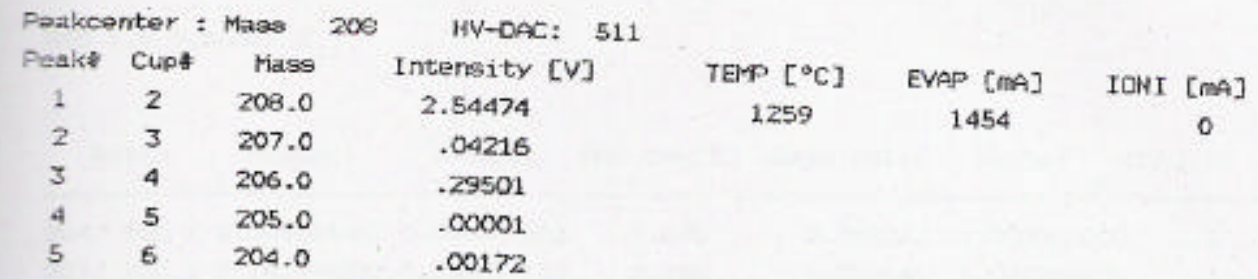

Elapsed Time:00/26/01

RED $1.5 *$ Block 6

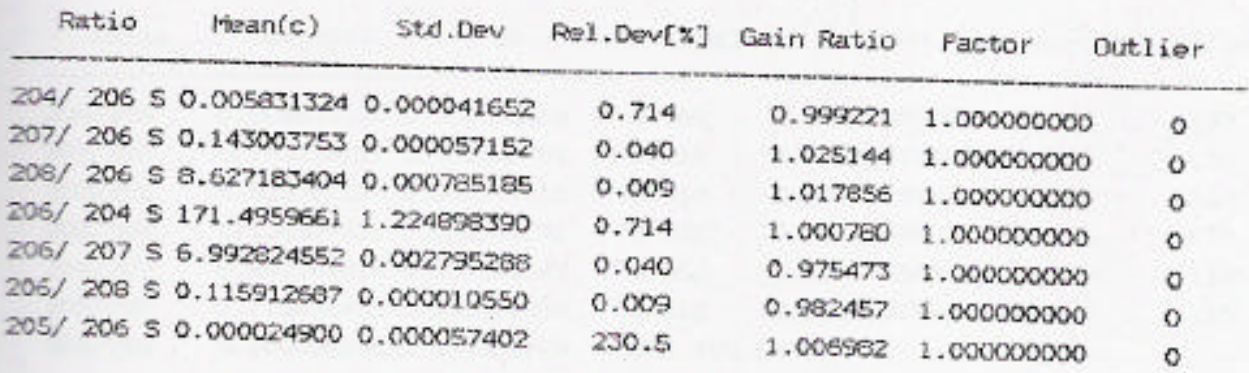

RUN SUMARY OF IMDIVIDUAL PATYOS (REed15)

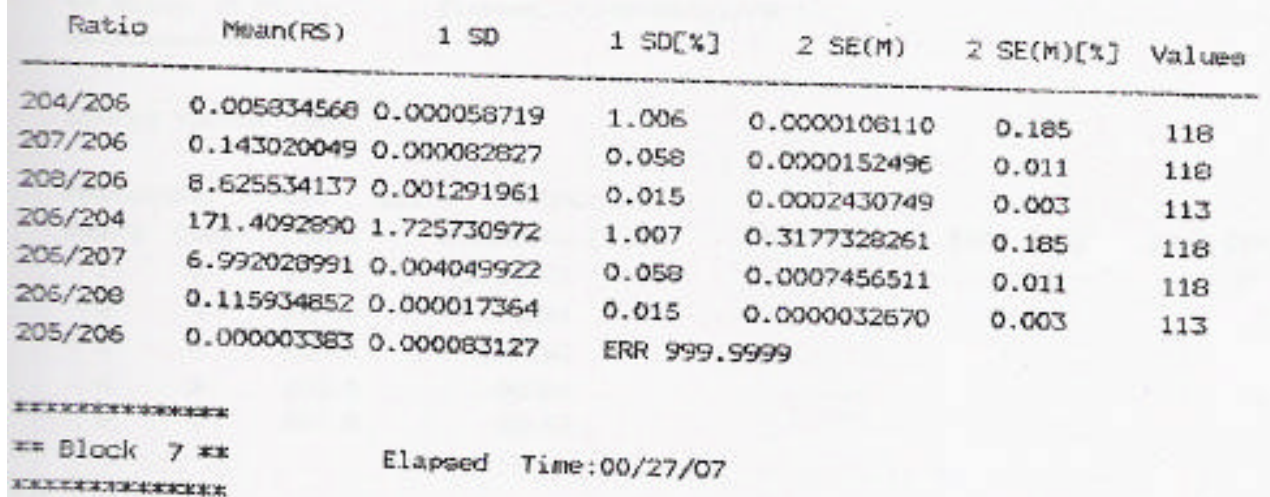

Source Vacuun [mbar]: $1.8 E-07$

Peakcenter: Mass 200 HV-OAC: 511 
Release 4.8 .2 of 15 May 1990 DATE: 12 Aug 2003

PAEE 28700

\begin{tabular}{|c|c|c|c|c|c|c|c|}
\hline Peakk & Cupł & Mass & Interaity $[Y]$ & TEMP $\left[{ }^{\circ} \mathrm{C}\right]$ & EVAP [MA] & IONI & {$[\mathrm{m} A]$} \\
\hline 1 & 2 & 208.0 & 2.44684 & 1260 & 1454 & & 0 \\
\hline 2 & 3 & 207.0 & .09055 & & & & \\
\hline 3 & 4 & 206.0 & .20350 & & & & \\
\hline 4 & 5 & 205.0 & -0.00000 & & & & \\
\hline 5 & 5 & 204.0 & .00164 & & & & \\
\hline
\end{tabular}

Elapsed Time:00/30/21

RED 1.5 * Block 7

\begin{tabular}{|c|c|c|c|c|c|c|}
\hline Ratio & Moan(c) & Std.Dev & $\operatorname{Rel}$-Dev $[\%]$ & Gain Ratio & Factor & Qutlier \\
\hline $204 / 206 s$ & 0.005824463 & 0.000040202 & 0.690 & 0.999221 & 1.000000000 & 1 \\
\hline $207 / 206 \mathrm{~s}$ & 0.142996692 & 0.000065713 & 0.046 & 1.025144 & 1.000000000 & 0 \\
\hline $200 / 2065$ & 8. 627305069 & 0.000713006 & 0.008 & 1.017856 & 1.000000000 & 0 \\
\hline $206 i 204 \mathrm{~s}$ & 171.6973730 & 1.183657057 & 0.609 & 1.000700 & 1. .000000000 & 1 \\
\hline $205 / 2075$ & 6.993170185 & 0.003213189 & 0.046 & 0.975473 & 1.000000000 & 0 \\
\hline $206 / 208 \$$ & 0.115911052 & 0.000009579 & 0.008 & 0.982457 & 1.000000000 & 0 \\
\hline $205 / 205 \mathrm{~s}$ & -0.00000002 & 0.000082351 & ERR -99 & .9999 & & \\
\hline
\end{tabular}

KUH SUMPARY OF INDIVIOUAL FATYOS (Fed15)

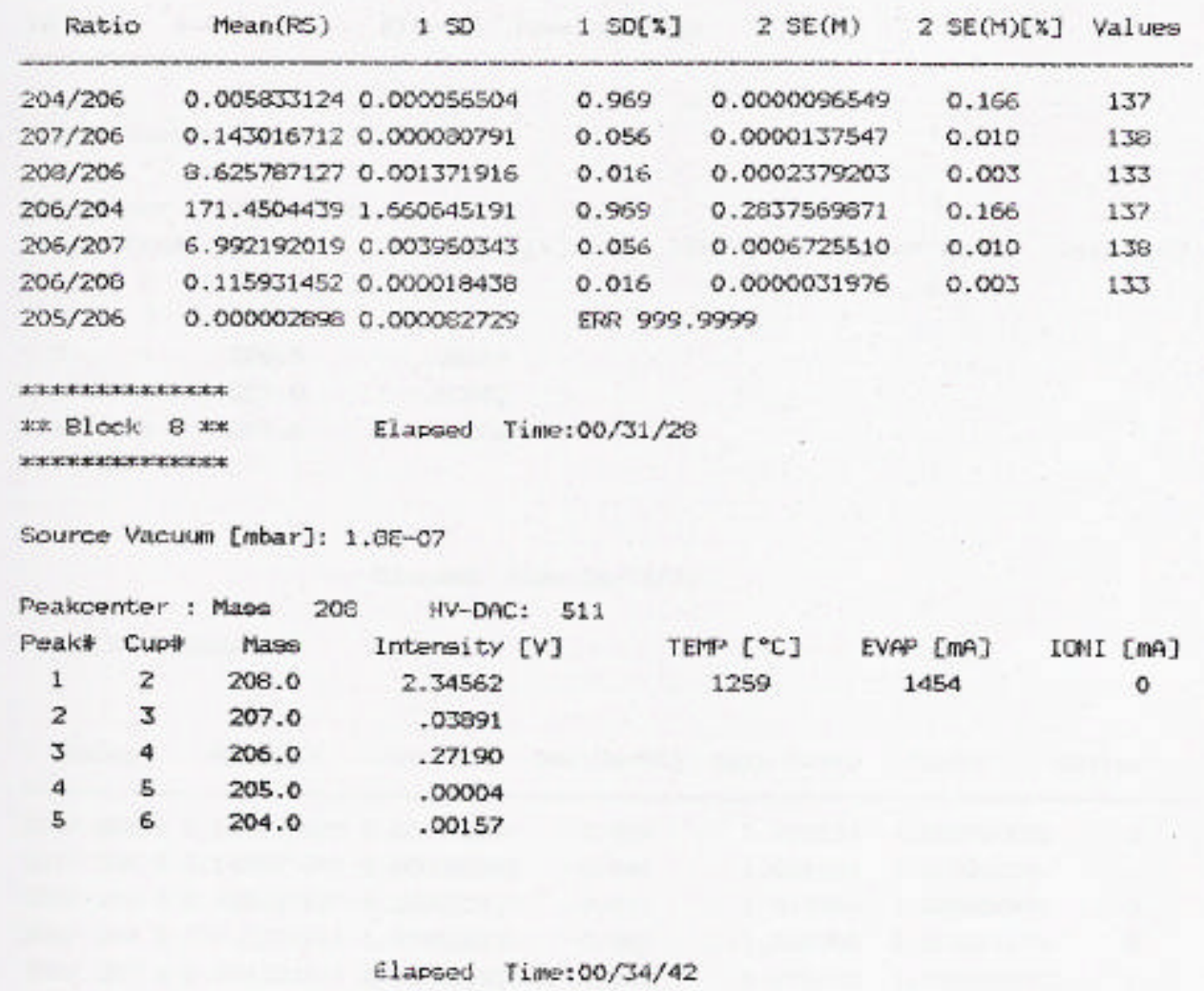

RED $1.5 \div$ Block 8 
Ratio Mean(c) Std.Den Rol.Dev[\%] Gain Ratio factor Dutlier

$204 / 205 \leq 0.005$ S6EY45 0.000044570 $207 / 20650.1429861240 .000051053$

$\begin{array}{llll}0.759 & 0.999221 & 1.000000000 & 0 \\ 0.043 & 1.025144 & 1.000000000 & 0 \\ 0.009 & 1.017856 & 1.000000000 & 0 \\ 0.762 & 1.000780 & 1.000000000 & 0 \\ 0.043 & 0.975473 & 1.000000000 & 0 \\ 0.009 & 0.902457 & 1.000000000 & 0 \\ \text { ERR - 257.262476825 } & & \end{array}$
$208 / 206$ s 8.6275911510 .000795133 $206 / 204$ s 170.41517251 .290795003 206/ $207 \$ 6.9935890100 .002905108$ 206/208 50.1159052650 .000010682 $205 / 206$ s -0.000032710 .000004140$ ERR -257.262476825

FUW SUMMARY OF INDTVTDUAL RATIOS (Bod15)

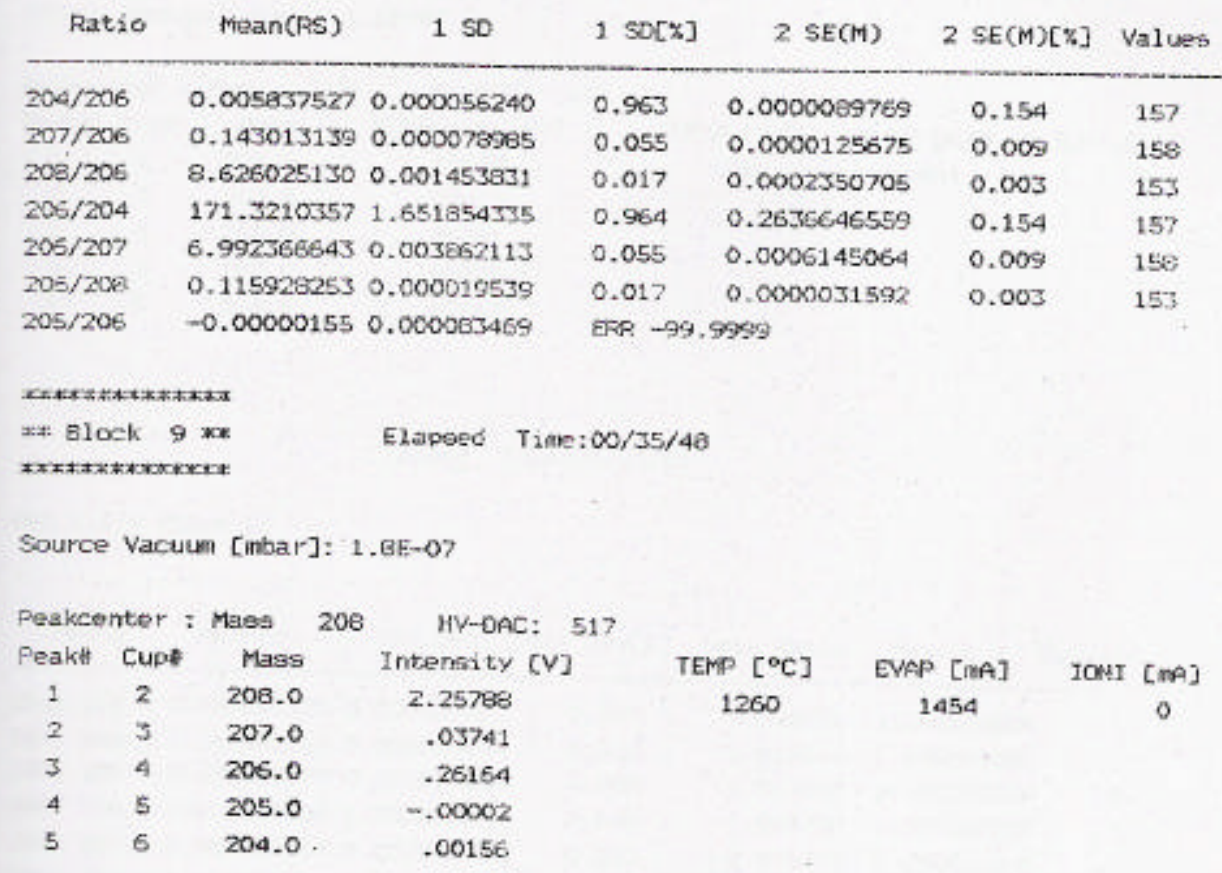

Elapred Time: $00 / 39 / 02$

RED $1.5 *$ Block 9

\begin{tabular}{|c|c|c|c|c|c|c|}
\hline Ratio & $\operatorname{Mean}(c)$ & Std.Dev & Fel $1 \cdot \operatorname{Dev}[x]$ & Gain Ratio & Factor & Outlier \\
\hline $204 / 2065$ & 0.005875020 & 0.000052794 & 0.899 & 0.999221 & 1. 000000000 & 0 \\
\hline $207 / 206 \mathrm{~s}$ & 0.142977607 & 0.000063593 & 0.044 & 1.025144 & 1. 000000000 & 1 \\
\hline $200 / 206 s$ & 8.628117527 & 0.0009932477 & 0.011 & 1.017855 & 1., 000000000 & 0 \\
\hline $206 / 204 \mathrm{~s}$ & 170.2252961 & 1.534656130 & 0.902 & 1.000780 & 1. 000000000 & 0 \\
\hline $206 / 207 \mathrm{~s}$ & 6.994103541 & 0.003110906 & 0.044 & 0.975473 & 1.000000000 & 1 \\
\hline $206 / 200 \mathrm{~s}$ & 0.115900138 & 0.000012526 & 0.011 & 0.982457 & 1. 000000000 & 0 \\
\hline $205 / 2065$ & -0.00004409 & 0.000072741 & ERF -16 & 049629769 & & \\
\hline
\end{tabular}

RUA SUMFARV OF IMDIVIDUAL, RATIOS (RED1E) 


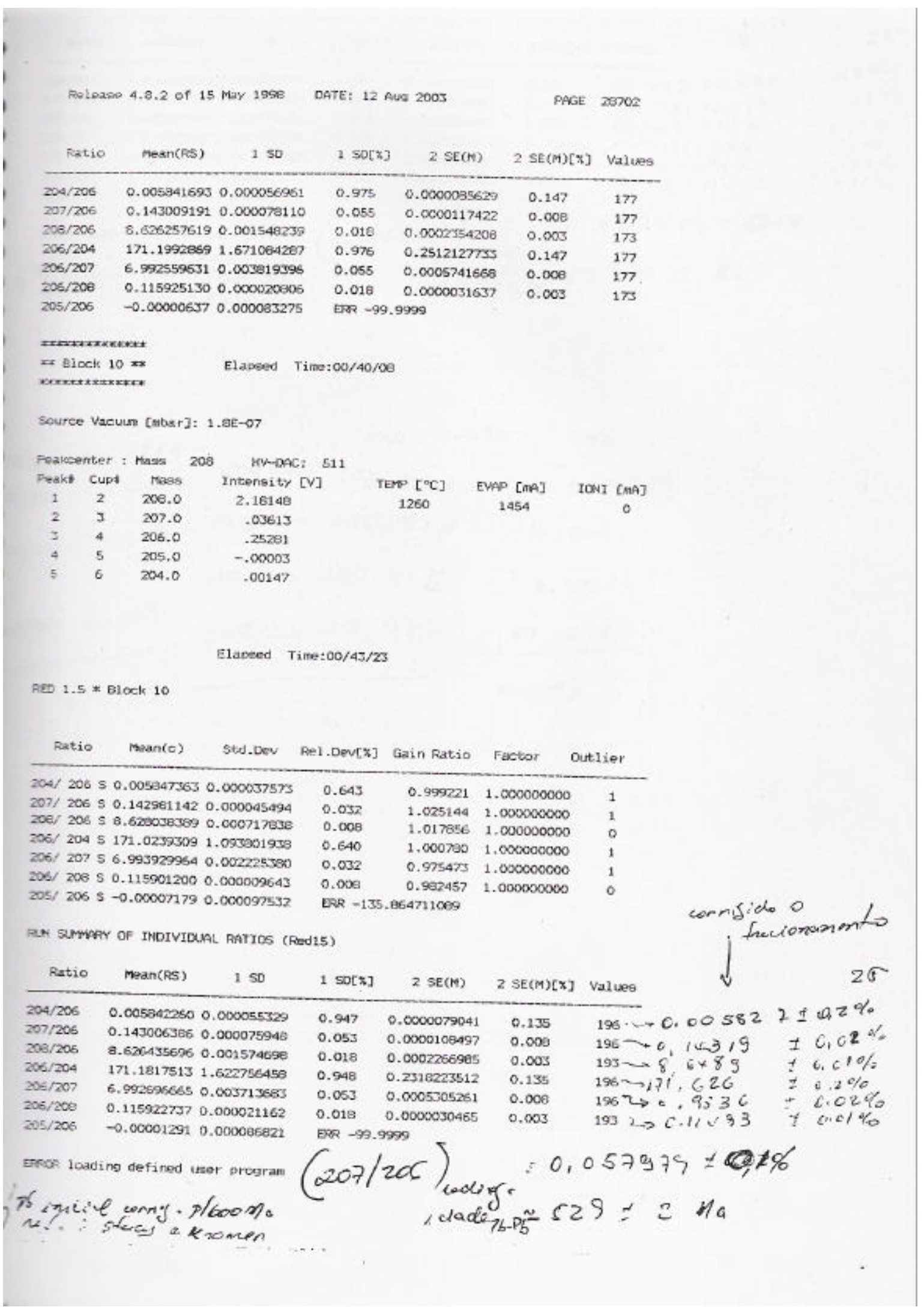




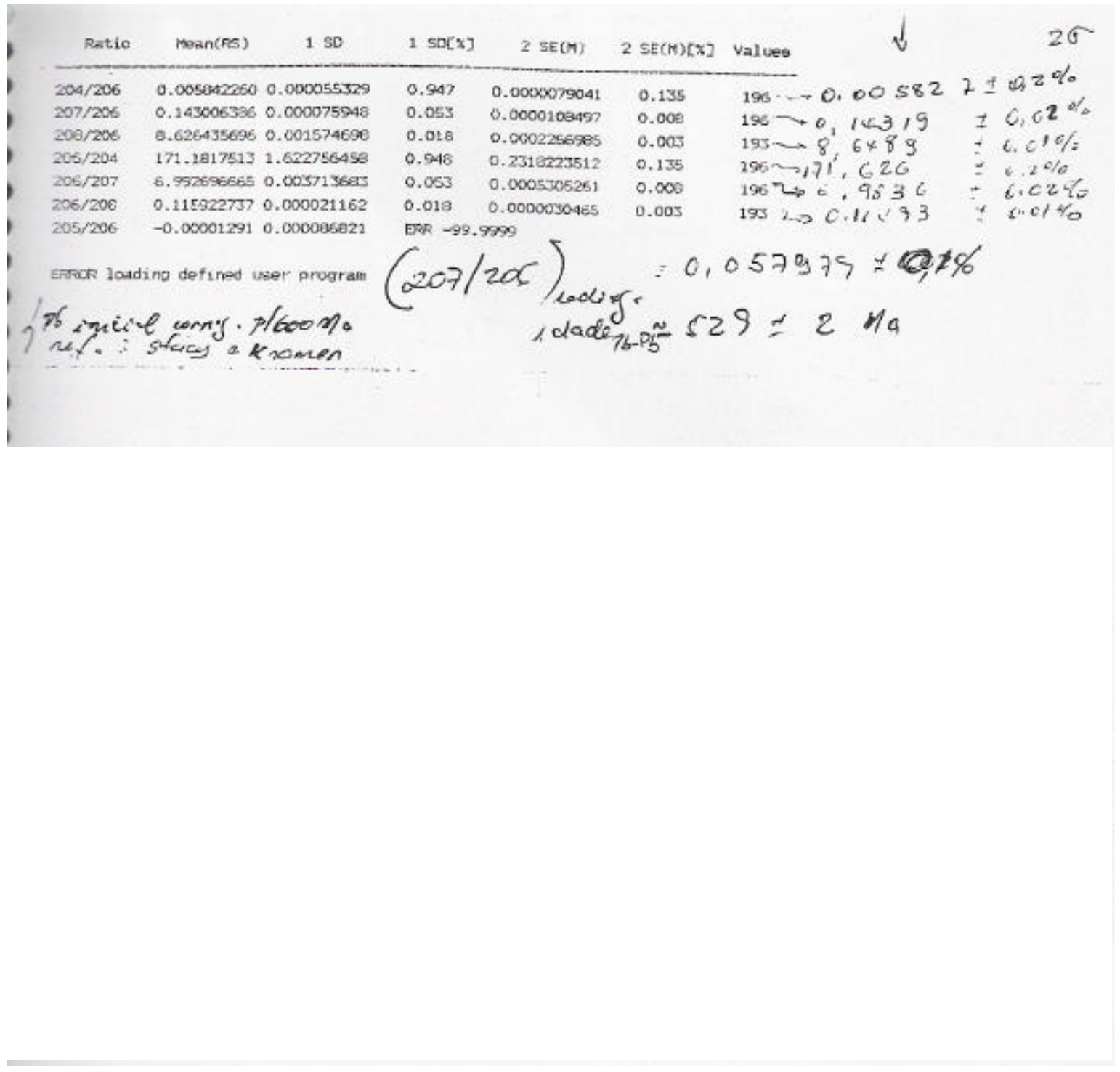




\section{4 sim sentodos th íns}

Rolease 4.8 .2 of 15 May 1998

DATE: 12 Aug 2003

PAGE 20705

waSe SIMULTAHEOUS IOH CONNING / FARADAY COL 1 WaN

$\begin{array}{llrl}\text { DATE: } & 12 \text { AUO } 2003 & \text { TIME: } & 16: 57: 38 \\ \text { IDENT: } & \text { SENEDA-BRONCO } & & \\ \text { PWALYSIS: } & \text { STATIC } & \text { COMMENT: } & 0 \\ \text { EXPERIMENT: } & 17 & \text { TITLE: } & \text { IC }(204) \text {-FAR }(205,206,207) \\ \text { NO. OF BLOCKS: } & 10 & \text { SCANS: } & 20 \\ \text { IONIZATION MOOE: POS. IONS } & \text { USER PROS: } & \text { ERAZIL }\end{array}$

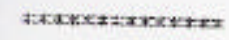

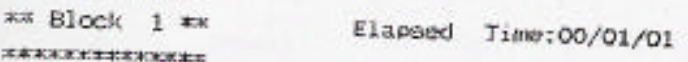

Source vacuun [abar]: $1.7 E-07$

Panalocenter : Mass 205 HV-DAC: 539

ICIn-Yield [CpoN]: $4.349 E+07$

Poukt Cups Mass Internity

13206.0

$.00067[\mathrm{Y}]$

$\begin{array}{cccc}2 & \mathrm{ICm} & 204.0 & 1545 \text { [Cps] } \\ 3 & 4 & 205.0 & .00909 \text { [V] }\end{array}$

TEMP [OC] EVAP [ma] IONI [IMA']

$\begin{array}{llll}4 & 2 & 207.0 & .00055\end{array}$

$\begin{array}{llll}5 & 6 & 203.0 & .00002[\mathrm{~V}]\end{array}$

Elapsed Time:00/04/17

RED $1.5 *$ Block 1

\begin{tabular}{cccccc} 
Ratio Mean(c) & Std.Dev & Rel.Dev[x] & Gain Ratio & Factor & Outlier \\
\hline $206 / 0204$ S 18.97784004 & 0.360151551 & 1.990 & 0.000000 & 1.000000000 & 0 \\
$206 / 205$ S 0.067515827 & 0.001175789 & 1.739 & 1.025144 & 1.000000000 & 0 \\
$206 / 207$ S 1.100739103 & 0.040547390 & 3.443 & 1.007160 & 1.000000000 & 0 \\
$203 / 205$ S 0.001267603 & 0.001623235 & 120.1 & 0.999221 & 1.000000000 & 0
\end{tabular}

RUN SUMARY OF INOTVIDIAAL RATIOS (REd15)

\begin{tabular}{|c|c|c|c|c|c|c|}
\hline Ratio & mean(RS) & $1 S D$ & 1 sor\%] & $2 \operatorname{SE}(M)$ & $2 \operatorname{SE}(M)[x]$ & V/aluses \\
\hline $206 / 3204$ & 16.97704004 & 0.360151551 & 1.899 & 0.1610646699 & 0.849 & 20 \\
\hline $206 / 205$ & 0.067615827 & 0.001175789 & 1.739 & 0.0005253290 & 0.778 & 20 \\
\hline $206 / 20 ?$ & 1.180739103 & 0.040647390 & 3.443 & 0.0131700556 & 1.540 & 20 \\
\hline $203 / 205$ & 0.001267603 & 0.001623285 & 228.1 & 0.0007259550 & 57.27 & 20 \\
\hline
\end{tabular}




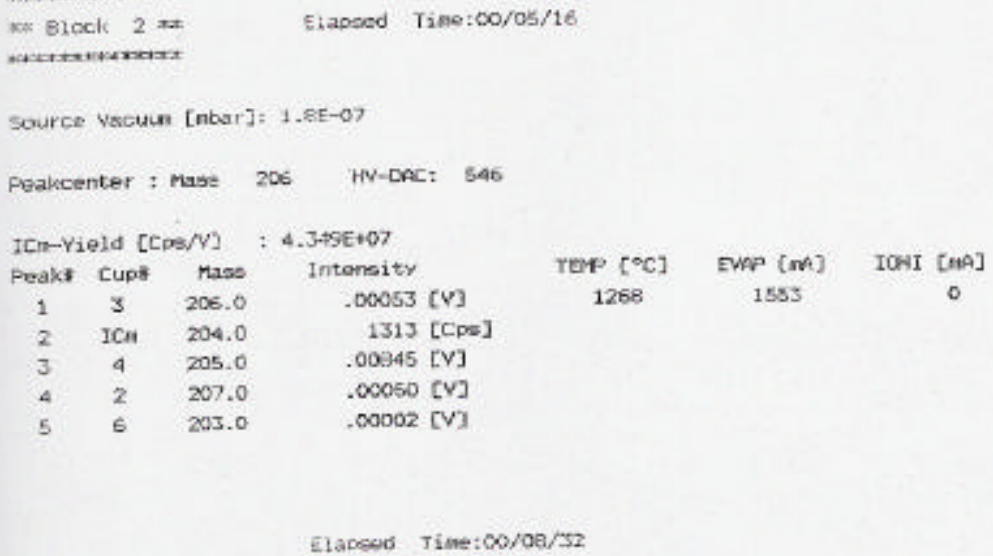

\begin{tabular}{|c|c|c|c|c|c|c|}
\hline Ratio & Beante) & Sted.Der & Bel. Dev [\%] & Gsin Ratio & Factor & outlier \\
\hline 200 & 18.935 & 8 & 2.203 & 0.000000 & 1.0000000000 & 1 \\
\hline $205 s$ & .067314006 & 0.001502307 & 2.677 & 1.025144 & 1. 0000000000 & 0 \\
\hline 2075 & 12 & c.0449as 108 & 3.956 & 1. 057260 & 1. .000000000 & 0 \\
\hline & & 031973232 & 81.11 & 0.999221 & 1.000000000 & 1 \\
\hline
\end{tabular}

RUN SUTWRY CF INOTVIDUAL RATIOS (FED15)

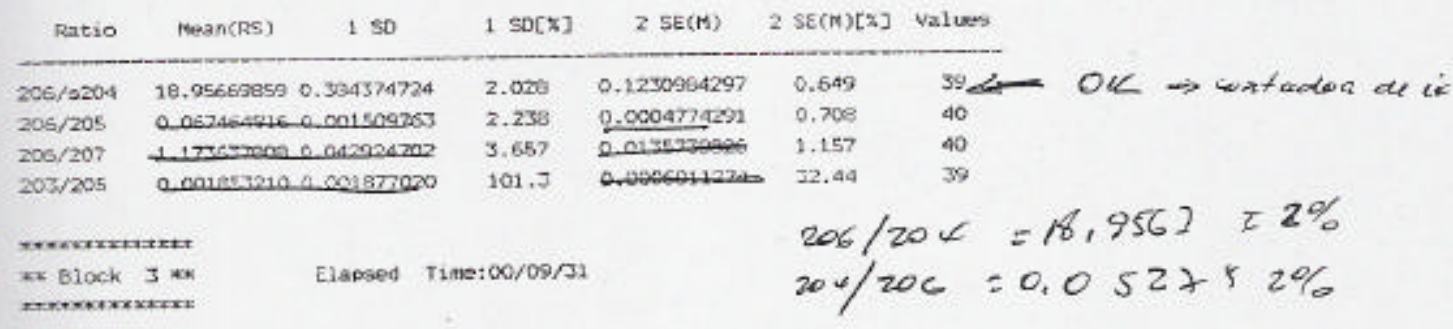

Source Yecuun $[$ masr ]: $1.8 E-0$ ?

-) Ekesor 1126 Peak Cencer: Mo paak to center DATE:12 Aus 2003 17:07:21

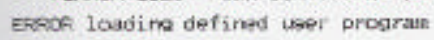




\section{REFERÊNCIAS BIBLIOGRÁFICAS}

1 -ABRÃO, A.; FREITAS, A.A. e CARVALHO, F. M. S. Preparation of highly pure thorium nitrate via thorium sulfate and thorium peroxide. Journal of Alloys and Compounds. v.323-324, p. 53-56, 2001.

2- ABRÃO, A. Química e Tecnologia das Terras -Raras. Rio de Janeiro:1994. ( Série Tecnologia Mineral , V. 66, CETEM/CNPq).

3- ABRÃO, A. Operações de troca iônica.São Paulo:1972, Instituto de Energia Atômica

4-ALLINSON, M. , MOORE, W. R. , RICHARDSON, A. E., PETERSON, D. T. e VOIGT, A. F. Determining Mesothorium. Nucleonics p. 32-34, 1954.

5- AMPHLETT, C.B. Inorganic ion exchangers. Amsterdan: Elsevier Publishing, 1964

6- BAILAR, J.C. e EMELÉUS, H. J. ; NYHOLM, R. Comprehensive Inorganic Chemistry Pergamon Press, 1973.

7- BRANDÃO Fำ, D. , HESPANHOL, E.C.B., BABA, S. , MIRANDA, L.E.T. e ARAUJO, J.A. Reaproveitamento do tório contido em resíduos provenientes da usina de purificação de tório. São Paulo. 1992 (IPEN -Pub- 375).

8- BATTELLE MEMORIAL INSTITUTE L. A. Bray; J. R. Des Chane. Method for separating Bi-213 from a solution of radionuclides. US Pat. 19970789973 / W09832513, 30 Jul. 1998.

9- BRIL, K. J. e KRUMHOLZ, P. Developments in thorium production technology, In: INTERNATIONAL CONFERENCE ON THE PEACEFUL USES OF ATOMIC ENERGY, aug 31- sep 9, 1964. Geneva. Proceedings of the international conference on the peaceful uses of atomic energy. Geneva:United Nations, 1965a. v.12, p.167-174.

10- BRIL, K. J. e KRUMHOLZ, P. Produção de óxido de tório nuclearmente puro. São Paulo, Instituto de Energia Atômica, Dez. 1965b ( IEA-115).

11- BRITISH NUCLEAR FUELS. PLC; ALAN RUSHTON, Removal of thorium from raffinate; US Pat. 4.943.318, 24 Jul 1990.

12- BROWN, C. G. e SHERRINGTON, L. G. Solvent Extraction used in industrial separation of rare earths. J. Chem. Tech. Biotechnology, v. 29, p. 193-209, 1979. 
13- CALVET, E. Química General aplicada a la industria con práticas de laboratorio. Salvat Editores, 1962.

14- CARVALHO, F. M. S., Uso da voltametria na determinação de urânio e elementos associados em compostos de interesse nuclear, 1988 .Dissertação (mestrado ) - Universidade de São Paulo, Instituto de Pesquisas Energéticas e Nucleares ( IEA ), São Paulo.

15- CHUNG, N. K. Chemical Precipitation. IN: FREEMAN, H. M. Standard handbook of hazardous waste treatment and disposal. N.York, McGraw-Hill Book Company. 1989, p.7.21-7.31.

16- COMISSÃO NACIONAL DE ENERGIA NUCLEAR. Licenciamento de Instalações Radiativas. Jul. 1998. (CNEN-NE-6.02-1998).

17- COMISSÃO NACIONAL DE ENERGIA NUCLEAR. Gerência de Rejeitos Radioativos em Instalações Radiativas. Jul. 1985(CNEN-NE-6.05-1985).

18- CORREA , F . Utilização de tório em reatores tipo PWR, 1976 .Dissertação (mestrado ) - Universidade de São Paulo, Instituto de Pesquisas Energéticas e Nucleares ( IEA ), São Paulo.

19- CUTHBERT, F. L. Thorium production technology. Reading, Mass., Addison-Wesley, 1958.

20- DANA, J. D . Manual de mineralogia. Rio de Janeiro, Livro Técnicos e científicos, 1981.

21- ECCLES, H. e RUSHTON, A. Separative Technologies for the removal of thorium from na acidic waste liquor. Separation Science and Technology v.28(13), pp. 59-79, 1993.

22- FAYA, A . J. G. Avaliação neutronica de blankets de tório metálico em reatores rápidos refrigerados por gás,1975. Dissertação ( mestrado ) USP, Instituto de Pesquisas Energéticas e Nucleares ( IEA), São Paulo.

23- FEIGL, F. Spot Tests in inorganic analysis. London: Elsevier, 1958.

24- FIGUEIREDO FQ, P. M. e GENTILE, E. F. Projeto diagnóstico materiais radioativos Tório e Urânio . Associação Brasileira de Metais Abril 1976.

25- FREEMAN, L. B.; BEAUDOIN, B.R.; FREDERICKSON, R.A. ; HARTFIELD,G.L.;HECKER,H.C.; MILANI,S.; SABER,W.K.; SCHICK,W.C. Physics experiments and lifetime performance of the light water breeder reactor.Nuclear science and engeneering. v. 102 (4) , p. 341-364, 1989. 
26 - FURUKAWA,K.; MITACHI,K.; KATO, Y.; Small molten-salt reactors with a rational thorium fuel-cycle. Nuclear engineering and design . v. 136 (1-2), p. 157-165, 1992.

27- GIBSON, W.M. The radiochestry of lead New Jersey: National Academy of Sciences-National Research Council, 1961.

28 - GORSUCH, T. T. The separation of lead-212 from thorium. Analyst, v. 84, p. 170-173, 1959.

29- HYDE, E. K. The radiochestry of thorium New Jersey: National Academy of Sciences-National Research Council, 1960.

30- IKUTA, A . Tecnologia de purificação de concentrados de tório e sua transformação em produtos de pureza nuclear. Estudo do sistema Th(N03)4 - HN03 - NaN03 - TBP- Varsol. 1977 . Dissertação ( mestrado ) - Escola Politécnica da Universidade de São Paulo, São Paulo.

31- JUANG, R.S. ; WANG, S.W.;LIN, L.C. Simultaneous recovery of EDTA and lead ( II ) from their chelated solutions using a cation exchange membrane. Journal of membrane Science. V. 160, p.25-233, 1999.

32- KAKODKAR, A.;SINHA, R. K. Energy from thorium. Indian Journal of power \& river valley development, p. 165- 172, 2002.

33- KAMENOV, G.D.; PERFIT, M. R.; JONASSON, I. R.; MULLER, P. Highprecision $\mathrm{Pb}$ isotope measurements reveal magma recharge as a mechanism for ore deposit formation. Examples from Lihir Island and Conical seamount, Papua New Guinea.Chemical Geology, v. 219 , n ( 1-4 ), p. 131-148, 2005.

34- KORKISCH, J. e SORIO, A. Determination of cadmiun, copper and lead in natural waters after anion-exchange separation. Analytica chimica acta v. 76, n. 2, p. 393-399, 1975.

35- KORKISCH, J. Separation of lead by anion exchange. Analytica chemistry v.36 n. 9, p. 1793-1796, 1964.

36-KOSAKA, N . Estudo da viabilidade neutrônica de um conjunto subcrítico de tório São Paulo: 1976 Dissertação ( mestrado ) - Universidade de São Paulo, Instituto de Pesquisas Energéticas e Nucleares ( IEA ).

37- KRAUS, K.A. e NELSON, F. Anion Exchange studies of the fission products. In:INTERNATIONAL CONFERENCE ON THE PEACEFUL USES OF ATOMIC ENERGY, aug 8-20, 1955. Geneva. Proceedings of the international conference on the peaceful uses of atomic energy. Geneva:United Nations, 1956. v.7, p.113-125. 
38- KRAUS, K. A. e HOLMBERG, R.W. Hydrolytic behavior of metal ions. III. Hydrolysis of thorium (IV) The journal of physical chemistry. V.58, p. 325-330, 1954.

39- KRUMHOLZ, P. Aspectos da industrialização da monazita Associação brasileira de metais p. 545-551, 1949.

40- KRUMHOLZ, P.; BRIL, K.; BRIL, S.;BEHMOIRAS,J.; GOTTDENKER,F. e LIMA, F.W. Brazilian practice in the separation of rare earths. In:INTERNATIONAL CONFERENCE ON THE PEACEFUL USES OF ATOMIC ENERGY, sept 1-13, 1958. Geneva. Proceedings of the second United Nations international conference on the peaceful uses of atomic energy. Geneva:United Nations, 1958. v.28, p.184-195.

41- KURITANI, T. E NAKAMURA, E. Precise isotope analysis of nanogram-level $\mathrm{Pb}$ for natural rock samples without use of double spikes. Chemical Geology. V.186, p. 31-43, 2002.

42- LAKE, J. A. Foundation for the fourth generation of nuclear power. Nuclear news, nov. p. 32-35, 2000.

43- LIMA, G. R. Indústria de terras raras no Brasil. In. ANAIS DA XXI REUNIÃO ANUAL DA SOCIEDADE BRASILEIRA PARA O PROGRESSO DA CIÊNCIA,1 julho, 1969, Porto Alegre, RS.

44- LIMA, F.W. e ABRÃO, A. Separation of Bismuth from Lead with EDTA Analytical Chemistry, v. 32, n.1, p. 492-494, 1960.

45- MARTINS, E. A . J. Reaproveitamento de valores nos efluentes líquidos das unidades piloto de urânio e tório 1990, Dissertação ( Mestrado )- Instituto de Pesquisas Energéticas e Nucleares, São Paulo.

46- MITACHI,K.; FURUKAWA,K.;MINAMI,K.; KATO, Y. Nuclear and burn-up characteristics of small molten-salt power reactor. J. atomic energy soc. of Japan v.32(4), p. 377-384, 1990.

47- MORAES, N. M. P. Avaliação da técnica de diluição isotópica por espectrometria de massa na determinação de elementos de terras-raras em material geológico. 1988,Tese ( Doutorado ) - Instituto de Pesquisas Energéticas e Nucleares, São Paulo.

48- MOREIRA, S. R. D. Determinação de $P b-210$ em águas minerais da cidade de Águas da Prata. 1993. Dissertação ( Mestrado ) - Instituto de Pesquisas Energéticas e Nucleares, São Paulo. 
49- MOREIRA, J.M. L. ; ABE, A. Y. ; FIGUEIREDO FQ, P. M. ; LAINETTI, P. E. O Uma proposta de estudo visando a utilização de tório em reatores . Relatório Interno, 1996.

50- MUGHABGHAB, S. F. Neutron cross sections. Neutron resonance parameters and thermal cross sections, v.1 New Jersey: National Academy of Sciences-National Research Council, 1984.

51- NASCIMENTO, J. A. Avaliação neutrônica de reator carregado com combustível metálico e refrigerado por chumbo. 2000. Tese (Doutorada) Instituto de Pesquisas Energéticas e Nucleares, São Paulo.

52- OOSTERKAMP, W. J e CORRER, F. Thorium utilization in the Angra dos Reis PWR São Paulo: 1976 ( IEA - Pub- 419 ) .

53- PAGANO, M.; PETRUZELLI, D.; TIRAVANTI G.; PASSINO R. Pb/Fe separation and recovery from automobile battery wastewaters by selective ion exchange. Solvent extraction and ion exchange v. 18, n. 2, p. 387-399, 2000.

54- PEDREIRA $F^{\circ}$., W. R. Determinação de impurezas metálicas em óxidos de terras raras de alta pureza pela espectrometria de massa ( setor magnético) com fonte de plasma induzida por argônio (HR ICP-MS) e cromotografia líquida de alto desempenho (HPLC),2000, Tese (Doutorado) - Instituto de Pesquisas Energéticas e Nucleares, São Paulo.

55- PEREIRA, S. A. Um conceito alternativo de um reator híbrido(conjunto sub-srítico acoplado com acelerador). 2002. Tese (Doutorado) - Instituto de Pesquisas Energéticas e Nucleares, São Paulo.

56- PETRONI, S. L.G. Avaliação cinética e de equilíbrio do processo de adsorção dos íons dos metais cádmio, cobre e níquel em turfa. 2004. Tese (Doutorado) - Instituto de Pesquisas Energéticas e Nucleares, São Paulo.

57- PICHTEL,J., VINE, B., KUULA-VAISANEN, P. e NISKANEN,P., Lead extraction from soils as affected by lead chemical and mineral forms. Environmental Engineering Science, v. 18, n.2, p. 91-98 , 2001.

58- POWELL, J. E., SPEDDING, F. H. e JAMES, D.B. The separation of rare earths. J. Chem. Education. V.37, n.12, p. $629-633,1960$.

59- PUCHE, R. S. ; CARO P. Rare Earths. Madrid: Editorial Complutense, 1998.

60- QUEIROZ, C. A. S. ; PEDREIRA, W. R.; SARKIS, J.E.S.; ABRÃO, A. A ten kilogram ion exchanger installation for preparation of spectrochemical grade lanthanum oxide. In: $4^{\text {th }}$ Internacional Conference on f-elements, September 17-21, 2000, Madrid. p. AP12. 
61- QUEIROZ, C. A. S. Terras raras fracionamento, purificação e controle analítico São Paulo: 1988. Dissertação ( Mestrado ) - Instituto de Química USP.

62- RUBBIA, C . et alli , The energy amplifier a year later - a summary for non specialists. CERN Web Office, 1995a .

63- RUBBIA, C . et alli , Conceptual design of a fast neutron operated high-powerenergy amplifier . CERN /AT/95-44 (ET) 1995b .

64- RYABCHIKOV, D. I. ; GOLBRAIKH, E. K. Analytical chemistry of thorium Russia, Arbor-Humphrey Science Publishers 1960.

65- SALVADOR, V. L. R., Estudo dos parâmetros instrumentais para a determinação de $\mathrm{Ca}, \mathrm{Cr}, \mathrm{Cu}, \mathrm{Fe}, \mathrm{Mn}$ e $\mathrm{Ni}$ em $\mathrm{UO}_{2}$ nuclearmente puro pela técnica de fluorescência de raios-X. 1982. Dissertação (Mestrado) - Instituto de Pesquisas Energéticas e Nucleares, São Paulo.

66- SCAPIN, M. A. Aplicação da difração e fluorescência de raios-X (WDXRF): ensaios em argilominerais. 2003. Dissertação (Mestrado) - Instituto de Pesquisas Energéticas e Nucleares, São Paulo.

67- SISTI, C. Aplicação de diferentes metodologias na preparação de matrizes orgânicas para a determinação voltamétrica de elementos traço. 2001. Dissertação de Mestrado - Instituto de Pesquisas Energéticas e Nucleares, São Paulo.

68- SEELMANN-EGGEBERT, W.; PFENNIG, G.;MÜNZEL,H.;KLEWENEBENIUS,H. Chart of nuclides. Institut für Radiochemie. Kernforschungszentrum Karlsruhe, November, 1981.

69- SHAVINSKII, B.M., MIT'KIN V. N. e KAMELIN, A. I., A laboratory-scale ionexchange method for extraction of trace amounts of rare-earth elements for quality control of uranium products. Industrial Laboratory, v. 66, n.9, p. 588-589, 2000.

70- SILVERNAIL, W. L . ; MCCOY, J . B. Thorium and thorium compounds In:Kirk-Othmer Encyclopedia of chemical Technology. v.20 p. 248-259, Interscience Publishers, 1969 .

71- SNELL, T Encyclopedia of Ind. Chemical Analysis . v.19,1974.

72- STELMANN, J. M. e DAUM, S. M. Trabalho e saúde na indústria. Risco físicos e químicos e prevenção de acidentes. São Paulo: Editora Universidde de São Paulo, v.2, p. 87-88, 1975. 
73- STEVENSON, P.C. e NERVIK,W.E. The radiochestry of the rare earths, scandium, yttrium, and actinium. California: National Academy of SciencesNational Research Council, 1961.

74- SYLLUS, C. e LEPEEKI, W. Gênese do Programa Brasileiro de Centrais Nucleares In: Congresso Geral de Energia Nuclear, Aug 31 - Sept 9, 1995, Rio de Janeiro, 1995.

75- THEYMANN, W. Status and prospects of the THTR 500 based on the THTR 300 operation experience and recent R\&D work . Nucl. Eng. Design., v.136, p. 127, 1990.

76- TUCKER, W.D. e WILHELM, H. A. Production of thorium metal. 1. Purification of thorium nitrate and subsequent production of thorium oxalate. In: Nuclear science and technology: extracts from Journal of metallurgy and ceramics, issue 1-6, July 1948- January 1961. Ames, lowa, Ames Lab, s.d. (TID-2501), p 163-172.

77- TURAN, M. D. ; ALTUNDOGEN, H.S.; TÜMEN, F. Recovery of zinc and lead from zinc plant residue. Hydrometallurgy, v. 75 , p. 169-176, 2004.

78- UNAK, T. What is the potential use of thorium in the future energy production technology.Progress in Nuclear Energy, v.37,(1-4), p. 137-144, 2000.

79- VASCONCELLOS, M. E. Resolução da mistura tório e terras raras por precipitação fracionada e tecnologia de troca iônica. São Paulo: 2000. Dissertação (Mestrado) - Instituto de Pesquisas Energéticas e Nucleares.

80- VERGARA, M. D. Caracterizações isotópicas e precentuais de material particulado respirável e de materiasi fontes afins da Cidade de Santiago do Chile usando Pb, Sr e Nd como traçadores naturais. 2001. Tese (Doutorado) Universidade de São Paulo - Instituto de Geociências, São Paulo.

81- VYJAYAN, S. , MELNYK, A. J.,SINGH, R.D. e NUTTALL, K. Rare earths: Their mining, processing, and growing industrial usage. Mining Engineering, v. Jan., p. $13-18,1989$.

82- WILLARD, H.; MERRITT Jr, L. e DEAN, J. Análise Instrumental. Lisboa, Fundação Calouste Gulbenkian, 1974.

83- WEI-FAN, Y., SHUANGGUI, Y., YANBING, X., YONGHOU,X.,KE-MING,F. e BING,X. Extraction of thorium traces from hydrochloric acid media by 1-phenyl-3methyl-4-benzoyl-pyrazolone-5. Journal of Radioanalytical and Nuclear Chemistry, v. 256, n.1, p. 149-152, 2003. 
84- YATSIMIRSKII, K.B. e VASIL'EV, V. P. Instability Constant of Complex Compounds. London, Pergamon Press LTD., 1960.

85- ZINNER, L. B. Produção e aplicação das terras raras, um campo pouco explorado no Brasil. In: QUÍMICA DAS TERRAS RARAS: VI SIMPÓSIO ANUAL DA ACIESP 9-11 Nov., 1981, São Paulo Anais do simpósio anual da ACIESP, São Paulo: USP, 1982, p.110 - 146 ( Publicação ACIESP 36 ). 